Check for

Cite as

Nano-Micro Lett.

(2021) 13:92

Received: 7 December 2020

Accepted: 31 January 2021

Published online: 16 March 2021

(c) The Author(s) 2021

\section{Recent Advancements in Nanomedicine for 'Cold' Tumor Immunotherapy}

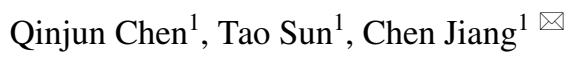

\title{
HIGHLIGHTS
}

- Mechanisms underlying immunosuppressive tumor immune microenvironment (TIME) in 'cold' tumor are summarized.

- Recent nanotechnology-based strategies for 'cold' TIME firing up are emphasized.

- Challenges and perspectives of nanomedicines for 'cold' tumor treatment are proposed.

\begin{abstract}
Although current anticancer immunotherapies using immune checkpoint inhibitors (ICIs) have been reported with a high clinical success rate, numerous patients still bear 'cold' tumors with insufficient $\mathrm{T}$ cell infiltration and low immunogenicity, responding poorly to ICI therapy. Considering the advancements in precision medicine, in-depth mechanism studies on the tumor immune microenvironment (TIME) among cold tumors are required to improve the treatment for these patients. Nanomedicine has emerged as a promising drug delivery system in anticancer immunotherapy, activates immune function, modulates the TIME, and has been applied
\end{abstract}

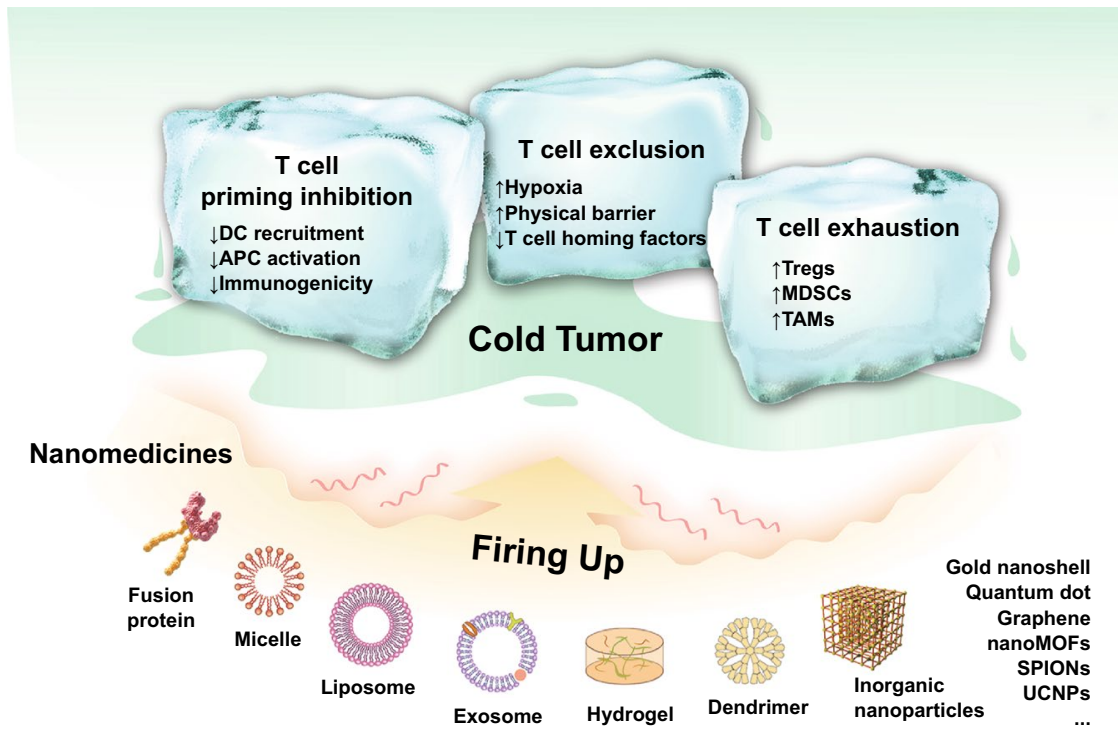
in combination with other anticancer therapeutic strategies. This review initially summarizes the mechanisms underlying immunosuppressive TIME in cold tumors and addresses the recent advancements in nanotechnology for cold TIME reversal-based therapies, as well as a brief talk about the feasibility of clinical translation.

KEYWORDS Tumor immune microenvironment; Cold tumor; Nanotechnology; Immunosuppressive; Combination therapy

Chen Jiang, jiangchen@shmu.edu.cn

1 Key Laboratory of Smart Drug Delivery (Ministry of Education), State Key Laboratory of Medical Neurobiology and MOE Frontiers Center for Brain Science, Institutes of Brain Science, Department of Pharmaceutics, and School of Pharmacy, Research Center on Aging and Medicine, Fudan University, Shanghai 201203, People's Republic of China 


\section{Introduction}

Immunotherapy has emerged as a novel and effective treatment for oncology patients by activating the host immune system to eliminate cancer cells [1]. Particularly, therapies involving immune checkpoint inhibitors (ICIs) have shown remarkable and long-lasting clinical outcomes in some advanced carcinoma, represented by programmed death protein-1 (PD-1) or its ligand (PD-L1) antibody and cytotoxic T-lymphocyte-associated antigen-4 (CTLA-4) antibody therapies. However, along with further clinical research, it was reported that the efficacy of ICI therapy was not uniform among cancer patients or cancer types, where only about $20 \%$ patients exhibited a positive $\mathrm{T}$ cell response and clinically benefited from this therapy [2-9]. Patients with favorable responses to ICI therapy always have a high level of tumor-infiltrating lymphocytes (TILs) in tumor lesions, and such tumors are normally labeled as hot tumors [10-12]. In contrast, patients responding poorly usually bear tumors with insufficient $\mathrm{T}$ cell infiltration, which are regarded as cold tumors [13]. In-depth mechanism studies on tumor immune microenvironment (TIME) of hot tumors have reported that immunosuppressive factors in hot tumors are involved in a negative feedback loop driven by TILs, such as the up-regulation of PD-L1, CTLA-4, and IDO [3, 14], which are rarely found in TIL-lack cold tumors. Instead, there are low immunogenicity and $\mathrm{T}$ cell exclusion in cold tumors $[15,16]$. Furthermore, numerous clinical studies have proposed that prognostic and clinical outcomes of immunotherapy greatly relied on the $\mathrm{T}$ cell infiltration rate in various tumors [17-21]. Therefore, it is critical and challenging to increase $\mathrm{T}$ cell infiltration for cold tumors.

In general, effective $T$ cell recruitment requires an enhanced immune circle in tumor lesions. First, the patrolling dendritic cells (DCs) are recruited to tumor lesions through inflammatory chemokines (such as CCL4) produced from tumors $[22,23]$ in early tumorigenesis. Thereafter, endogenous adjuvants (including cytosolic DNA) released from dying tumor cells activate the $\mathrm{CD} 103^{+}$subset of DCs to recognize the targeted tumor cells (via DNA-cGAS-STING pathway), following by type I interferon (IFN) generation which in turn recruits DCs and promotes DC translocation into tumor-draining lymph nodes (TDLNs) for the tumorspecific T cell activation [24-27]. At the TDLN stage, the maturity and functionality of DCs and immunogenicity of its presented epitopes determines the extent of $\mathrm{T}$ cell immune response [28, 29]. Then, the activated effector $\mathrm{T}$ cells enter the bloodstream and screen for inflammatory microenvironments through surface-expressed homing molecules, i.e., P-selectin and E-selectin ligands and the chemokine receptor CXCR3 [30, 31]. Finally, accompanied with the selectin-mediated endothelial adhesion and chemokine-mediated integrin activation, effector $\mathrm{T}$ cells can thus successfully migrate into tumor tissues and kill tumor cells [32].

In the TIME of cold tumors, as expected, the immune circle is interrupted in three major pathways (Fig. 1). First is $\mathrm{T}$ cell priming inhibition, including decreased immunogenicity and failed antigen-presenting cells (APCs) and T cell recruitment, which is mainly caused by genetic mutation. Second is T cell exclusion. The deposition of extracellular matrix and stiff stroma-induced hypoxia in cold tumor lesions can build a physical and chemical barrier to obstruct the T cell infiltration. Furthermore, numerous immunosuppressive cells, represented by myeloid-derived suppressor cells (MDSCs), Regulatory T cells (Tregs) and tumor-associated macrophages (TAMs), are widely settled in the TIME of cold tumors and suppress the cytotoxicity of $\mathrm{CD} 8^{+} \mathrm{T}$ cells via $\mathrm{T}$ cell exhaustion. Therefore, a multiple combinatorial therapy addressing these characteristics of cold TIME is desiderated for reversing immunosuppressive TIME and conquering the cold tumors.

Nanomedicine is the medical use of nanoscaled cargo to prolong circulation time, to protect the loaded-drug from degradation, and to promote the accumulation and drug release into targeted tissues and cells, which has been extensively developed as diagnostic, therapeutic and preventive medicine in healthcare [33-38]. Up to date, there has been over 200 products of nanomedicines either approved or under clinical investigation, covering almost all types of nanomaterials, for example, liposomes (Doxil), protein-based nanoparticles (Abraxane), polymeric micelles (Apealea), liposomal gene delivery formulation (NCT02369198) and inorganic nanoparticles $\left(\right.$ Sienna $\left.^{+}\right)$[39]. Similarly, the application of nanomedicines in anti-tumor immunotherapy has also received enormous attention and shown great advantages over traditional strategies. Abraxane and Doxil are the two most studied products of nanomedicine in combination with immunotherapy, particularly with PD-1/PD-L1 antibody therapy, among which, the combination of Abraxane 


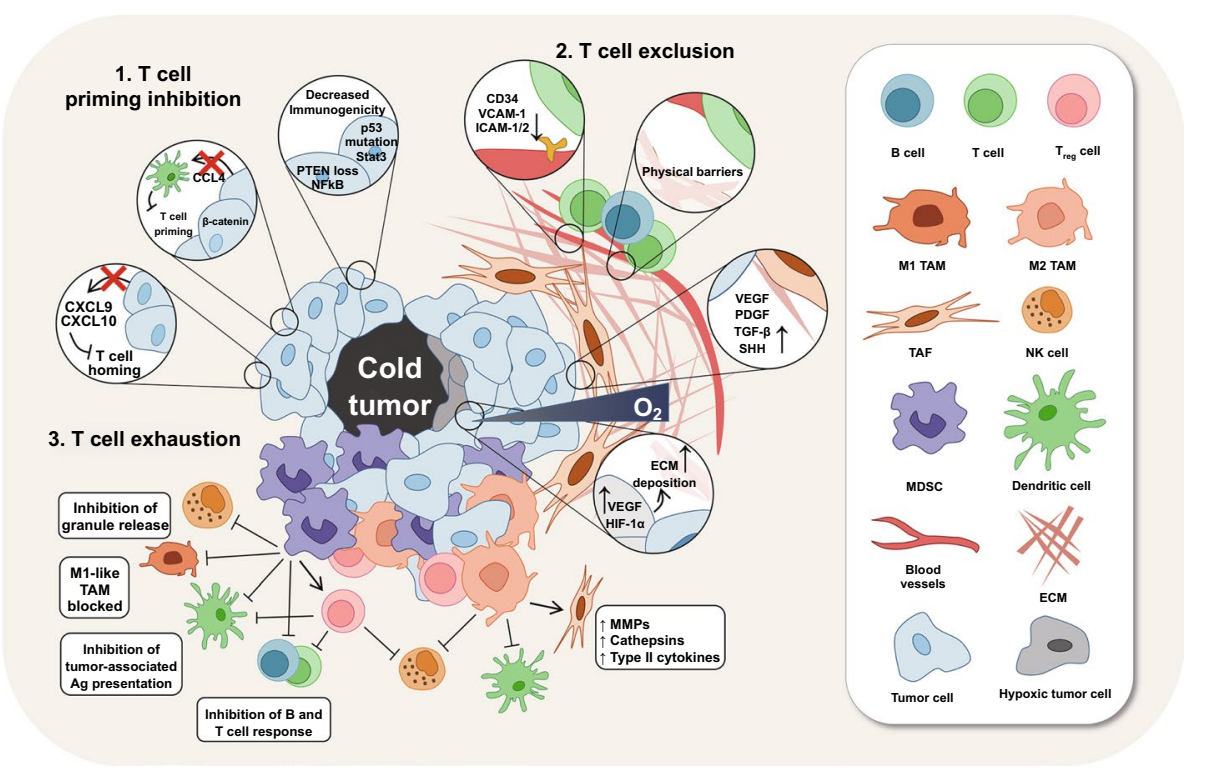

Fig. 1 Immunosuppressive mechanisms of the tumor immune microenvironment in cold tumors. STAT3, signal transducers and activators of transduction-3; NF-кB, nuclear factor kappa-B; CCL4, CC-chemokine ligand 4; CXCL9/CXCL10, CXC-chemokine ligand 9/10; VCAM-1, vascular cell adhesion molecule 1; ICAM-1/2, intercellular adhesion molecule-1/2; VEGF, vascular endothelial growth factor; PDGF, plateletderived growth factor; TGF- $\beta$, transforming growth factor- $\beta$; SHH, sonic hedgehog; ECM, extracellular matrix; HIF- $1 \alpha$, hypoxia-inducible factor $1 \alpha$; TAM, tumor-associated macrophages; MMPs, matrix metalloproteinases; TAF, tumor-associated fibroblast; NK cell, natural killer cell; MDSCs, myeloid- derived suppressor cells

and atezolizumab has been the first immunotherapeutic regimen approved by FDA for locally advanced or metastatic triple-negative breast cancer [40]. Furthermore, autoimmune toxicity caused by nonspecific immune stimulation remains as a major challenge to current immunotherapies, and numerous studies have shown that delivery of immunomodulatory agents via nanocarriers can not only protect the cargo from leakage and degradation, but also enables its targeted accumulation, resulting in alleviated toxicity and reinforced $\mathrm{T}$ cell responses as opposed to systemic administration of free agents [41-43]. As expected, several advanced nanomedicines involving nucleic acids and vaccines have been processed in clinical trials, such as mRNA nanovaccine (lipo-MERIT) for melanoma (NCT02410733), anti-EGFR bispecific antibody minicells with microRNA for mesothelioma and non-small cell lung cancer (NCT02369198) and autologous cell vaccines for breast cancer (NCT00317603) [44].

As to cold tumors, co-stimulating multiple immunosuppressive pathways synergistically is on demand for APCor T cell-based immune initiation [45-47]. However, it is difficult to accomplish this goal by systemic administration of various immunomodulatory agents due to their differences in the pharmacodynamic and pharmacokinetic properties. In this regard, incorporation of these agents in one nanoparticle would serve as an ideal approach for synergic drug exposure [44]. Furthermore, desmoplastic extracellular matrix (ECM) in cold tumor lesions can act as a physical barrier to both obstruct $\mathrm{T}$ cell infiltration and impair the permeation of free drugs, requiring the early breaching of the matrix barrier before the therapeutic process. It has been widely reported that various nanomaterials can endow the corresponding cargos with capability to penetrate the matrix barriers by particle size reduction or charge reversal from negative to positive upon meeting the enzymes, light or lower $\mathrm{pH}$. Moreover, the highly modifiable chemical groups on the surface of the nanoparticles provide the feasibility to target multiple cells in the tumor microenvironment $[17,48-52]$. In this review, we summarize the mechanisms underlying immunosuppressive TIME in cold tumors and address recent advancements in nanomedicine for cold TIME reversal-based therapies, as well as the feasibility of clinical translation of nanomedicine for immunotherapy. 


\section{Application of Nanomedicines in Treating Cold Tumors}

In recent years, as the rapid development of medical test and diagnostic procedures, there has been an increasing number of voices calling for treating cancer patients with precision medicine based on the specificity of TIME characteristics [53]. Meanwhile, various nanomaterials have been developed in accordance with the healthcare requirements. Therefore, in the following sections, the application of nanomedicines would be introduced according to the characteristics of TIME in cold tumor rather than materialdependence, which would be divided into three main categories, including strategies for $\mathrm{T}$ cell priming resumption, $\mathrm{T}$ cell exclusion overcoming and $\mathrm{T}$ cell exhaustion reversion. In each category, the characteristic of TIME would be outlined first, and the corresponding strategies would be proposed therewith.

\subsection{Strategies for T Cell Priming Resumption}

\subsubsection{Characteristics of T Cell Priming Inhibition in Cold Tumors}

APCs (mostly DCs) play an important role in de novo generation of T cell specific immunity; however, APC functions are always disrupted by numerous factors in cold tumors $[22,54]$. The Wnt- $\beta$-catenin pathway is the first identified tumor-intrinsic oncogene pathway mediating the disruption of APC recruitment in patients with cold tumor. During the activation of the Wnt- $\beta$-catenin signaling pathway, tumors induce activating transcription factor 3 (ATF3)-dependent transcriptional suppression of CCL4, a DC recruitmentsupporting chemokine, thus reducing DC recruitment and inhibiting $\mathrm{T}$ cell priming $[22,55]$. Meanwhile, activation of the Cox1/2-prostaglandin E2 (PGE2) pathway deters DC infiltration through the down-regulation of DC chemoattractants CCL5 and XCR1 owing to natural killer (NK) cell impairment [56].

Furthermore, cytokines including macrophage colonystimulating factor (M-CSF) [57], transforming growth factor $\beta$ (TGF- $\beta$ ) [58], interleukin (IL)-6 [59], and IL-10 [60] in the TME potentially disrupt DC maturation and antigen presentation in tumors, thus inhibiting T cell priming. Meanwhile, MYC-driven up-regulation of CD47 [61], an antiphagocytic protein inhibiting the phagocytic effects of macrophages and DCs on tumor cells, on tumor cells can ultimately impair the potential of APCs to prime effector T cells.

Thirdly, alterations in the conformation and number of epitopes presented to APCs are the major mechanisms regulating antigen processing and presentation in APCs [62]. For example, the alterations in the proteasomal or postproteasomal machinery can impair antigen processing by disrupting the epitope binding to major histocompatibility complex (MHC) molecules [63, 64], and mutations and epigenetic changes in MHC-I can regulate the presentation of processed epitopes on the tumor cell surface $[65,66]$. The loss-of function mutations in PTEN or activation mutations in PI3K can reduce the autophagy in cold tumors, which results in decreased presentation of danger signals to APCs. Furthermore, antigenic discontinuum owing to the oncogenic mutations (including those in KRAS) or chromosome rearrangements (such as $B C R-A B L 1$ ) can induce a nondestructive immune response that is aberrantly considered as tumor immunity [67-69].

\subsubsection{Recruitment and Functional Enhancement}

According to the characteristic of $\mathrm{T}$ cell priming inhibition, DC recruitment is the first step for T cell activation. CCL4 is a crucial chemokine for $\mathrm{CD} 103^{+}$DC recruitment; however, it is usually lacking in tumor lesions [70], and the retention of external CCL4 in tumor lesions is still a problem. Recently, a fusion protein of CCL4 and collagen-binding domain (CBD) of von Willebrand factor was generated to achieve stromal-targeted delivery of CCL4 to increase the retention of CCL4. As expected, intravenous administration of CBD-CCL4 can remarkably enhance the recruitment of $\mathrm{CD} 103^{+} \mathrm{DCs}$ and $\mathrm{CD} 8^{+} \mathrm{T}$ cells, exhibiting significant antitumor effects in multiple tumor models in combination with ICB immunotherapy [26]. Furthermore, recent studies have revealed that autophagy in DCs can promote both MHC class I and II presentation of endogenous or exogenous antigens. Hence, Wang et al. tried to conjugate both autophagyinducing peptide (Bec1) and OVA peptide to the terminals of a pH-responsive polymer to form a nano-activator for $\mathrm{T}$ cells activation [71] (Fig. 2a). In this work, they reported that the buffering capability and low-pH-triggered morphology swollen of nano-activator were beneficial to endosomal escape and peptide exposure, which could increase the cross talk between autophagy and functional antigen presentation, 

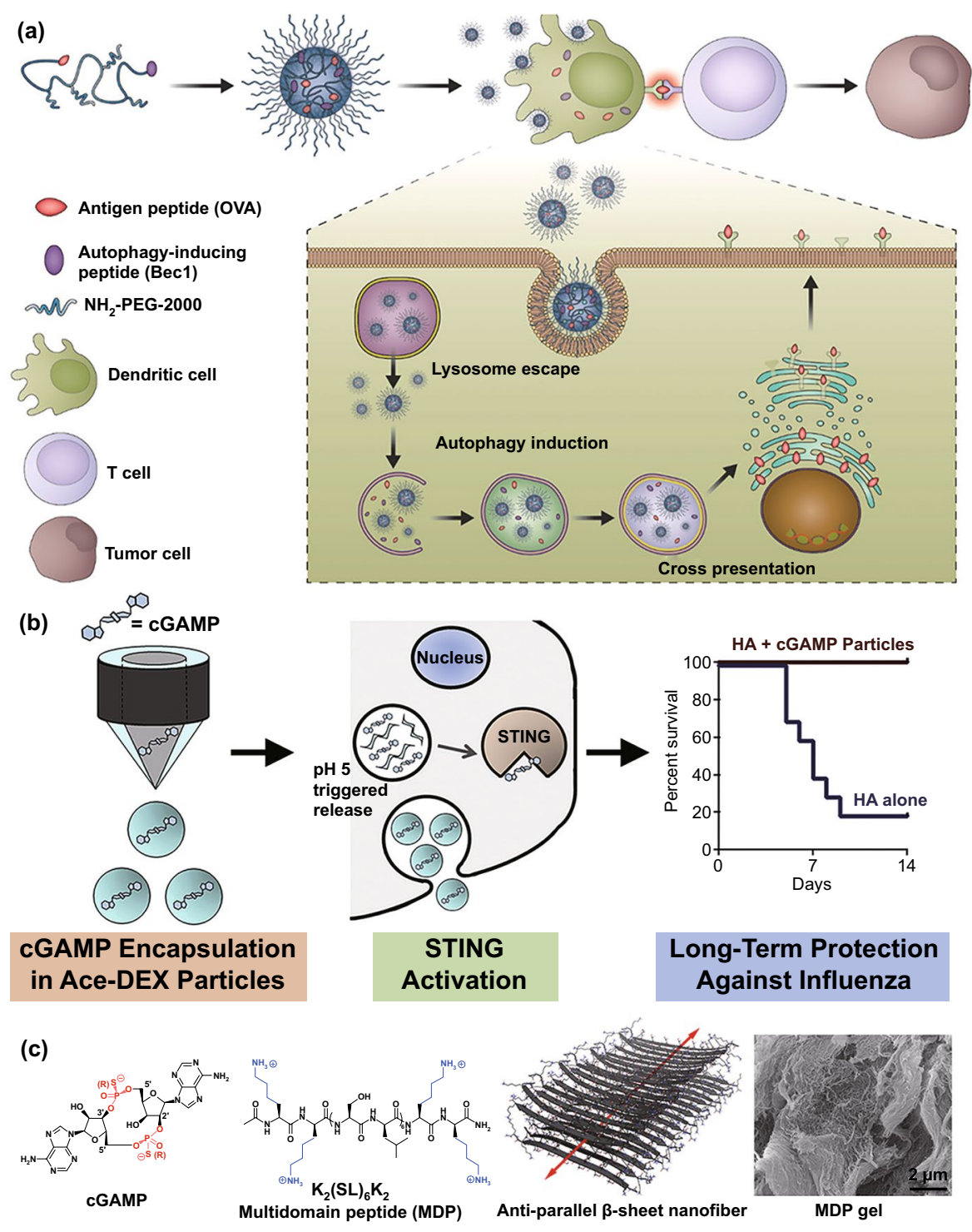

Fig. 2 Nanomedicines for cGAMP. a In vivo up-regulation of the autophagy pathway in DCs via a nano-activator comprising the antigenic peptide and autophagy-inducing peptide (Bec1). Reproduced with permission from Ref. [77]. b pH-sensitive acetylated dextran (Ace-DEX) polymeric microparticles. Reproduced with permission from Ref. [73]. c Anti-parallel $\beta$-sheet nanofibrous hydrogels. Reproduced with permission from Ref. [78]

eventually leading to the high-efficiency antigen cross-presentation and antigen-specific $\mathrm{T}$ cell generation. Stimulator of IFN genes (STING) plays a crucial role in cyclic dinucleotide (CDN)-driven DC maturation [72], and its potent agonist, 2'3'-cyclic guanosine monophosphate-adenosine monophosphate (cGAMP), are widely used to activate DCs in encapsulation with various cationic nanocarriers including cationic liposomes [73]. Nevertheless, the toxicity of these macromolecular cationic materials and inefficient cytosolic cargo transport greatly limit the cGAMP delivery $[74,75]$. Currently, some novel $\mathrm{pH}$-sensitive cationic polymers offer the potential solutions. A pH-responsive cross-linkable polymersome was developed by Shae et al. to encapsulate cGAMP to promote endosomal escape of cargos in response to endolysosomal acidification to disassemble membrane-destabilizing segments [76]. In another study, cGAMP was encapsulated into $\mathrm{pH}$-sensitive acetylated dextran (Ace-DEX) polymeric microparticles (MPs) to achieve an approximately 50-fold in vivo increase in type I IFN responses I comparison with soluble cGAMP [77] 
(Fig. 2b). Furthermore, a previous study introduced thixotropic and extracellular matrix-mimicking multi-domain peptides (MDPs) to load cGAMP in the form of anti-parallel $\beta$-sheet nanofibrous hydrogels in solution, which markedly improved the overall survival in a challenging murine model with an eightfold lower cGAMP release rate as opposed to standard collagen hydrogel-mediated delivery [78] (Fig. 2c).

Adjuvants, such as the agonists of Toll-like receptors (TLR), are a major class of immune-modulatory molecules that can effectively activate DC cells and promote antigen presentation to T cells [79]. Currently, there are 11 types of TLRs found in the cells and their locations that can be divided into two categories: on cytomembrane or endosomal membrane [80]. Particularly, TLR1, TLR2, TLR4, TLR5, TLR6, TLR10, and TLR11 are located on cytomembrane, and TLR3, TLR7, TLR8, and TLR9 are located on endosomal membrane. As for the delivery of TLR agonists, releasing the cargo in appropriate location can maximize the efficacy of agonists, while avoiding rapid diffusion of agonists from the site of injection is also the concerns we should take seriously so as to reduce the severe systemic inflammation. In regard to the cell membranelocated TLR activation, adequate and effective exposure of their agonists to cell surface is warranted. Monophosphoryl lipid A (MPLA) is an FDA-approved detoxified derivative of lipooligosaccharide (LOS) with immune stimulatory effects through engagement of TLR4. According to the TLR4 located on cell membrane, Traini et al. [81] developed a nanovaccine featuring MPLA adhered to mIONPsp through hydrophobic interactions and model antigen (OVA) linked by hydrazine bonds to create adjuvant-exposed and antigen-protected nanostructures for maximum TLR4-based DC activation, and the results indicated that it would be a promising strategy to improve the immunostimulatory properties and reduce cytotoxicity through exposed delivery of MPLA and OVA by mIONPsp. Furthermore, it's also critical to release cargo from the nanovaccine in endosome for delivery of endosomal membrane-located TLRs' agonists. Thus, the mildly acidic and hydrolase-rich microenvironment of endosome might be served as trigger for controlled drug release. For instance, Nuhn et al. [82] developed a self-assembled, pH-degradable TLR7/8 agonist-ligated nanoparticle carrier (IMDQnano) that can protect TLR7/8 agonist from systemic bio-distribution and unfavorable degradation, while retaining the valid anti-tumor efficacy of localized IMDQ treatment. Meanwhile, a study from
Wang et al. [83] reported an amphiphilic conjugation of TLR7/8 agonist to poly (ethylene glycol) (PEG) via endosomal enzyme-responsive linker that self-assembled to form a nano-vesicular structure to achieve lymph node-focused drug delivery and enzyme-triggered release of native drugs after endocytosis, eventually inducing robust maturation of DC cells in vivo (Fig. 3).

Finally, artificial DC-derived nano-vaccines, regardless of DC membrane coating formulations [84] or DC-derived microvesicles [85], have been reported to have the inherent potential of antigen presentation and $\mathrm{T}$ cell stimulation from activated DCs and to exert marked therapeutic and prophylactic effects against tumors.

\subsubsection{Synchronous Delivery of Adjuvants and Neoantigens}

Efficient induction of antigen-specific adaptive immunity requires two conditions: successful tumor-specific neoantigen delivery to APCs and sufficient APC activation, a so-called adjuvant effect [86-88]. Recent studies on nanotechnology-based co-delivery strategies, apart from ICD induction [89], have reported that subunit antigens (including ovalbumin [90]) and antigen-coded mRNAs [91] are the most commonly used model antigens, and these applied adjuvants were primarily classified as TLR agonists including lipopolysaccharide (LPS) for TLR4 [92], imiquimod and resiquimod for TLR7/8 [93], and CpG for TLR9 [94].

Simultaneous co-delivery of specific antigen epitopes and immunostimulant moieties is required for efficient vaccine immunogenicity [45]. Owing to the nucleic acidlike property of $\mathrm{CpG}$ and the facile modification of nucleic acids, Jin et al. [95] reported a self-assembling lipidDNA-peptide nano-aggregation (INA) hybridized with the CpG motif, lipid-DNA, and antigen peptide-DNA for co-delivery of multiple adjuvants and antigens together (Fig. 4). The hybrid-DNA nanostructures could efficiently co-deliver the antigen peptide and $\mathrm{CpG}$ to $\mathrm{CD} 8 \alpha^{+} \mathrm{DCs}$ in the tumor-DLN, promoting potent antigen presentation to regulatory T cells via DC activation. Finally, INA treatment could exhibit anti-tumor and anti-metastasis effects against carcinoma and melanoma in vivo. Another study reported a generalizable conjugation approach for co-delivering peptide antigens and adjuvants in a self-assembling vaccine platform (SNP-7/8a) of uniform size $(\sim 20 \mathrm{~nm})$ 


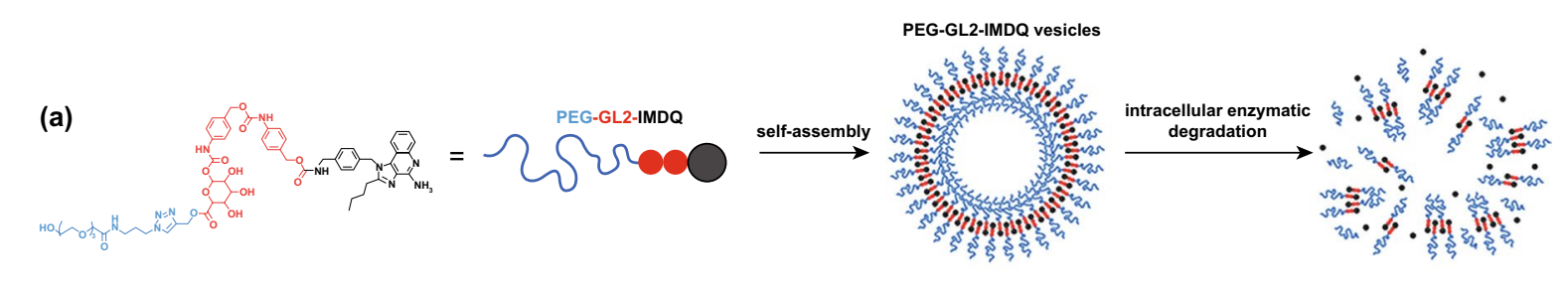

(b)

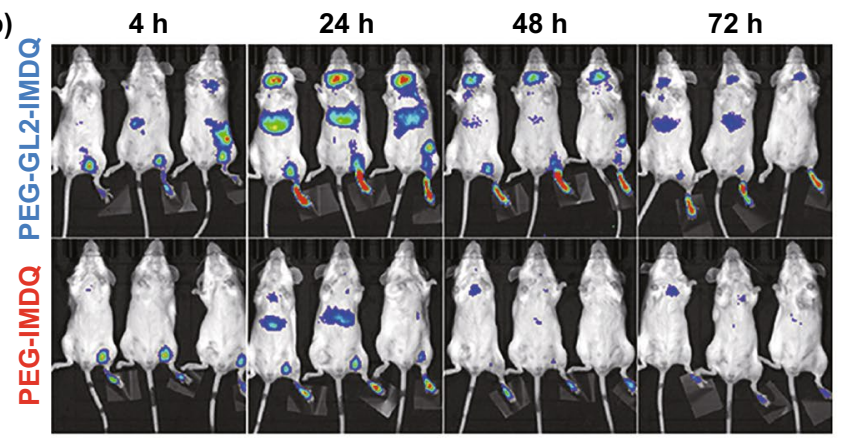

(c)

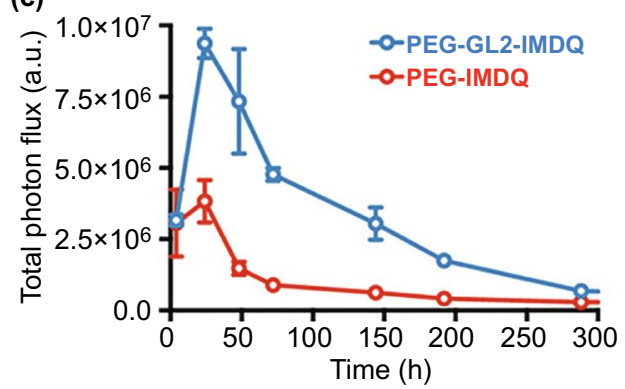

(d) $\square$ blank control

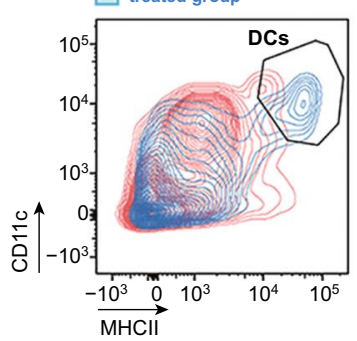

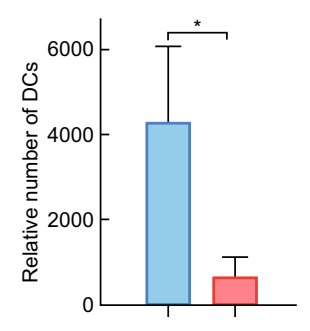

(e) $\square$ blank control

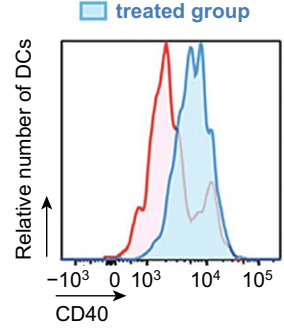

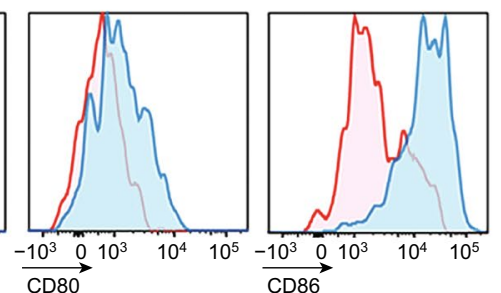

Fig. 3 a Schematic representation of the fabrication of IMDQnano: block copolymers composed of mTEGMA and PFPMA self-assemble in DMSO into micellar nanoparticles driven by solvophobic interaction between PFPMA moieties. Covalent IMDQ-ligation, cross-linking with a pH-sensitive cross-linker, and transformation of unreacted PFP esters into hydrophilic repeating units yield stable hydrogel nanoparticles that can disassemble into soluble polymers in response to an acidic $\mathrm{pH}$. b Size distribution measured by DLS and IMDQ loading of IMDQnano and empty nanoparticles. c TEM images of IMDQnano and empty nanoparticles. $\mathbf{d}$ Tumor growth of B16 tumors in mice, in response to treatment monotherapy and combination therapy $(n=6)$. e Confocal microscopy image of a tissue section collected from a B16 tumor treated with IMDQnano, anti-PDL1, and Flt3L combination immunotherapy. f Confocal microscopy image of a tissue section collected from a B16 tumor treated with PBS control. Reproduced with permission from Ref. [83]

[96], containing hydrophilic positive charge-modified antigen peptide, cathepsin degradable linkers, and hydrophobic poly-TLR-7/8 agonists. Subcutaneous vaccination of SNP-7/8a containing 179 types of predicted neoantigens in mice activated CTLs against $~ 50 \%$ of neoantigens with high predicted binding affinity of MHC-I, thus reinforcing tumor clearance.

\subsubsection{Targeted Intracellular Delivery of Adjuvants and Neoantigens}

Endogenous antigen can directly activate antigen-specific CTLs via MHC-I-mediated antigen presentation, while exogenous antigens are presented by MHC-II to activate regulatory $\mathrm{T}$ cells, which facilitates CTL-mediated cellular immunity or B cell-mediated humoral immunity [97]. Hence, cytosolic delivery of exogenous antigens is necessary for the antigen to be considered an endogenous antigen and presented to CTLs via MHC-I. However, most adjuvants are ligands of TLR7/8/9, expressed in DC endosomes [98]. In order to deliver not only adjuvants, such as CpG-DNA, to endosomes but also antigens to the cytosol of DCs, Yoshizaki et al. developed liposomes modified with a pH-sensitive polymer (MGlu-HPG) loaded with cationic lipids (TRX), Toll-like receptor 9 ligand (CpG-DNA), and the antigen peptide (ovalbumin) for efficient antigen delivery and DC activation [94]. After 


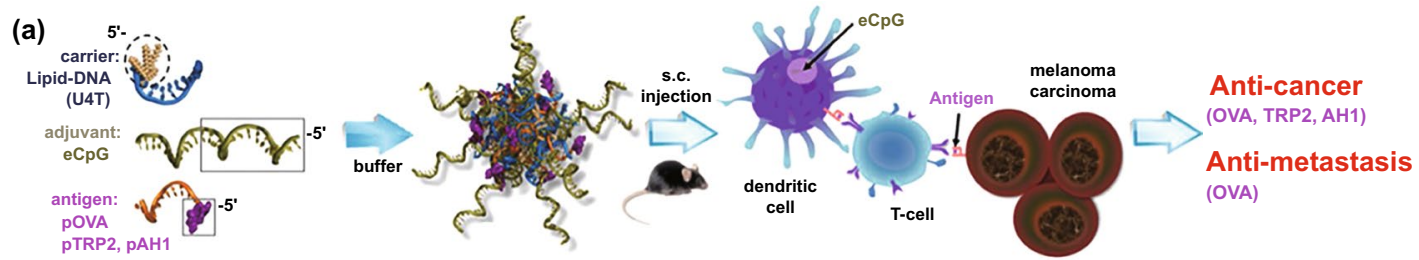

(b) (i)

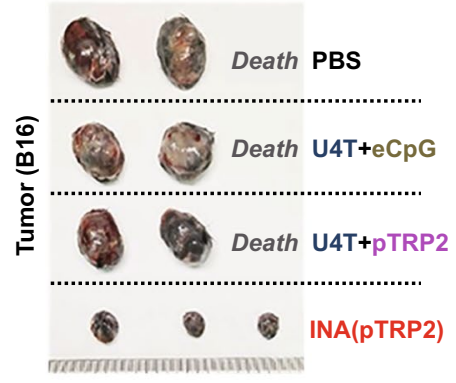

(iv)

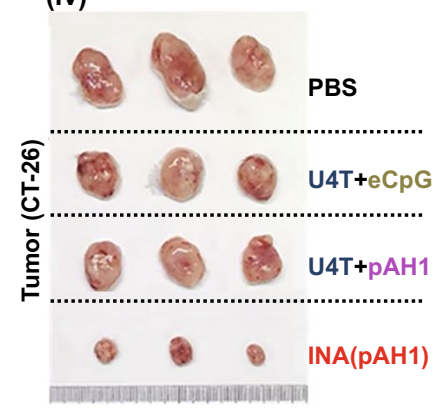

(ii)

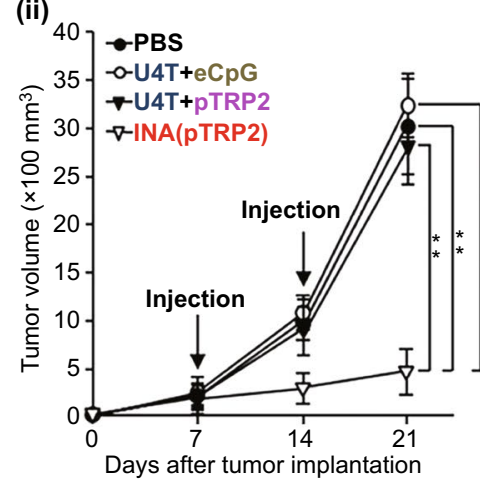

(v)

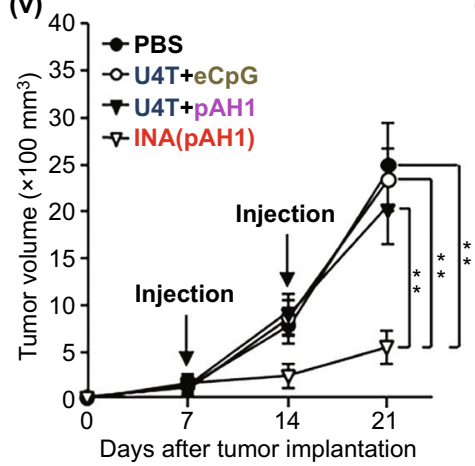

(iii)

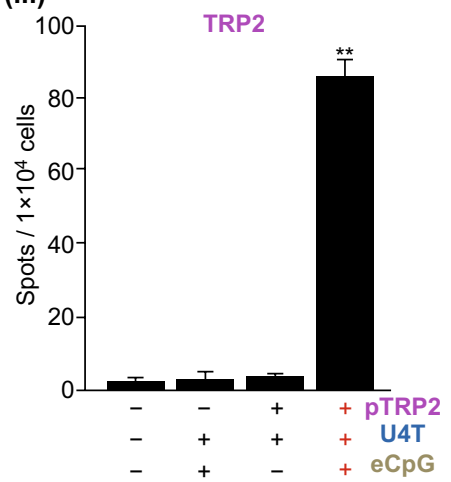

(vi)

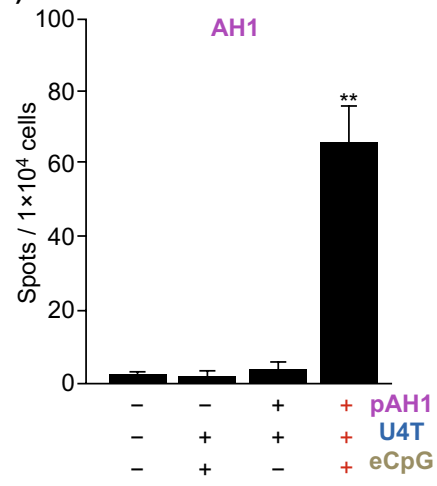

Fig. 4 a Carrier (U4T) is a lipid-DNA that consists of four dodec-1-ynyluracil (U) nucleobases at the 5'-end and eight regular deoxyribonucleotides. In aqueous media, lipid-DNA strands are hybridized with eCpG. At the 5'-end, the 20-nucleobases long murine TLR-9 ligand (phosphorothioate linkage, italicized) was extended with 12-bases complimentary to the lipid-DNA and antigen (pOVA, pTRP2 or pAH1, Ovalbumin1 (OVA) peptide epitope (AA sequence: SIINFEKL, magenta) is covalently attached to a peptide nucleic acid sequence complementary to lipid-DNA (orange).) in an equimolar ratio. Thus, immunotherapeutic nucleic acid (INA) loaded with both multiple adjuvants and antigens is formed. Subcutaneous injection of INA into tumor-bearing mice induces an antigen-specific immune response via CD8 $\alpha+$ DCs and subsequent presentation of antigen via regulatory T cells. The antigen-specific immune stimulation by INA results in successful therapeutic effects (inhibited growth of multiple tumors and metastasis). b Cancer Ag-specific anticancer effect of INA, including cancer Ag of melanoma (TRP2) or carcinoma (AH1). (i) Sizes of tumor masses on day 21 after introduction of the melanoma tumor cells, (ii) B16 melanoma tumor growth over time, (iii) TRP2 peptide-specific IFN- $\gamma$ production was measured in tumor-drLN by ELISpot. Mean \pm SEM $(n=6)$. **p $<0.01$. (iv-v) BALB/c mice were injected s.c. with CT-26 carcinoma cells and treated with INA on day 7 and 14 following tumor injection, iv) sizes of carcinoma tumor masses on day 21, (v) tumor growth curve of carcinoma, vi) AH1 peptide-specific IFN- $\gamma$ production and the mean number of spots are shown. Mean $\pm \operatorname{SEM}(\mathrm{n}=6) . * \mathrm{p}<0.01$. Reproduced with permission from Ref. [95]

the classic receptor-mediated endocytosis, adjuvants, TRX, and CpG-DNA bound to their cognate endosomal receptors and stimulated DC activation (up-regulation of co-stimulatory molecules and cytokine production). Thereafter, owing to the $\mathrm{pH}$-sensitive membrane fusion potential of MGlu-HPG, the endosomal membrane was gradually degraded and the loaded antigen was released into the cytosol for MHC-I-mediated cross-presentation to CTLs, resulting in high immunity-inducing effects for effective cancer immunotherapy. 


\subsection{5 mRNA-Based Vaccines}

Recently, mRNA encoding antigen-based vaccines have received increasing attention for developing anti-tumor immunity [99, 100]. Compared with conventional liveattenuated or subunit vaccines, the advantages of mRNAbased vaccines are obvious [101], including less safety concerns, the potential to produce various personalized tumor antigens with GMP quality, and intra-cytosolic translation of selected antigens in DCs, which can be directly presented to CTLs via MHC-I [97]. Nano-delivery strategies have facilitated effective intra-cytosolic delivery of mRNAs in DCs; however, it is not that easy to successfully translate the delivered mRNAs into coding antigens in DC cells. Verbeke et al. and other groups have reported that foreign mRNA is usually recognized by the intracellular danger-sensing receptors, such as TLRs, thus inducing an innate immune response and burst release of type I IFNs, which in turn reduce the mRNA stability and further translation [91, 102, 103]. Therefore, it is critical to develop a delivery system that can not only protect mRNA, but also enable efficient release and translation at the appropriate time for mRNA vaccine delivery. Primarily, researchers have generated nucleotide-modified mRNA to protect mRNA by preventing the release of mRNA recognition-associated type I IFNs; however, this strategy resulted in the loss of mRNA-related self-adjuvant effects, thus affecting DC activation and $\mathrm{T}$ cell priming. Furthermore, they developed a lipid nanoparticle encapsulating nucleoside-modified mRNA and TLR4 agonist monophosphoryl lipid A (MPLA) to ensure both antigen up-regulation and moderate the DC activation [91]. Similarly, to compensate for reduced DC stimulation owing to the reduced type I IFN, they assessed a combined delivery tactic of immune-silent nucleoside-modified mRNA and activator of invariant natural killer T cells (iNKT), glycolipid $\alpha$-galactosylceramide $(\alpha-G C)$ in their recent study [104]. In this study, $\alpha-G C$ served as an indirect adjuvant for inducing controllable DC activation via bidirectional activation between iNKT cells and $\alpha$-GC-presenting DCs, thus contributing to sevenfold tumor infiltration of antigen-specific CTLs than the current "gold standard" on the administration of mRNA vaccines.

\subsubsection{Lymph Node Targeting}

Lymph nodes (LN) are crucial secondary lymphoid organs where abundant APCs and T cells reside and interact for immune surveillance and responses against pathogens and tumors [105]. Therefore, increasing the transport of vaccines to LNs would be a beneficial strategy for reinforcing the immune responses. Numerous previous studies have demonstrated that nano-vaccines containing antigens and adjuvants exhibited the superior capability of increasing lymph node accumulation due to their cargo protection and lymph node-targeting transport [106]. In general, there are two ways for peripherally administrated vaccines traveling to lymph nodes that is passive transport through afferent lymphatics or peripheral DC cells-mediated active transport. Nowadays, it is a common agreement that translocating vaccines through the passive transport is much more efficient than the active pathway [107]. Thus, we will focus on the novel strategies that reinforced the lymph node accumulation via passive transport in this section. Recently, Nakamura et al. [108] reconfirmed that the negatively charged 30-nm-sized lipid nanoparticles (LNPs) were more efficiently translocated to the deep cortex of LNs and taken up by $\mathrm{CD}^{+}{ }^{+} \mathrm{DC}$ cells through afferent lymphatics than the larger-sized LNPs or neutral/positively charged 30-nm-sized LNPs (Fig. 5a). Many researchers [106] also suggested that modifying the smallsized nanoparticle with DC-targeting molecular (such as, mannose [109], Fc receptor [110] or alginate [111]) could improve the possibility of nanoparticles being ingested by DC cells after entering the lymphatic vessels, thereby facilitating their trafficking to LNs. Similarly, endogenous vectors, represented by albumin, with the capability of entering lymphatics in the interstitium can also be exploited for LNtargeting drug delivery. Irvine group [112] was the pioneer to discover that long-chain fatty acids or hydrophobic molecules can bind to albumin with hydrophobic interaction, and they have developed a variety of long-chain fatty acids coupled adjuvant products and demonstrated their readily facilitating $\mathrm{LN}$ accumulation of adjuvants by hitch-hiking the albumin. Furthermore, several strategies focusing on the regulation of lymphatic vasculature have also been developed to facilitate nanoparticle LN delivery. Nitric oxide (NO) is a potent agonist for vascular and lymphatic vessel dilation. Recently, 

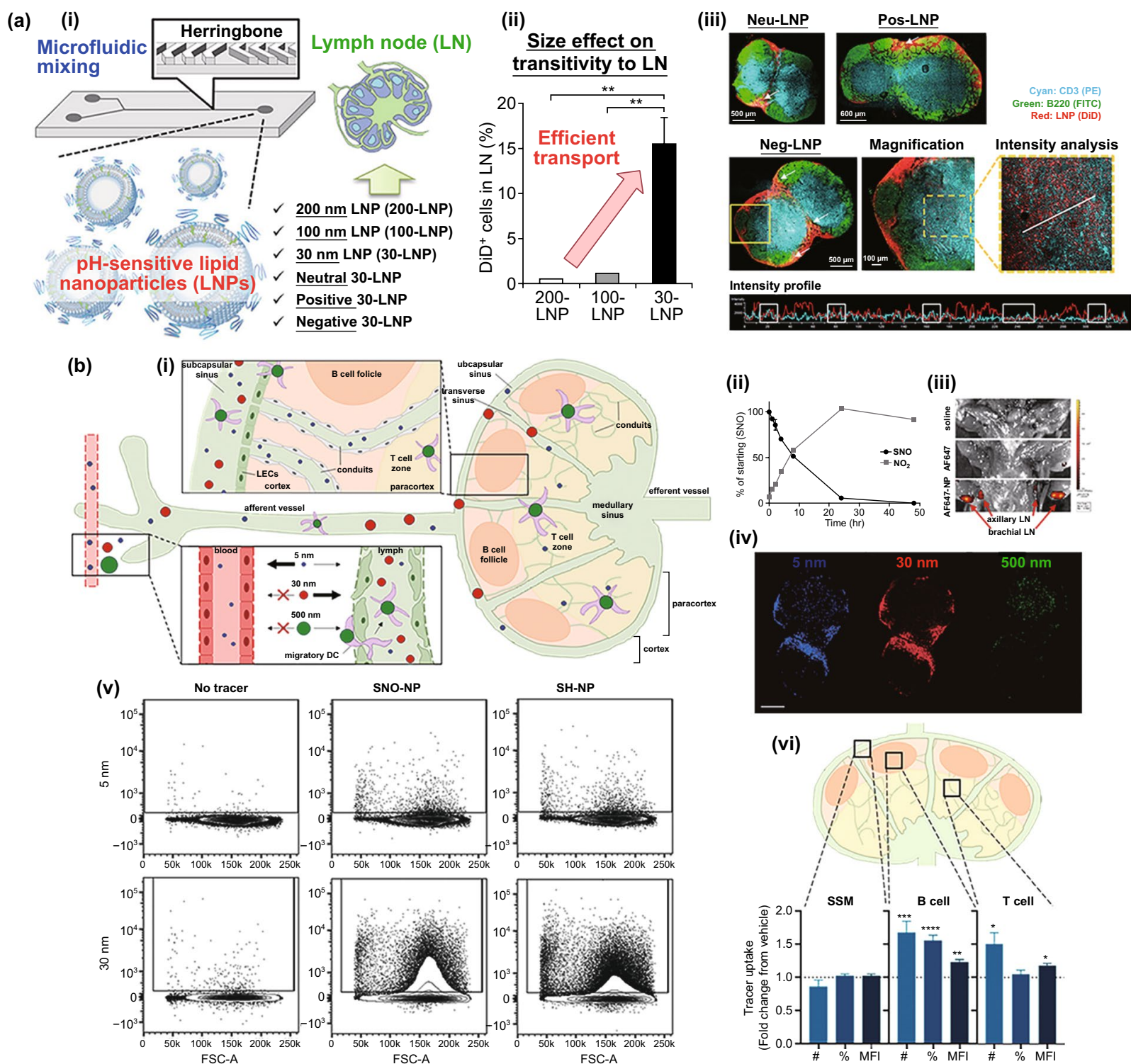

(ii)

(iii)
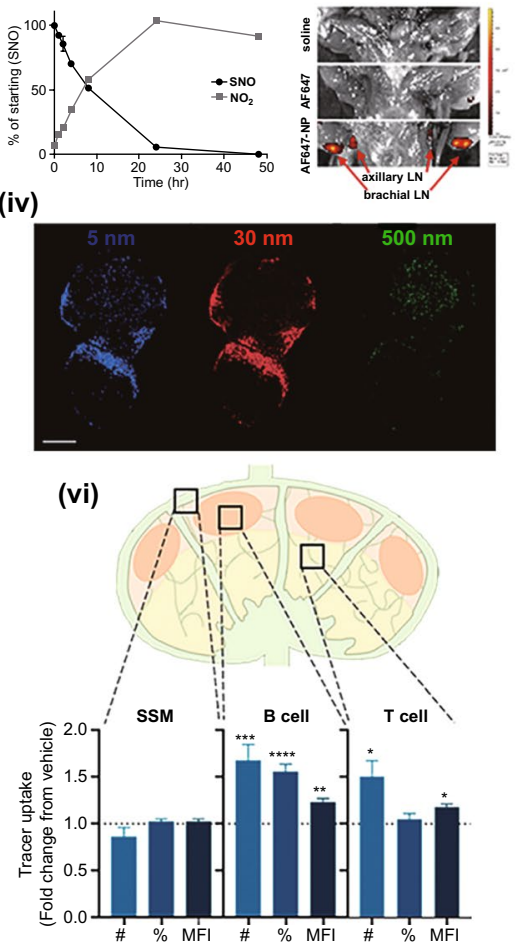

Fig. 5 a (i-ii) Scheme of effect of size and charge of lipid nanoparticles prepared by microfluidic mixing on their lymph node transitivity and distribution. (iii) CLSM images of LNs treated with each LNP. The white arrows represent yellow dots showing the colocalization of B220 ${ }^{+}$ cells and LNPs. An intensity analysis was performed in the range of the white line. White squares in the intensity profile represent the colocalization of $\mathrm{CD}^{+}$cells and LNPs. Cyan, green, and red show CD3 (PE), B220 (FITC), and LNP (DiD), respectively. Reproduced with permission from Ref. [108]. b (i) Schematic of size-based effects on molecule drainage from the interstitium and into draining LNs $(\mathrm{dLNs})$. Blue $=5 \mathrm{~nm}$, red $=30 \mathrm{~nm}$, and green $=500 \mathrm{~nm}$ molecules, (ii) S-nitrosothiol (SNO) and nitrite $\left(\mathrm{NO}_{2}\right)$ concentration in a solution of SNO-NP over time, (iii) IVIS imaging of AF647-labeled NP draining to axillary and brachial LN from a forelimb injection, (iv) confocal microscopy images of tracer distribution within a brachial LN $72 \mathrm{~h}$ after ipsilateral forelimb injection. Scale bar $=500 \mu \mathrm{m}$, (v) representative examples of CD45 $+\mathrm{LN}$ cells without 5 and $30 \mathrm{~nm}$ tracers, or with tracer and SNO-NP or SH-NP treatment, vi) effect of SNO-NP treatment on tracer uptake by barrier, cortex, and paracortex cell populations. Reproduced with permission from Ref. [113]

Sestito et al. [113] employed a controlled NO release nanocarrier (SNO-NP) to investigate the effect of lymphatic-targeted NO on LN accumulation, distribution and uptake of codelivered nanoparticles. In this study, they demonstrated that a sustained NO release in the lymphatic system could expand the lymphatic vessel and enhance the LN penetration, as well as the lymphocytic uptake of co-delivered nanoparticles after i.d. injection (Fig. 5b). Besides, Park et al. [114] reported that pre-treatment with chitosan can improve the movement of nanoparticles across the vaginal epithelium to LNs. 


\subsubsection{ICD Induction}

The heterogeneity of tumor antigens and inevitable systemic safety concerns of adjuvants are two major challenges associated with the development of an effective co-delivery system for adjuvants and antigens to induce antigen-specific CTLs [115-119]. Ideally, each patient requires personalized treatment. Recent treatments stimulating tumor cells to undergo immunogenic apoptosis and facilitating in situ exposure of multiple neoantigens and DAMPs, termed as immunogenic cell death (ICD), have received increasing attention in personalized medicine [89, 120-122]. Apart from neoantigen release, the major immunogenic characteristics of ICD are mediated through DAMP exposure, including surface exposure of calreticulin (CRT), ATP secretion, and post-apoptotic exodus of heat shock proteins (HSPs) and high mobility group protein B1 (HMGB1). In particular, secreted ATP stimulates the intra-tumoral recruitment of APCs and CTLs, surface-translocated CRT serves as an 'eat me' signal for DC phagocytosis, and milieu-released HSPs and HMGB1 serve as activators for DC maturation and promote antigen presentation to CTLs. Ultimately, ICD treatment results in a vaccine-like effect in situ, leading to an antigen-specific immune response.

Certain current chemotherapeutics [123-125] including doxorubicin, mitoxantrone, oxaliplatin, and cyclophosphamide, radiotherapy (RT) [126], photodynamic therapy (PDT) [127], photothermal therapy (PTT) [128], and magnetic hyperthermia (MT) [129] are frequently reported ICD inducers. ICD refers to apoptosis due to ROS [130], and current studies on ICD induction are aimed at enhancing the ROS-inducing effect of ICD inducers through reformation or combination strategies [131-134]. For most chemotherapeutic ICD inducers, stimulating ICD-associated danger signaling is usually a collateral effect of their cytotoxicity [135]. Thus, we developed a combinatorial treatment strategy involving oxaliplatin and ferroptosis as prodrug-loaded $\mathrm{Fe}_{3} \mathrm{O}_{4}$ nanoparticles, to improve the ICD effect of oxaliplatin [132]. With advancements in biomedical equipment, microinvasive PTT and PDT have received increasing attention owing to their accuracy and high efficiency during tumor destruction and during ROS-associated ICD induction [136-139]. For example, Zhang et al. [140] proposed that the tumor starvation therapy performed by PTT-inducing gelation shrinkage could comprehensively suppress the tumor growth, whether the tumor is in situ, metastatic or recurrence.

Furthermore, Zhou et al. reported combination of PDT and chemical ICD inducer via TME-stimulating prodrugloaded vesicle could synergistically reinforce the growth inhibition of both primary and abscopal tumors in addition to CD47 blockade [52]. Meanwhile, Chen et al. put forward that upon irradiation, mitochondrial targeted aggregationbased emission photosensitizers [131] could evoke superior and larger-scale ICD than the popularly used photosensitizers, such as pheophorbide A and chlorin e6. Moreover, apart from encapsulating PSs into organic nanocapsules or attaching PSs onto nanoparticle surfaces, the metal-organic framework (MOF) self-assembled from PSs and metal clusters by coordination bonds have displayed great potential as nano-PSs for PDT within a high PS loading but less selfquenching [137, 141-143]. Besides, Park et al. reported that the 90-nm-sized nanoMOF exhibited 1.7-fold PDT efficacy than free PS [144] and Shao et al. developed a core-shell heterostructure comprising a UCNP core and porphyrinic an MOF shell for enhanced anti-tumor activity of combined PDT, hypoxia-activated chemotherapy, and immunotherapy $[145,146]$. Meanwhile, some studies introduced low-dose deeply penetrating $X$-ray as alternatives, with the incorporation of high-Z elements as transducers, thus enabling radiodynamic therapy to significantly cause tumor regression at very low X-ray doses with less side effects [147-149].

Since the ultrasound is non-radiative, which is superior to laser and X-ray in terms of penetration, sonodynamictherapy (SDT) has attracted increasing interest in ICD induction. Yue et al. [150] proved that combination therapy of checkpoint blockade and SDT based on clinically approved material comprising HMME/R837@ Lip can not only reduce the tumor growth, but also prevent metastases and re-challenged tumor in mice. However, the low ROS generation caused by poor energy conversion efficiency from ultrasound to ROS-related chemicals is a challenge limiting SDT adoption. In order to improve the outcome of SDT, Zhang et al. contributed greatly. As oxygen is the key substrates for ROS production, they fluorinated the hollow mesoporous organosilica nanoparticles (HMONs) for oxygen immobilization, as well as narrowing the distance between sonosensitizer (IR780) and oxygen, eventually relieving hypoxic and facilitating the efficiency of SDT against PANC-1 solid tumor [151] (Fig. 6a). In addition, they have enabled SDT-based nanoparticles with continuous $\mathrm{CO}_{2}$ bubble generation to 
promote ROS production and enhance the effect of ICD against breast carcinoma [152]. Recently, there is a growing perspective that induced ROS can be depleted by reductive species (such as GSH) for intra-tumoral redox metabolism equilibrium. In this regard, Guan et al. [153] developed metabolism-engineered and SDT-based nanoplatform $\left(\mathrm{Nb}_{2} \mathrm{C} / \mathrm{TiO}_{2} / \mathrm{BSO}-\mathrm{PVP}\right)$ wherein GSH synthesis inhibitor and sonosensitizer $\left(\mathrm{TiO}_{2}\right)$ are accommodated by the $\mathrm{Nb}_{2} \mathrm{C}$ nanosheets to reduce ROS depletion and so as to improve the ROS production synergistically (Fig. 6b).

(a)

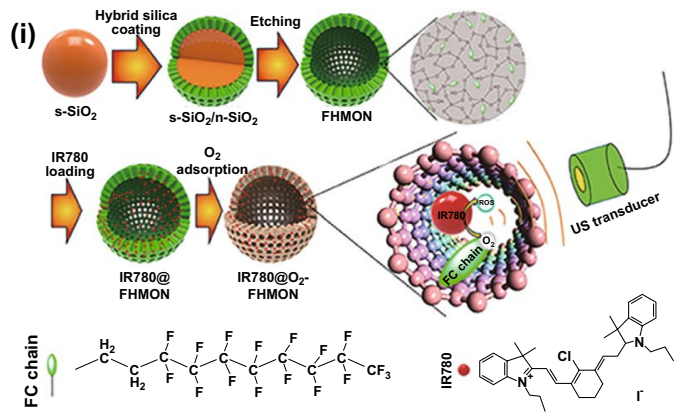

(iii)

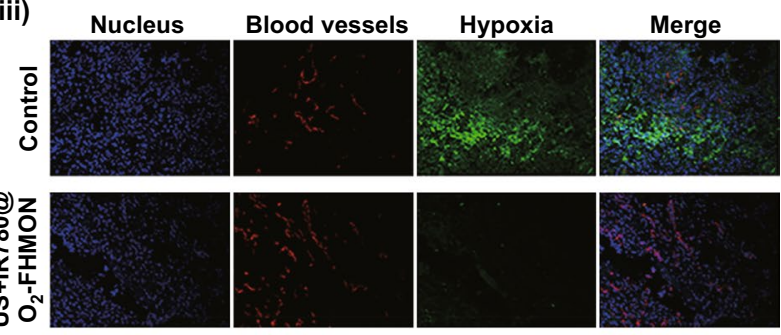

(ii)
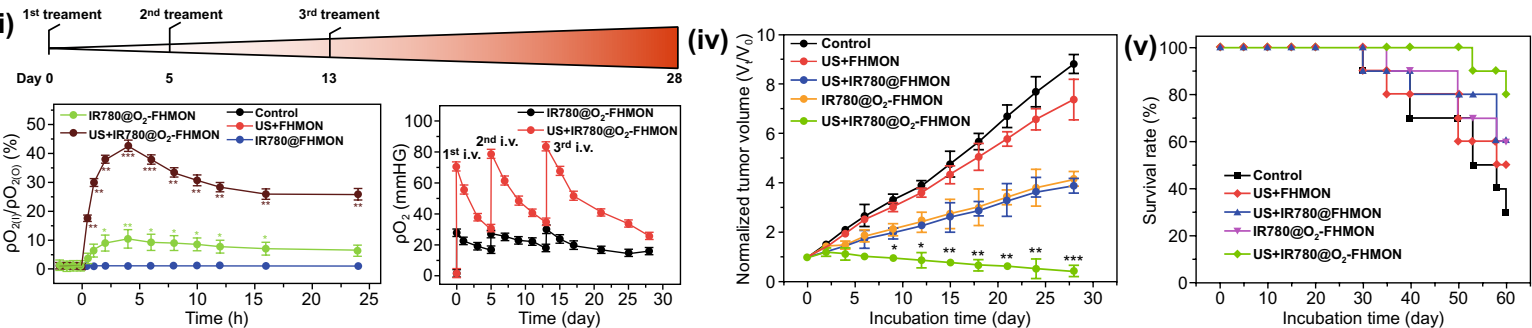

(b) (i)

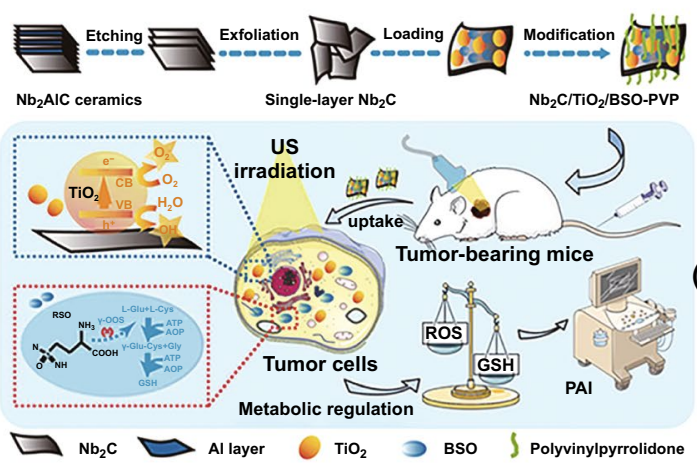

(ii)
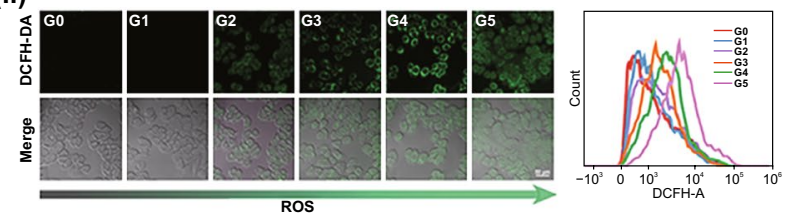

(iii)
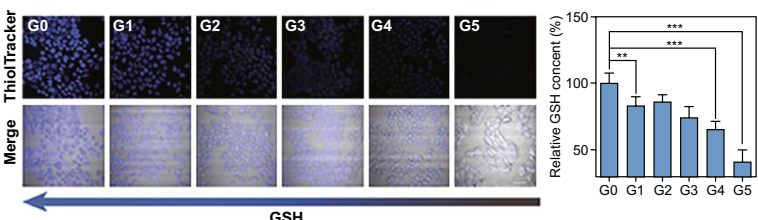

Fig. 6 a (i) Synthetic process and action principle of IR780@ $\mathrm{O}_{2}$-FHMON and characterization of FHMON carriers, (ii) In vivo therapeutic scheme of SDT on mice tumor xenograft and Relative $\mathrm{pO}_{2}$ variation of PANC-1 solid tumor after the first treatment within $24 \mathrm{~h}$, significance was obtained via comparing to control $\left(*, * *\right.$, and *** represent $\mathrm{p}<0.01,0.005$, and 0.001 , respectively), as well as $\mathrm{pO}_{2}$ of $\mathrm{PANC}^{*} 1$ solid tumor during the complete SDT experimental period, (iii) LCSM images of nuclei, blood vessels, and hypoxic regions stained by DAPI, hypoxia probe, and CD31 immunochemical methods in PANC-1 solid tumor slices of all groups at day=28, (iv) time-dependent tumor volume variation of PANC-1 solid tumor treated with the above different groups. Data are presented as the mean value \pm SD $(n=6)$, significance is obtained via comparing to the control group $(* \mathrm{p}<0.01$, $* * \mathrm{p}<0.005$, and $* * * \mathrm{p}<0.001)$, (v) survival rate of tumor-bearing nude mice after treatments with the above different groups during the complete experimental period. Reproduced with permission from Ref. [151]. b (i) Schematic on the preparation process and enhanced SDT mechanism of $\mathrm{Nb}_{2} \mathrm{C} / \mathrm{TiO}_{2} / \mathrm{BSO}-\mathrm{PVP}$, (ii) CLSM images and corresponding FCM data of $4 \mathrm{~T} 1 \mathrm{cells}$ after different corresponding treatments in G0-G5 and subsequent DCFH-DA staining, (iii) CLSM images of 4T1 cells after different corresponding treatments in G0-G5 and subsequent ThiolTracker Violet dye staining, scale bar $=50 \mathrm{~nm}$, as well as relative intracellular GSH content in 4T1 cells determined by Ellman's reagent after different corresponding treatments in G0-G5. Data are expressed as mean \pm standard deviation (SD) $(\mathrm{n}=3)$ and $* \mathrm{p}<0.05$ and $* * * \mathrm{p}<0.001$, which were obtained using t-student test. Note: G0-G5 represent $\mathrm{Control}, \mathrm{Nb}_{2} \mathrm{C} / \mathrm{TiO}_{2} / \mathrm{BSO}-\mathrm{PVP}, \mathrm{US}$, $\mathrm{TiO}_{2}-\mathrm{PVP}+\mathrm{US}, \mathrm{Nb}_{2} \mathrm{C} / \mathrm{TiO}_{2}-\mathrm{PVP}+\mathrm{US}$, and $\mathrm{Nb}_{2} \mathrm{C} / \mathrm{TiO}_{2} / \mathrm{BSO}-\mathrm{PVP}+\mathrm{US}$, respectively. Reproduced with permission from Ref. [153] 


\subsection{Strategies for Overcoming $\mathrm{T}$ cell Exclusion}

\subsubsection{Characteristics of T cell Exclusion in Cold Tumors}

Binding of chemokine ligands CXCL9 and CXCL10 to CXCR3 is required for active $\mathrm{T}$ cell migration and infiltration into tumor beds [30]. However, this phenomenon is normally suppressed in cold tumors. Histone modifications and DNA methylation are the major epigenetic factors that can directly down-regulate $C X C L 9$ and $C X C L 10$, resulting in decreased $\mathrm{T}$ cell recruitment $[154,155]$. Furthermore, R-2-hydroxyglutarate generation associated with mutations in isocitrate dehydrogenase 1 and 2 (IDHI and IDH2, respectively) can inhibit intra-tumoral CXCL9 and CXCL10 production [156]. Since CXCL9 and CXCL10 are IFN-responsive genes [157], the factors affecting $\mathrm{CD}_{103^{+}}$DC recruitment, such as Wnt- $\beta$-catenin pathway activation, might decrease $\mathrm{T}$ cell infiltration by affecting type I IFN expression.

Furthermore, the activation of tumor-associated fibroblasts (TAFs) and subsequent extracellular matrix (ECM) deposition might be another factor affecting $\mathrm{T}$ cell infiltration at tumor sites by the formation of physical barriers $[158,159]$. TAF heterogeneity is associated with their tissue of origin, e.g., TAFs are regarded to originate from the bone marrow-derived precursors (BMDP), mesenchymal stem cells (MSC), liver and pancreas stellate cells, resting tissue fibroblasts and probably from several certain types of epithelial cells [160]. First, tumor cells harboring KRAS or NF- $\mathrm{KB}$ mutations release mitogenic and fibrogenic factors that can reprogram normal pro-fibrotic cells into active TAFs, including vascular endothelial growth factor (VEGF), platelet-derived growth factor (PDGF), TGF- $\beta$, and sonic hedgehog (SHH) [161-164]. Thereafter, a positive feedback expression of pro-inflammatory cytokines (including VEGF and TGF- $\beta$ ) produced from TAFs further promotes the TAF activation and promotes the production of abundant ECM components (including collagens, glycoproteins, elastin, and hyaluronan), resulting in extensive ECM deposition. The dense and compact ECMs tend to serve as a physical barrier to the entry of oxygen and nutrients and an impediment to active $\mathrm{T}$ cell migration. Furthermore, the activated TAFs produce factors including CXCL12 to limit the T cell recruitment to tumor lesions [165].

Third, the growing desmoplastic stroma can obstruct inner tumor cells from blood vessels, thus generating a highly hypoxic tumor cell-rich islet. In turn, the hypoxiainduced positive feedback loops reinforce ECM deposition by up-regulating pro-inflammatory cytokines including VEGF and TGF- $\beta$, while this further deters the T cell infiltration [162]. Simultaneously, hypoxia microenvironment increases the demand for tumor angiogenesis through hypoxia-inducible factor- $1 \alpha$ (HIF- $1 \alpha)$-mediated up-regulation of various growth factors (represented by VEGF) [166], which in turn activates the FasL on tumor endothelial cells, thus triggering apoptosis in $\mathrm{T}$ cells upon binding to Fas expressed on $\mathrm{T}$ cells and reducing $\mathrm{T}$ cell infiltration [167]. Owing to the up-regulation of pro-angiogenic signaling (e.g., VEGF signaling), the tumor neovascularization network is weakened, with a lack of pericyte coverage and loose endothelial cell junctions, thus disrupting blood vessel integrity and affecting blood flow [168]. Such increased neovascular permeability facilitates the extravasation of plasma proteins including fibrin, facilitating the influx of fibroblasts and inducing ECM deposition [158]. Moreover, VEGF up-regulation can induce a clustering defect among leukocyte adhesion molecules on endothelial cells, which deters the T cell extravasation, e.g., intracellular adhesion molecule-1/2 (ICAM-1/2), vascular cell adhesion protein-1 (VCAM-1), and CD34 [169].

\subsubsection{Stroma Normalization}

Currently, three types of approaches for overcoming physical barriers have been reported: incentive control, matrix component degradation, and penetrating-nanoparticle exploitation. First, strategies for incentive control, also known as stroma normalization [170, 171], are primarily focused on inhibiting known factors contributing to matrix deposition, including VEGF [172], TGF- $\beta$ [173], CXCL12 [174], HIF- $\alpha$ [175], and the hedgehog pathway [176]. Chen et al. reported that normalization of tumor vasculature upon being treated with EGFR inhibitors at a moderate dose could not only improve the tumor perfusion of oxygen and nanoscale therapeutic agents, but also alter the immunosuppressive TME by relieving the tumor hypoxia [170]. Another study reported that blockade of CXCR4/CXCL12 signaling with Plerixafor could also alleviate the desmoplasia and immunosuppression, in turn decompressing tumor vessels and increasing $\mathrm{T}$ cell infiltration, eventually enhancing immunotherapy in cold breast 
tumors [177]. Moreover, Papageorgis et al. reported that suppression of TGF- $\beta$ signaling with antifibrotic drugs can significantly enhance the efficacy of nanoparticles with various sizes by reducing the ECM, decreasing interstitial fluid pressure, and improving tumor perfusion [178]. Furthermore, Ji et al. developed a $\beta$-cyclodextrin $(\beta$-CD)modified matrix metalloproteinase-2 (MMP-2)-responsive liposome for co-delivery of antifibrotic and chemotherapeutic drugs [179] (Fig. 7). Upon the MMP-2 cleavage in the TME, the antifibrotic drug pirfenidone in $\beta$-CDs was maintained in the stroma and suppressed TGF- $\beta$ and collagen I in pancreatic stellate cells (PSCs), thereby downregulating fibrosis and decreasing the stromal barrier, thus enhancing drug-encapsulated liposome perfusion, ultimately improving the efficiency for pancreatic cancer therapy without overt side effects.

\subsubsection{Matrix Degradation}

Since the major matrix components include fiber, collagen, and hyaluronic acid (HA) [180, 181], direct degradation of these matrix components is another strategy to disrupt the physical barrier, among which the hyaluronidase-mediated HA degradation has received maximum attention [182-184]. Several studies have reported that the direct injection of hyaluronidase into tumors can effectively degrade intratumor HA and increase tumor (a)

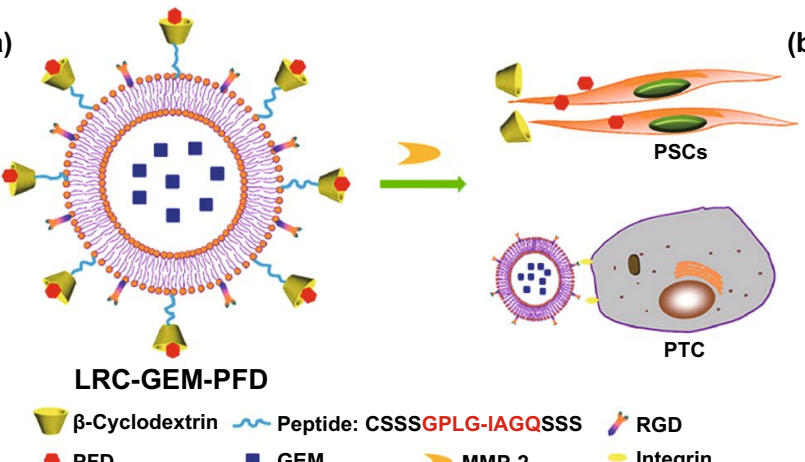

(c)
- GEM

$>M M P-2$
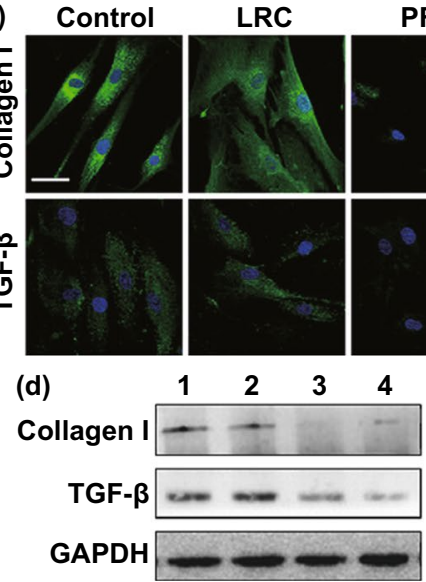

PFD

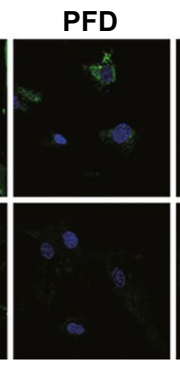

LRC-PFD

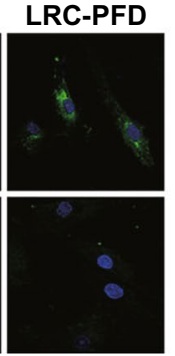

1. Control

2. LRC

3. PFD

4. LRC-PFD

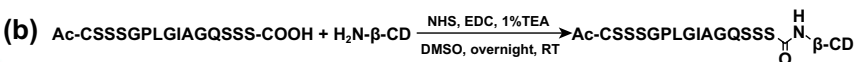

pep-CD

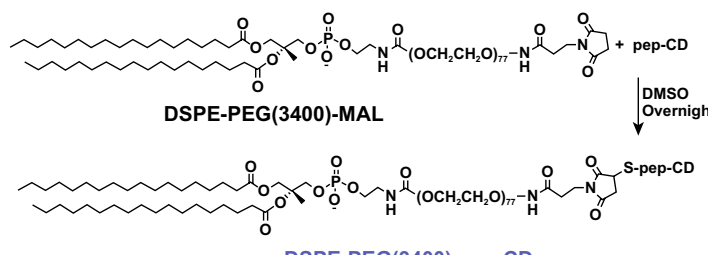

DSPE-PEG(3400)-pep-CD

DSPE-PEG(3400)-MAL + HS-CHRGD $\underset{\text { Overnight, RT }}{\stackrel{\text { DMSO }}{\longrightarrow}}$ DSPE-PEG(3400)-RGD

(e)
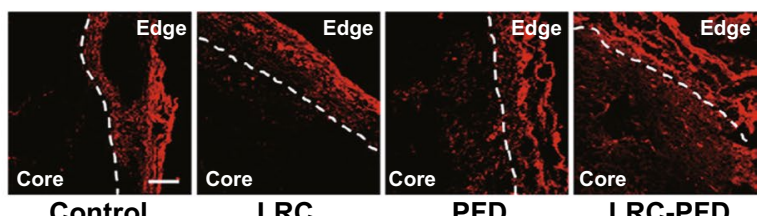

(f) $800,-$ Control

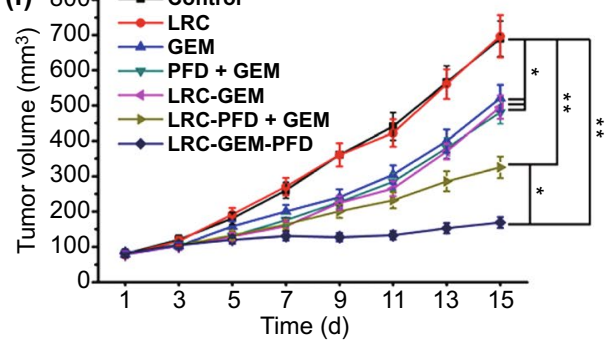

Fig. 7 a The PFD inserts into the hydrophobic chamber of $\beta-C D$, and the GEM was encapsulated in the liposome. If the LRC-GEM-PFD is cleaved by MMP-2, the PFD part will regulate the PSCs, and the GEM containing liposome will recognize and kill the PTCs. b Synthesis of pep-CD, DSPE-PEG(3400)-pep-CD, and DSPE-PEG(3400)-RGD. c The immunofluorescence staining of collagen I and TGF- $\beta$. Blue: HOECHST, green: FITC-labeled collagen I or TGF- $\beta$. The scale bar: $50 \mu \mathrm{m}$. d The Western blot analysis of the collagen I and TGF- $\beta$ in the conditioned medium of PSCs. e Penetration of Rhd into pancreatic tumor (Panc-1 and PSCs coimplanted) tissues after intravenous injection of different PFD formulations. Red: Rhd. The scale bar is $100 \mu \mathrm{m}$. f Tumor growth curves of PSCs/Panc-1 pancreatic tumors in mice treated by different GEM formulations. GEM dose: $20 \mathrm{mg} / \mathrm{kg}$. Data were presented as mean \pm standard deviation $* \mathrm{p}<0.05$, ** $\mathrm{p}<0.01$ vs control. Reproduced with permission from Ref. [179] 
accumulation and penetration of various nanoparticles and the levels of antigen-specific $\mathrm{T}$ cells at tumor sites [185, 186]. Furthermore, to prevent unnecessary degradation of a large amount of HA, thus potentially improving tumor progression, Zhou et al. conjugated hyaluronidase to the surface of PLGA nanoparticles through the click reaction to only degrade the matrix during nanoparticle diffusion [187] (Fig. 8). The study reported that covalently conjugated $\mathrm{rHuPH} 20$ was more efficient than free $\mathrm{rHuPH} 20$ in enhancing the nanoparticle diffusion in the matrix, thus inhibiting the growth of aggressive 4T1 tumors at a low drug dose. Moreover, another study used an exosome (a)
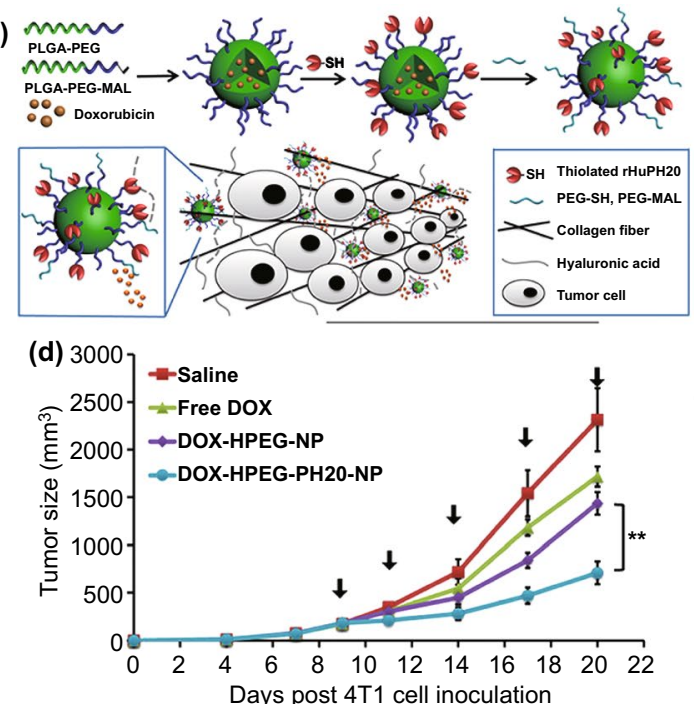

(e)

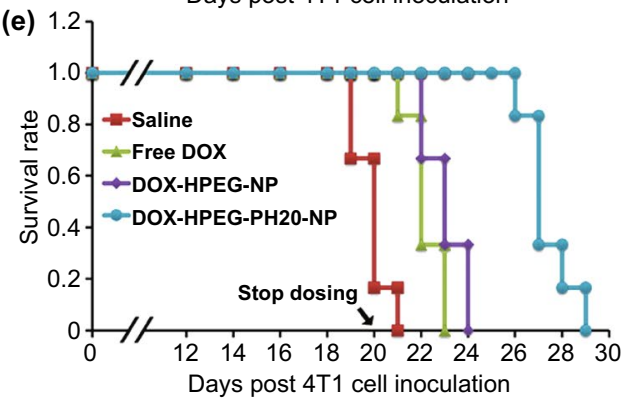

(b)
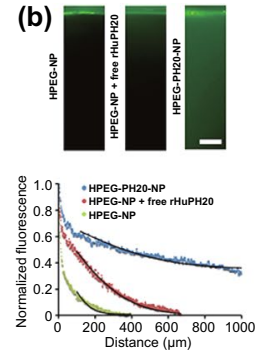

(f)

(f) TUNEL
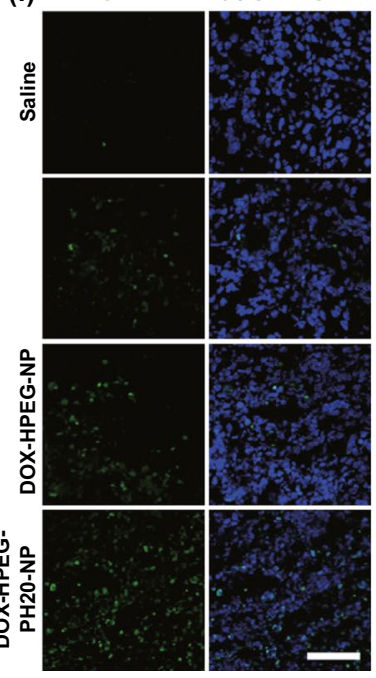
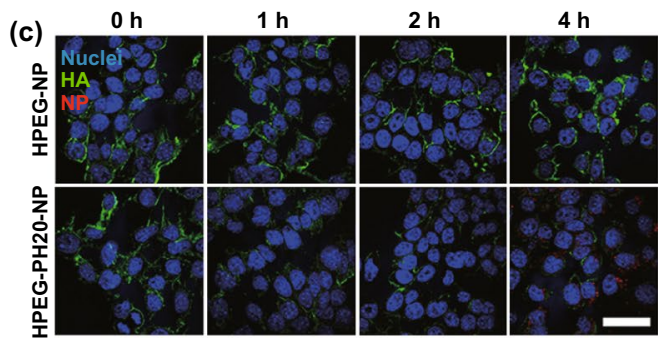

(g)
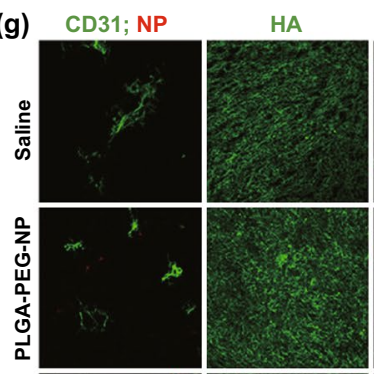

a-SMA
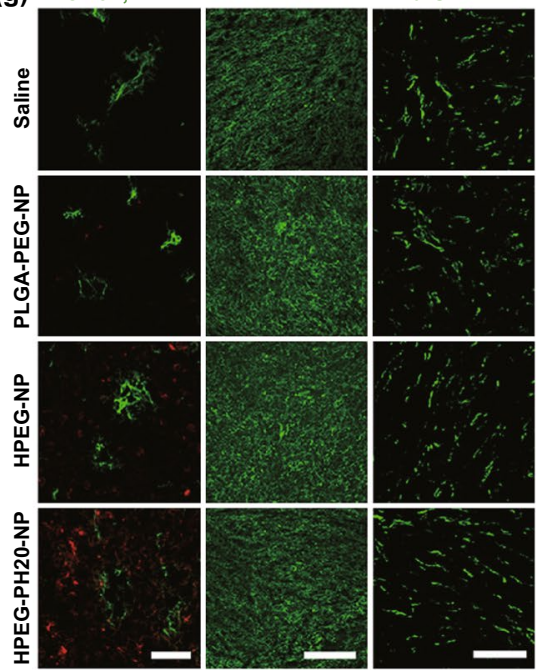

Fig. 8 a Schematic illustration of NP fabrication and penetration in tumors via the degradation of hyaluronic acid (HA). The NPs were fabricated by conjugating thiolated rHuPH20 on the first PEG layer followed by anchoring the second PEG layer. b NP diffusion in ECM-mimicking gels. (Scale bar: $200 \mu \mathrm{m}$ ). The gels composed of $6.5 \mathrm{mg} \mathrm{mL}^{-1}$ of rat collagen I and $1 \mathrm{mg} / \mathrm{mL}$ of HA in capillary tubes. Ten microliters of $1 \mathrm{mg} \mathrm{mL}{ }^{-1}$ of NPs (green) were added on the top of gels and incubated at $37^{\circ} \mathrm{C}$ for $1.5 \mathrm{~h}$ before being imaged. The activity of free or conjugated rHuPH20 was $500 \mathrm{U} \mathrm{mL}^{-1}$ and normalized NP fluorescence with diffusion distance in gels. Images were analyzed via ImageJ. Diffusion coefficients were obtained by fitting the data to a one-dimensional diffusion model in MATLAB. Black lines display theoretical intensity profiles for particles with diffusion coefficients of $1.66 \times 10^{-7}, 7.17 \times 10^{-8}$, and $1.11 \times 10^{-8} \mathrm{~cm}^{2} \mathrm{~s}^{-1}$. c Confocal microscopy images of $4 \mathrm{~T} 1 \mathrm{cells}$ treated with $0.02 \mathrm{mg} \mathrm{mL}^{-1}$ of either HPEG-NPs or HPEG-PH20-NPs with enzyme activity of $10 \mathrm{U} \mathrm{mL}^{-1}$ for $0,1,2$, and 4 h. HA, nuclei, and DiD-labeled NPs were shown in green, blue, and red, respectively. The signal included both internalized particles and particles bound on cell surfaces (Scale bar: $50 \mu \mathrm{m}$ ). d In vivo tumor growth inhibition curves for 4T1 tumor-bearing mice that were treated with either saline, free DOX, DOX-HPEGNPs or DOX-HPEG-PH20-NPs. The dose of DOX was $2 \mathrm{mg} \mathrm{kg}^{-1}$ for free DOX and DOX-encapsulated NPs. Values indicate mean \pm SD $(\mathrm{n}=6$ ). $* * \mathrm{P}<0.01$. Black arrows indicate the time of injection. e Survival rate plots show the percentage of animals remained alive in the study. Mice were sacrificed and were no longer counted for survival rate when their tumor size exceeded $2000 \mathrm{~mm}^{3}$. $* * \mathrm{P}<0.01$. f TUNEL staining of sectioned tumor tissues that were collected after the completion of all doses for the groups treated with saline, free DOX, DOX-HPEG-NPs, and DOX-HPEG-PH20-NPs. Green, TUNEL; blue, nuclei. Scale bar: $100 \mu \mathrm{m}$. g Staining of sectioned tumor trusses that were collected $24 \mathrm{~h}$ post the administration of saline or NPs. The mice were $i v$ injected with saline or DiD-labeled NPs on day 9 post 4 T1 cell inoculation. Left column showed the staining of CD31 (green, representing blood vessels) and the distribution of NPs (red). The middle column showed the HA staining and the right column showed the $\alpha$-SMA staining for the four study groups. Scale bar: $50 \mu \mathrm{m}$ (left); $200 \mu \mathrm{m}$ (middle); $100 \mu \mathrm{m}$ (right). Reproduced with permission from Ref. [187] 
surface-displaying method to generate a naturally derived GPI-anchored PH20-harbored exosome to address the limitations of enzyme immobilization-induced activity decline [188]. Similarly, exosome surface-linked hyaluronidase displayed higher activity in cancer therapy than the previously assessed recombinant $\mathrm{PH} 20$ proteins. Furthermore, Zinger et al. reported a 100-nm liposome encapsulating collagenase, called collagozome [189]. Once being pretreated with the collagozome, the level of fibrotic tissue in the pancreas was reduced from $12.8 \pm 2.3 \%$ to $5.6 \pm 0.8 \%$, thus increasing the drug penetration into the pancreas and initiating pancreatic ductal adenocarcinoma (PDAC) treatment.

\subsubsection{Nanoparticle Penetration}

Irrespective of the normalization strategy or matrix degradation approach, during the initial dosage, the already existing high interstitial fluid pressure [190], dense extracellular matrix [191], and tightly packed tumor cells [192] substantially limit the nanocarrier infiltration from the perivascular regions to distal cells [193, 194]. Thus, along with the adequate tumor accumulation, deeper tumor delivery of the formulation is required [195-198]. Most recent studies on penetrating nanoparticles are focused on reductions in particle size or charge reversal in response to TME-related factors (such as lower pH [199], hypoxia [200] and higher ROS level [201], rich GSH [202], and various enzymes [203-205]) or exogenous physical interventions (including laser irradiation [206], ultrasound [207], and thermal treatment [208]). Considering strategies to decrease the particle size, first is a complete nanocarrier with a smaller size, such as albumin [209], gold nanoparticles [202], nano-dots [208], and PAMAM [199], on which the cargo loading is easy. Thereafter, cross-linking of this nanocarrier together via various stimuli-responsive cleaved chemical bonds to generate a larger nanocarrier-aggregate with a suitable particle size of approximately 100-200 nm for long-term blood circulation, which could be dissociated into smaller drug-loaded segments on being triggered by certain stimuli at tumor sites, thereby achieving tumor penetration. Second, in some studies, ultra-small nanoparticles (about $5 \mathrm{~nm}$ ) into a porous nanocarrier with a larger size of approximately 100-200 nm and then usually a biofilm was used to prevent the cargo leakage during the delivery [210]. Until triggered on by $\mathrm{pH}$ or near-infrared irradiation, the nano-cargo was released and infiltrated deep into the tumor. Charge reversal is similar to a process of protection and de-protection, wherein PEG $[203,206]$ or zwitterion $[31,205]$ is the commonly used disguise for shielding the inner positive charge of nanoparticles along with the introduction of stimuli-responsive cleaved chemical bonds. Upon $\mathrm{pH}$, enzyme, or irradiation activation, the shielding part was eliminated, to result the cationic conjugate assisted the tumor infiltration of the remaining cargo-encapsulated nanoparticles. In particular, Zhou et al. reported that cationization in situ could effectively facilitate nanoparticle penetration across multiple cell layers through caveolae-mediated endocytosis and transcytosis pathways [205]. Along with the aforementioned two major categories, Liu et al. developed a device comprising two oppositely polarized external magnets facilitating magnetism-guided penetration of magnetic nanoparticles into deeper tumors, displaying a fivefold increase in the penetration rate than enhanced permeability and retention effect (EPR) [211] (Fig. 9). Furthermore, Lee et al. used host tumor-recruiting CD1 $1 b^{+}$myeloid cells as a second active vector [212], and through an immune recognition reaction and bio-orthogonal click chemistry in vivo, tetrazine-functionalized drug-loaded nanoparticles might be associated with the second vector, then following myeloid cells through the depth of tumors.

\subsubsection{Hypoxia Alleviation}

Hypoxia is distinctly associated with stromal improvement [213]. For oxygen generation, endogenous $\mathrm{H}_{2} \mathrm{O}_{2}$, as a tumor metabolite present at high levels (ranging from $100 \mu \mathrm{M}$ to $1 \mathrm{mM}$ ) owing to excess ROS generated under hypoxia [214-216], can be used as an important source of $\mathrm{O}_{2}$. Apart from catalase [217], various inorganic $\mathrm{H}_{2} \mathrm{O}_{2}$ catalysts have been developed as nanocarriers for in situ catalytic $\mathrm{H}_{2} \mathrm{O}_{2}$ decomposition to $\mathrm{O}_{2}$ and hypoxia alleviation, e.g., $\mathrm{MnO}_{2}$ [218], copper/manganese silicate [219], Mn-carbon dots [220], porous platinum nanoparticles [221], Pt nanozymes [222], and Prussian Blue nanoparticles [223]. Moreover, Jiang et al. reported that $\mathrm{H}_{2} \mathrm{O}$ is another potential source of $\mathrm{O}_{2}$ when catalyzed by biomimetic ultrathin graphdiyne oxide (GDYO) nanosheets through near-infrared irradiation [224] (Fig. 10). For the oxygen delivery strategies, perfluorocarbons (PFCs) [225-228] and hemoglobin (Hb) [229-232] were two frequent categories of high oxygenaffiliative materials used as nanocarriers for oxygen loading, 

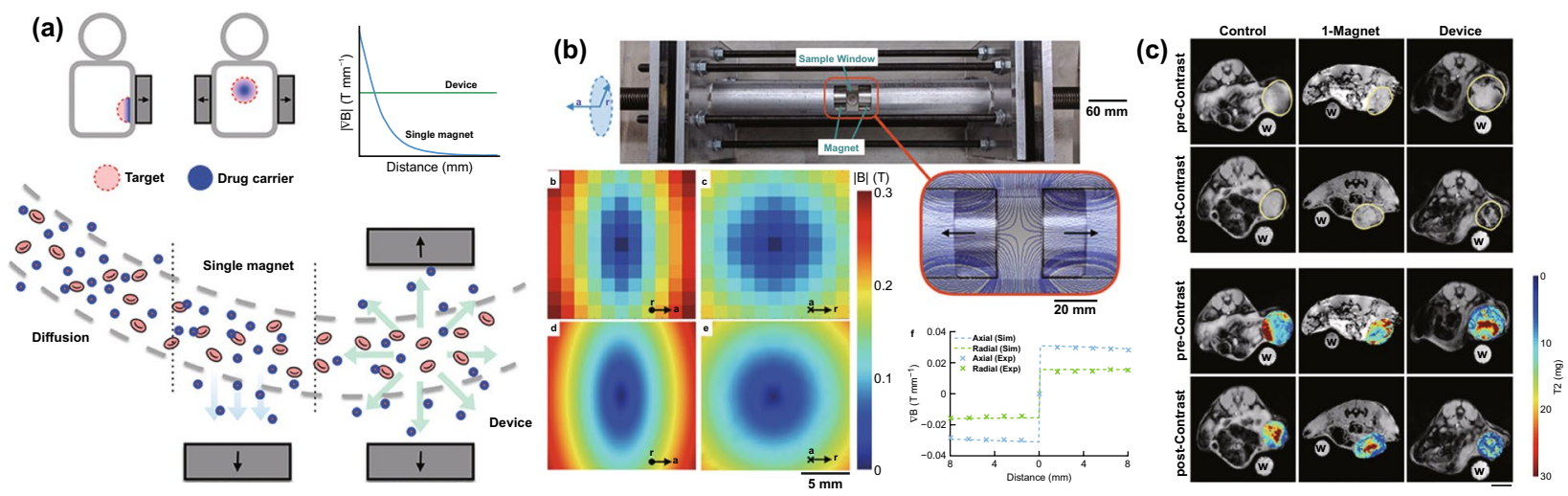

Fig. 9 a Magnetic device, comprising two oppositely polarized magnets, enhances magnetic drug targeting in deep tissues. b Magnetic device contains a sharp zero point surrounded by constant field gradients. $\mathbf{c}$ Pre- and postcontrast images have similar signal distributions in the control. However, mice that have been exposed to the device show much less T2 signal (hypointensity) postcontrast. Water control labeled "w". Scale bar $=5 \mathrm{~mm}$. Reproduced with permission from Ref. [211]

which were functionalized and encapsulated into liposomes or biomimetic membrane-camouflaged nanoparticles to facilitate oxygen delivery to hypoxic tumor sites with a low partial pressure of $\mathrm{O}_{2}$ and alleviating hypoxia to reinforce the efficacy of various anticancer modalities. Recently, through catalase-triggered $\mathrm{H}_{2} \mathrm{O}_{2}$ decomposition-dependent $\mathrm{O}_{2}$ generation, Song et al. developed a two-dose schedule to sequentially deliver catalase and exogenous $\mathrm{H}_{2} \mathrm{O}_{2}$ into hypoxic areas through well-established liposomes, which could decompose $\mathrm{H}_{2} \mathrm{O}_{2}$ into oxygen in tumors and were suitable for clinical translation for cancer radio-immunotherapy [233]. Furthermore, nanoparticles comprising $\mathrm{CuO} @ \mathrm{ZrO}_{2}$ [234], $\mathrm{Au}_{2} \mathrm{O}_{3}$ [235], or $\mathrm{CaO}_{2}$ [236, 237] were also used as oxygen carriers recently, which could be activated through microwave treatment or a reduction in $\mathrm{pH}$, thereby producing $\mathrm{O}_{2}$ for the hypoxia alleviation.

\subsection{Strategies for Rescuing $\mathbf{T}$ cell Exhaustion}

\subsubsection{Characteristics of T Cell Exhaustion in Cold Tumors}

Immunosuppressive cells (primarily MDSCs [238], TAMs [239], and Tregs [240]), which are largely recruited to solid tumors under the influence of hypoxic stress [241-243], play an equally crucial role in generating an immunosuppressive microenvironment as factors affecting T cells homing to cold tumors [244]. MDSCs are a heterogeneous population of myeloid cells including immature myeloid cells and myeloid progenitor cells and accumulate in tumor regions under the influence of various tumorsecreting factors including cyclooxygenase 2 (COX-2), granulocyte-macrophage colony-stimulating factor (GMCSF), VEGF, TGF- $\beta$, and IL-6 [238]. Similarly, because of the signaling pathways associated with these factors, most of which converge on the Janus kinase (JAK) protein family members and signal transducer and activator of transcription 3 (STAT3), MDSCs are expanded and activated to exert remarkable immunosuppressive effects in the TME $[238,245,246]$. These functions include (i) the activation of arginase (ARG)-1, deprivation of $L$-arginine, which are not produced by $\mathrm{T}$ cells and critical for $\mathrm{T}$ cell proliferation and anti-tumor responses [238, 247]; (ii) the activation of nicotinamide adenine dinucleotide phosphate oxidase (NOX) and inducible NO synthase (iNOS), producing ROS and NO, respectively, leading to the oxidation of chemokines essential for $\mathrm{T}$ cell migration and nitration of $\mathrm{T}$ cell receptor (TCR)-induced reduction of antigen recognition and subsequent apoptosis in T cells and NK cells [248-250]; (iii) reinforcing TGF- $\beta$ and IL-10 production and PD-L1 up-regulation, disrupting DC differentiation, migration, and antigen presentation, and inducing TAF activation and ECM deposition in conjunction with matrix metalloproteinase production [245, 251, 252]; (iv) up-regulation of angiogenic factors including VEGF, basic fibroblast growth factor (bFGF), and platelet-derived endothelial cell growth factor (PD-ECGF), thus promoting tumor neovascularization [253, 254]; (v) activation of regulatory 
(a)

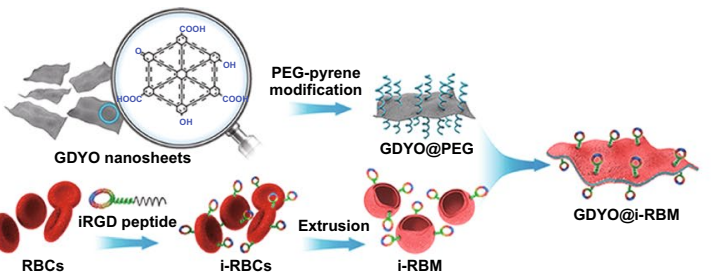

(b)

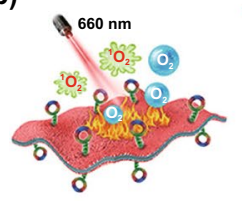

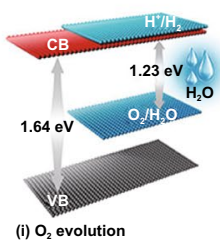

(i) $\mathrm{O}_{2}$ evolution

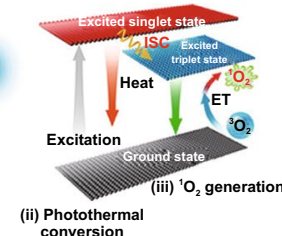
conversion

(d)
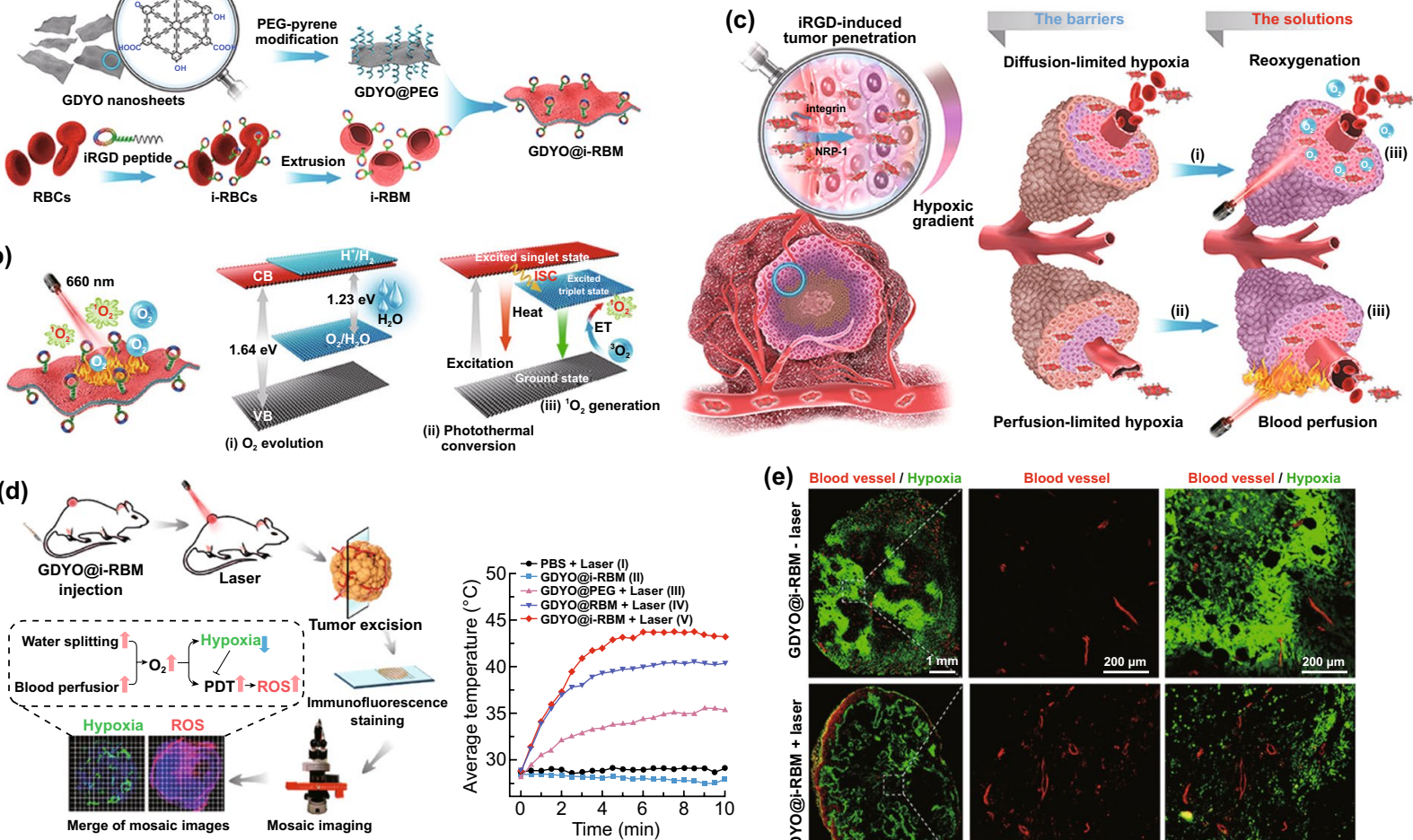

(e)
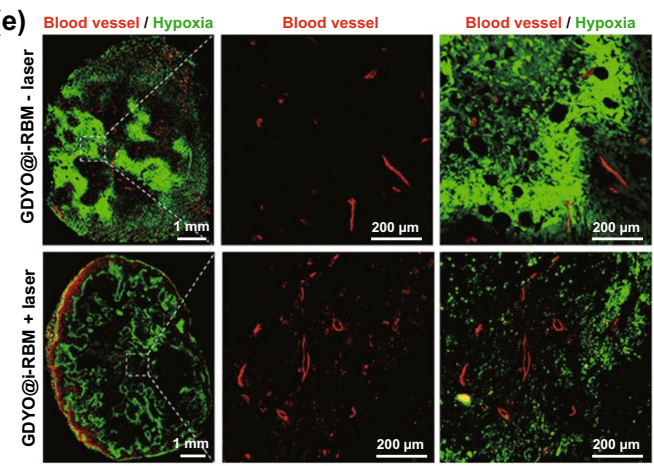

(f)
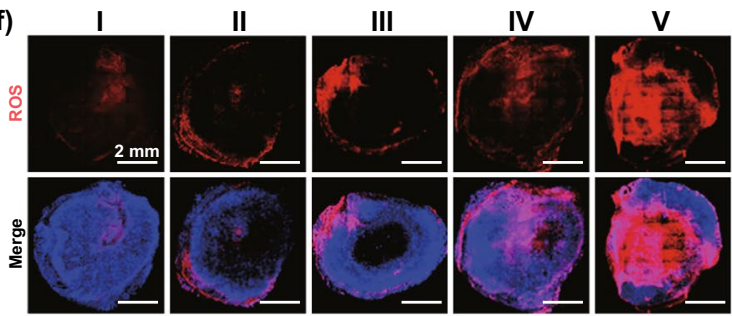

(g)

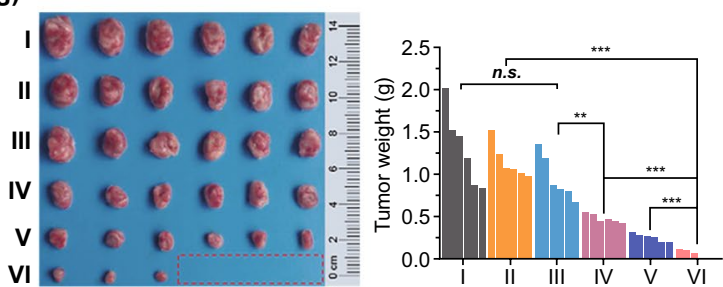

Fig. 10 a Schematic illustration of the synthetic process of GDYO@iRBM. GDYO@i-RBM was obtained by coating PEG functionalized GDYO nanosheet with i-RBM, which were extracted from iRGD anchor-modified RBCs followed by extrusion through a porous membrane. b Schematic illustration of the working principles of GDYO@i-RBM. c i-RBM on the surface of GDYO facilitates the accumulation and deep penetration in the tumor. Meanwhile, under $660 \mathrm{~nm}$ laser irradiation, $\mathrm{O}_{2}$ evolution and hyperthermia caused by GDYO can overcome $\mathrm{O}_{2}$-diffusion-limited and perfusion-limited hypoxia barriers and lead to efficient PDT ablation of tumors. d Schematic illustration showing the evaluation of hypoxia and ${ }^{1} \mathrm{O}_{2}$ levels in tumor, and temperature increase of the tumors upon irradiation. e Hypoxia immunofluorescence and vessel morphometric analyses of tumor slices. The blood vessels and hypoxia regions were stained with anti-CD31 antibody (red) and hypoxia probe (green), respectively. f Representative ROS fluorescence images of tumor slices. $\mathbf{g}$ Photos and weight of the tumor tissues obtained on day 22 post-treatment. Reproduced with permission from Ref. [224]

T cell (Treg) differentiation through cytokine production or through direct cell-cell interactions [238, 241].

Once immune cells were recruited to the tumor lesions, macrophages are extraordinarily abundant and are present in all stages of cancer progression under a gradient of tumorderived chemo-attractants including CCL-2, tumor necrosis factor (TNF), IL-8, IL-6, VEGF-A, and CSF-1 [255, 256]. The HIF-1 pathway [257], PI3K-PTEN-AKT pathway [258, 259], and loss of serine/threonine liver kinase B1 (LKB1)
[260] are the mechanisms involved in the recruitment and activation of tumor-associated macrophages (TAMs) into solid tumors, usually through CXCL12 and CCL2 engagement with their receptors CXCR4 and CCR2, respectively. Other than normal macrophages, the potential of TAMs to present tumor-associated antigens is decreased, instead of several pro-tumoral M2 phenotype-associated functions, including angiogenesis, matrix remodeling, immunological suppression, and tumor metastasis [261]. For example, 
TAMs participate in pro-angiogenic phenomena by expressing angiogenic factors including Wnt7b, TIE2, and thymidine phosphorylase (TP), thus stimulating vascular endothelial cells to produce VEGF, leading to an angiogenic switch [255]. Expression of PD-1 and CTLA-4 ligands can suppress the cytotoxic functions of T cells and NK cells [261, 262]. Furthermore, TAMs can up-regulate the ligands for death receptors including TRAIL and Fas to induce apoptosis in targeting cells $[261,263]$. Secreted cytokines TGF- $\beta$ and IL-10 inhibit the effector functions of T cells $[264,265]$ and induce the release of chemokines including CCL5, CCL20, and CCL22 for Treg recruitment [266, 267]. Beyond that, TAMs can produce matrix metalloproteases (e.g., MMP2 and MMP9) and factors (e.g., TGF- $\beta$, PDGF, IL-6, urokinase plasminogen activator (u-PA), and tissue-type plasminogen activator (t-PA)) to degrade the ECM for tumor invasion and migration [268, 269].

Apart from the tumor-infiltrating $\mathrm{CD} 8^{+} \mathrm{T}$ cells (major in hot tumor), tumor cells, M2-like TAMs, and MDSCs can facilitate Treg tumor infiltration by increasing CCL22 secretion in cold tumors [270]. Furthermore, Tregs can actively produce IL-10 and TGF- $\beta$, thus suppressing cytotoxic T cells and immune tolerance [271]. In addition, Tregs can exhibit immunosuppressive functions through direct mechanisms including IL-2 deprivation, CD39/CD73-mediated adenosine generation, and competition with CD28 (a co-stimulator on CTLs) for binding to CD80/CD86 on APCs by inducing CTLA-4 (a co-inhibitor) expression [3].

\subsubsection{MDSC-Targeting Treatments}

Among the immunosuppressive cells in cold tumor lesions, MDSCs have been considered as the most versatile cells [272, 273], for which plenty of approaches have been developed to abrogate its suppressive activity in vivo, including the following: (i) MDSC elimination, (ii) blockade of MDSC recruitment, (iii) inhibition of MDSC suppression, and (iv) facilitating MDSC differentiation. Unfortunately, nanotechnology has not been extensively applied in this field, and most treatment strategies have focused on the development of chemicals or antibodies [273-275]. Therefore, a brief description of therapeutic agents has been provided below, facilitating the guidance of the development of MDSC-targeting nanoformulations.
Low-dose chemotherapy, including gemcitabine [276] and 5-fluorouracil [277], has proven effective in depleting MDSC populations in tumor bearers, and tyrosine kinase inhibitors (including Sunitinib [278]) have successfully eliminated MDSCs in cancer patients by blocking VEGF, STAT3, and c-KIT signaling. Furthermore, regarding the blockade of MDSC recruitment, antagonists of chemokines (CCL2, CCL5, CSF-1, and G-CSF) and their receptors (CXCL2, CCR5, and CSF-1R) engaged in tumor chemotaxis of MDSCs have been identified as strategically promising therapeutic agents to inhibit MDSC migration to tumor lesions to restrict tumorigenesis [279-282], and most of these agents have been reported in previous clinical trials [283], e.g., phase II clinical trials on CXCR2 antagonist Reparixin for TNBC (NCT02370238) and phase 1 clinical trials on CCR5 antagonist Maraviroc for metastatic colorectal cancer (NCT01736813). Moreover, STAT3 inhibitor (AZD9150) [284], reactive nitrogen species (RNS) inhibitor (AT38) [285], nitroaspirin (NCX4060 and NCX4016) [286], phosphodiesterase-5 inhibitors (sildenafil) [287, 288], triterpenoids (CDDO-Me) [246], COX-2 and PGE2 inhibitors (Celecoxib, ASA) [289, 290], HDAC inhibitor (Entinostat) [291], and very-small-sized proteoliposomes (VVSP) [292] have effectively attenuated the potent immunosuppressive functions of MDSCs to reconstitute T cell responses and the success of immunotherapy. Finally, differentiation of suppressive MDSCs into mature myeloid cells (including macrophages and DCs) through treatment with Vitamin D3 [293], all-trans-retinoic acid (ATRA) [294], taxanes (docetaxel and paclitaxel) [295], TLR9 activation (CpG) [296], curcumin [297], whole-glucan particles (WGP) [298], and casein kinase inhibitor (tetrabromocinnamic acid) [299] can overtly modulates MDSCs and decrease the tumor growth in tumor-bearing mice and cancer patients.

As expected, several nanotechnology-based strategies have been developed for MDSC-targeting therapies, such as gemcitabine-loaded nanocarriers to eliminate MDSCs [205, 300-303] (Fig. 11), hypoxia alleviation-mediated MDSC elimination by platelet membrane-based co-encapsulation of metformin and IR780 [304], phosphoinositide-3-kinase- $\gamma$ (PI3K- $\gamma$ ) inhibition-mediated MDSC remodeling by IPI-549loaded targeted polymeric nanoparticles [305], disruption of MDSC expansion by pseudoneutriphil cytokine sponges [306], co-delivery of RNAi and chemokines in polyarginine 

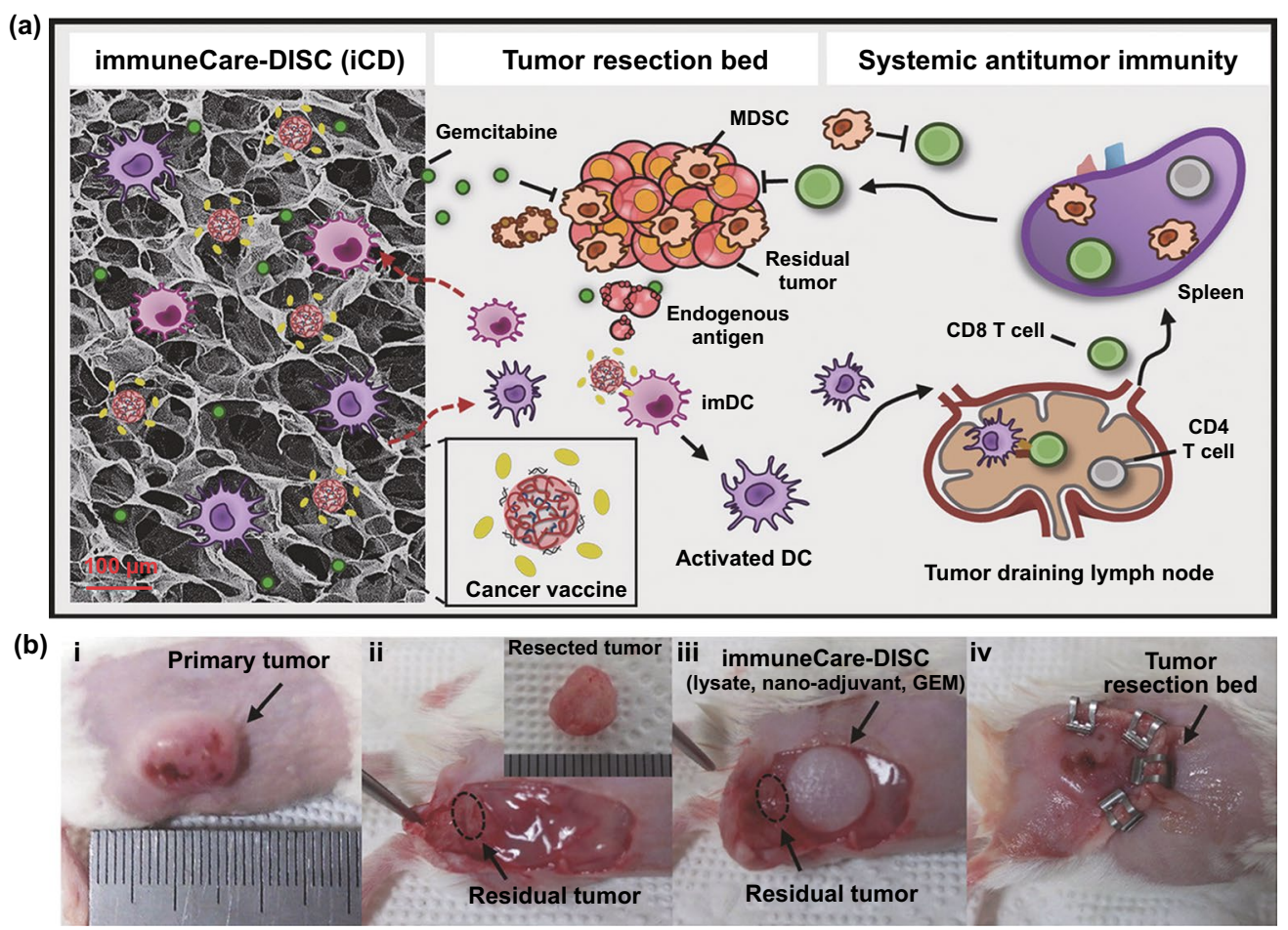

Fig. 11 a Schematic diagram showing the design of the iCD, which codelivers GEM, as an MDSC-depleting drug to revert the immunosuppressive microenvironment, and cancer vaccines consisting of whole tumor lysates and nanoadjuvants carrying TLR3 agonists, to provide immunostimulation and elicit an anti-tumor immune response. Release of the vaccine induced the infiltration, activation, and homing of DCs to the lymph nodes, which initiated an antigen-specific adaptive immune response in a host environment where tumor-induced immunosuppression was depleted by MDSCs. b Implantation approach: (i) surgery was performed after the tumor volume reached $\approx 300 \mathrm{~mm} 3$, (ii) tumor dissection mimicking incomplete tumor removal ( $\approx 90 \%$ of primary tumor was excised), (iii) implantation of the iCD containing GEM and cancer vaccines, (iv) wound closure. Reproduced with permission from Ref. [300]

nanocapsules for MDSC modulation [307], and inhibition of MDSC recruitment by micellar hypotoxic low molecular weight heparin-tocopherol succinate nanoparticles [308].

\subsubsection{TAM-Targeting Treatments}

Three main categories of TAM-targeting therapies have been reported so far, including chemotaxis blockade, M2-like TAM elimination, and M2-TAM repolarization, of which the delivery via nanocarriers has been extensively studied [309-312]. Peripheral monocytes, TAM predecessors, are recruited into the tumor lesions through the engagement of CSF1/ CSF1R [313] and CCL2/CCR2 [310]; hence, the blockade of these factors might potentially reduce the accumulation of TAMs in tumors, thereby overcoming the TAM-related immunosuppression and enhancing tumor-specific $\mathrm{T}$ cell responses. For example, Shen et al. generated monocytetargeting cationic nanoparticles to deliver CCR2 siRNA for inhibiting the recruitment of Ly6 $\mathrm{C}^{\text {hi }}$ monocytes by blocking CCL2-CCR2 pathways [314, 315]. Furthermore, Ramesh et al. developed a CSF1R- and SHP2-inhibitor-loaded nanoparticle for reinforcing cytotoxic activity and phagocytosis of TAMs [316]. Herein, the CSF1R-inhibitor was used for inhibiting the recruitment and differentiation of TAMs into the M2-like phenotype, and the SHP2-inhibitor could potentially increase TAM phagocytosis by suppressing the downstream 'eat-me-not' signals of the CD47-SIRP $\alpha$ axis [61]. Regarding M2-TAM elimination, induction of TAM apoptosis via nanocarriers is a common approach [309]. Bisphosphonates (BPs) constitute first-line low-cost agents for treating metabolic bone diseases and exhibit selective toxicity to TAMs [317-319]. Tian et al. mineralized BPs with $\mathrm{Ca}^{2+}$ to synthesize a BP-loaded nanoparticle and then functionalized the nanoparticle with poly(ethylene glycol) [320]. Furthermore, to endow the BP nanoparticle with theranostics, a singlephoton-emission computed tomography (SPECT) contrast 
element, ${ }^{99 \mathrm{~m}} \mathrm{Tc}$, was introduced into the system via coordination bonds. As revealed through the SPECT imaging, BP nanoparticles exhibited efficient tumor retention post-injection (i.v.) and facilitated effective depletion of TAMs within the tumor (Fig. 12). Moreover, another attractive strategy for tumor eradication is reversing TAM polarization from an immunosuppressive M2 to a tumoricidal M1 phenotype [321]. Effective approaches in animal models have involved TLR7/8 ligation with R848-loaded $\beta$-CD nanoparticles (CDNP-R848) [322], up-regulation of pro-inflammatory signals (iNOS and TNF) with liposome-encapsulated zoledronate acid treatment
[323], and nanoparticle-mediated delivery of M1-like TAMrelated active microRNAs, such as miR-125, for TAM reprogramming [324, 325]. Recently, several independent studies have consistently reported that superparamagnetic iron oxide nanoparticles (SPIONs) can also reorient M2-like TAMs into an M1-like phenotype through multiple approaches [326-329], e.g., interferon regulatory factor 5 (IRF-5) signaling-mediated M1 polarization and M2-like phenotype-related arginase-1 down-regulation [326]. Moreover, surface-mannosylation has been widely used to harness TAM-targeting nanocarrier systems [218, 330-333]. (a)

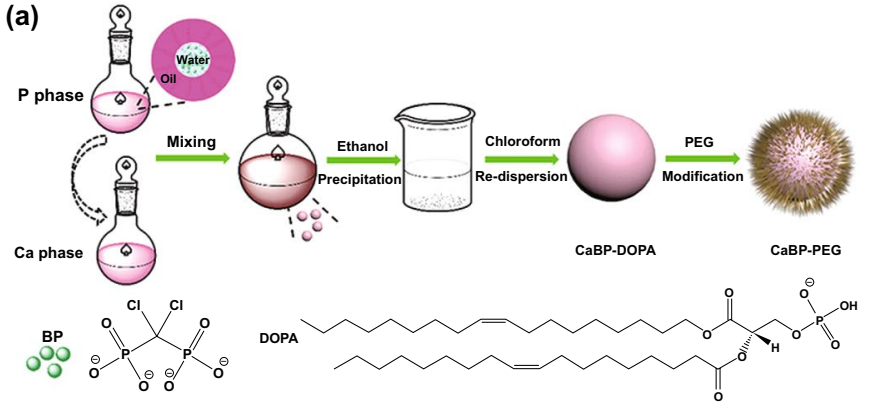

(b)
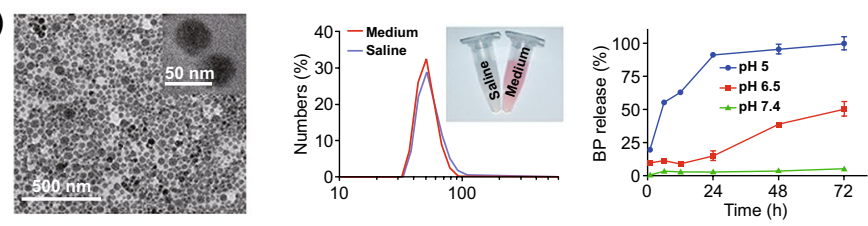

(c)
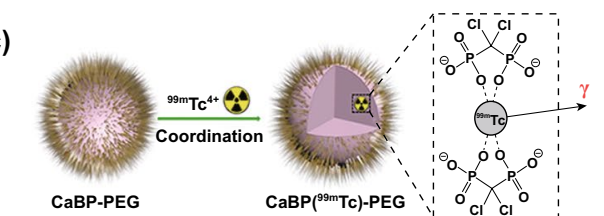

(d)
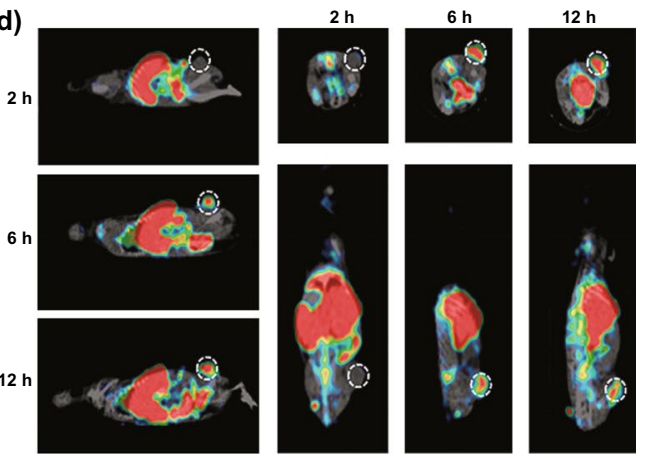

(e)

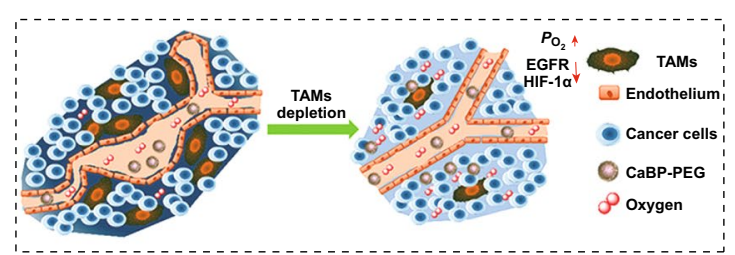$$
\text { (f) }
$$

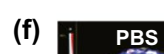

$\mathrm{Oh}$

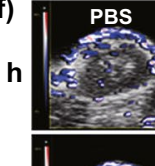

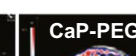
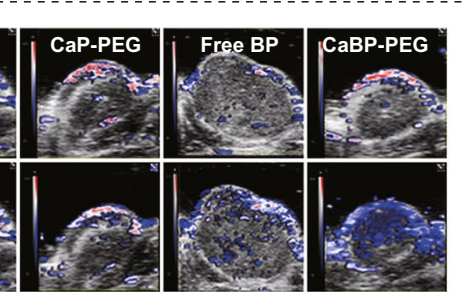

(g)

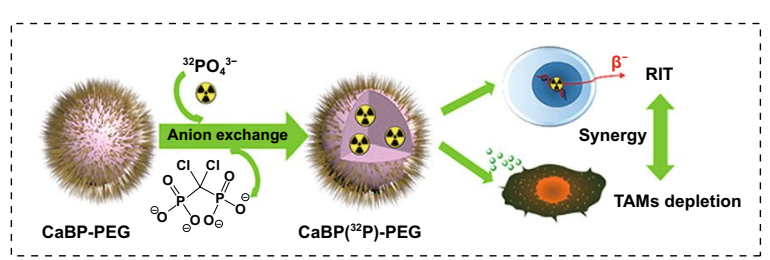

(h)

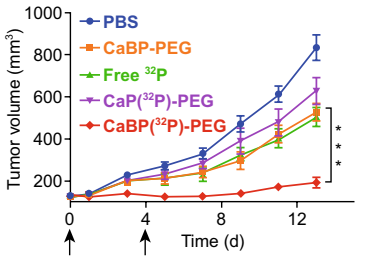

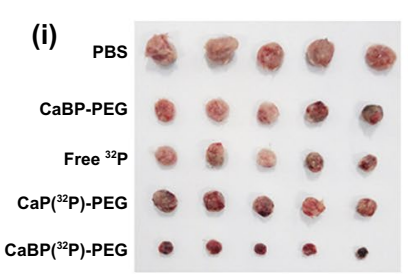

Fig. 12 a Schematic illustration to show the preparation of CaBP nanoparticles. b TEM image and dynamic light scattering data and photo of CaBP-PEG nanoparticles in PBS and cell culture medium buffer, as well as release of BP from CaBP-PEG nanoparticles under different pH values. c Scheme illustrating the ${ }^{99} \mathrm{mTc}$ radiolabeling of CaBP-PEG nanoparticles for tracing the in vivo fate of nanoparticles. d SPECT images of mice at 2, 6, and $12 \mathrm{~h}$ after intravenous injection of $\mathrm{CaBP}\left({ }^{99} \mathrm{mTc}\right)$-PEG nanoparticles. Tumors of mice are highlighted by the dotted circles. $\mathrm{e}$ Scheme showing the normalized tumor vasculature, enhanced perfusion, and relieved tumor hypoxia after TAM depletion. f Scheme illustrating $\mathrm{CaBP}(32 \mathrm{P})$-PEG nanoparticles for synergistic combination RIT with TAM depletion. $\mathrm{g}$ Photoacoustic imaging showing tumor saturated $\mathrm{O}_{2}$ levels of mice after i.v. injection of PBS, CaP-PEG, free BP, or CaBP-PEG nanoparticles. $\mathbf{h}$ Tumor volume curves of mice with various treatments. Doses for each injection: $100 \mu \mathrm{Ci}$ of 32P, $200 \mu \mathrm{g}$ of BP. The mice were treated twice at day 0 and 4 (black arrows). i Photographs of tumors collected on the 14th day after the first treatment. Reproduced with permission from Ref. [320] 


\subsubsection{Treg-Targeting Treatments}

Tregs represent the third major cell type contributing to the immunosuppressive TME in cold tumors [334, 335]. In fact, the interactions among the three categories of inhibitory cells are closely associated [241, 243, 336]. Therefore, regardless of immunotherapy aimed at MDSC or TAM modulation, the quality and number of Tregs would also be simultaneously affected [241, 337-339]. Furthermore, antibodies against surface molecules (including CD25 [340], CCR4 [341], CTLA-4 [342], OX40 [343], and GITR [344, 345]) exhaust Tregs in various tumor models, and molecules (such as cyclophosphamide [346] and Raf-kinase inhibitor sorafenib [347]) can also preferentially deplete Tregs upon systemic administration. As expected, the application of nanotechnology in Treg-targeting treatments was in accordance with the two aforementioned categories. Li et al. developed CTLA-4-siRNA loaded PLGA nanoparticles to successfully deliver CTLA-4-siRNA into both $\mathrm{CD} 4+$ and $\mathrm{CD} 8+\mathrm{T}$ cell subsets at the tumor sites, thereby down-regulating CTLA-4 in activated T cells and enhancing anti-tumor immune responses [348]. Similarly, Liu et al. encapsulated anti-CTLA-4 into PLGA nanoparticles for protein-protective delivery [349]. Furthermore, strategies involving the loading of cyclophosphamide into vehicles including in situ-developed fibrin scaffolds [350] or engineering of PD-1-presenting platelets [351] exhibited selective depletion of Tregs and effective postsurgical prevention of cancer relapse in combination with anti-PD therapy.

\subsection{Strategies for Treatment of Pseudo-Cold Tumor}

Although the positive PD-L1 expression and T cell infiltration have been considered as a predictor of effective outcome of PD-1/PD-L1 antibody therapy, there are a growing number of patients with PD-L1 overexpression that cannot benefit from the anti-PDs treatment [352]. Among these patients, some patients showed primary resistance to treatment like having a cold tumor with low mutational burden, infiltrated immunosuppressive cells or up-regulated immunosuppressive factors, and others usually developed an adaptive resistance to continuation of PD-1/PD-L1 blockade therapy after a period of robust initial response. Since they are also ineffective against anti-PDs therapy, but different from the cold tumors in terms of TIME, we refer to them as pseudo-cold tumor.

In regard to primary resistance, several studies proposed that genetic mutations might be responsive for the primary resistance of PD-L1-positive patients [353]. In a clinical study on patients with non-small cell lung cancer (NSCLC), researchers found that patients with EGFR mutations and ALK rearrangements showed a low $\mathrm{CD}^{+} \mathrm{T}$ cell infiltration-associated poor response to anti-PDs therapy despite a high rate of PD-L1 expression, which implied that the expression of PD-L1 could also be constitutive rather than just responding to inflammatory stimuli [354]. However, it is unfortunate that the mechanism of action between theses mutations and apparent $\mathrm{T}$ cell exclusion remains unclear. As far as we know, it would be a promising approach for the reversal of primary resistance to combine the therapeutic strategies for cold tumors and mutant proteintargeted therapy. Besides, it has been identified that there were also various immunosuppressive cells such as MDSC, TAMs, Tregs existing to impair the functionality of anti-tumor T cells. Hence, the previously mentioned strategies for rescuing $\mathrm{T}$ cell exhaustion are applied.

Recently, in addition to PD-1, several biomarkers have been identified as alternative checkpoint receptors that are upregulated and involve in $\mathrm{T}$ cell dysfunction during anti-PDs therapy, resulting in adaptive resistance [355]. These include cytotoxic T-lymphocyte antigen 4 (CTLA-4), T cell immunoglobulin and mucin domain-containing-3 (TIM-3), T cell immune receptor with Ig and ITIM domains (TIGIT), lymphocyte activation gene-3 (LAG-3), V-domain Ig suppressor of $\mathrm{T}$ cell activation (VISTA), and so forth. For these patients, if possible, a needle biopsy and in-depth immune analysis of the new or increasing site of resistance can first be performed to determine the mechanism of resistance and treat it according to the cause. Nowadays, it is a hot-spot to develop effective antibodies against these targets, as there are numerous cases of clinical trials underway for each one [356].

Furthermore, some researchers have proposed that the outcome of PD-L1 antibody therapy greatly relies on the distribution of PD-L1 [357]. According to PD-L1 distribution, the PD-L1 can be classified into four formats: serum PD-L1 (sPDL1), membrane PD-L1 (mPD-L1), cytoplasm PD-L1 (cPDL1), and nuclear PD-L1 (nPD-L1). Among them, mPD-L1 is the major format that can bind to its receptor (PD-1) to enable immunologic tolerance, which can be blocked by utilization of PD-L1 antibody. However, as for cPD-L1 and nPD-L1, due to their intracellular location, the blockade of cell membrane can 
theoretically impair the efficacy of PD-L1 antibody against these formats. Considering the translocation of PD-L1s, the cPD-L1 and nPD-L1 may be the reservoir for MPD-L1 to be translocated onto the surface when treated anti-PD-L1s have been eliminated, resuming the immune escape. At the same time, the mPD-L1 can be also translocated into the cytoplasm to be cPD-L1 to avoid being tracked during the anti-PD-L1 treatment. In a clinical study on papillary thyroid carcinoma [358], patients with cPD-L1 up-regulation showed a shorter disease-free survival compared to those lack of cPD-L1, which highlighted the function of cPD-L1. Therefore, the positive expression of intracellular PD-L1 could be an underlying incentive for adaptive resistance and therapeutic strategies, such as PD-L1 gene silencing, sPD-1 mRNA or plasmid transfection, and chemical inhibitor treatment, that can suppress the functions and sources of entire PD-L1 may be advantageous over antibody blockade. In this regard, up to now, there have been various and countless nanocarriers developed to enable efficient gene delivery or controlled delivery of small molecule drugs alone or in combination, which is thus not described in this article.

\section{Conclusion and Perspectives}

As described in this review, there are three major challenges in anti-cold tumor immunotherapy: T cell priming inhibition, $\mathrm{T}$ cell exclusion, and $\mathrm{T}$ cell exhaustion. Nanomedicines, within the capability of cargo protection and controlled release, as well as the designability for tumor or immune cell targeting, have shown effective therapeutic outcomes in reversing these limitations. In regard to normalize $\mathrm{T}$ cell priming, it is critical to recover the antigen presentation of APCs. Strategy that delivering STING agonists (represented by cGAMP) by DC-targeting nanocarrier can significantly increase the accumulation of cGAMP in DCs, reduce the off-target side effect, and accelerate the DC maturation. Meanwhile, stimuli-responsive nanomedicines can enable the loading adjuvants and antigens controllable release in cell as needed, so as to exert their capability of DC activation preferably. Secondly, the deposition of extracellular matrix in cold tumor lesions builds a physical barrier to exclude $\mathrm{T}$ cell infiltration. Codelivery of therapeutic agents with matrix catabolic enzymes or deposition inhibitors via nanomedicine has shown capability to loose extracellular matrix from the lateral side and facilitate agents and $\mathrm{T}$ cell penetration. In addition, nanomedicines with TME-responsive sizechange or charge-shift can escort their cargos across the matrix barrier and arrive at the deeper tumor, resulting in appropriate microenvironment for $\mathrm{T}$ cell infiltration. Furthermore, the designability of nanomaterials endows the nanomedicines with the capability of targeting multiple immunosuppressive cells. Although the application of nanomedicines has accelerated the research on anti-coldtumor immunotherapy and holds enormous promise, we are still in initial stage of the clinical translation of nanomedicines for immunotherapy, and there are several overlooked key problems in preclinical research which have to be addressed. First, do we employ the right tumor-bearing animal models? It is a fundamental but critical question for therapeutic evaluation of nanomedicines developed for anti-cold-tumor immunotherapy in preclinical studies. At present, more and more scholars have highlighted that the right therapeutic regimens should be applied in the right patients/tumors when possessing the clinical trials [40]. However, many current preclinical studies of cold tumor treatment were carried out on inappropriate animal models, for example, a common hot tumor-bearing model (subcutaneous melanoma) was widely used as a cold tumor

Table 1 Characteristics of $\mathrm{T}$ cell priming inhibition in cold tumors

\begin{tabular}{|c|c|c|c|}
\hline Categories & Components & Mechanism & Refs. \\
\hline \multirow[t]{7}{*}{ Inhibition of $\mathrm{T}$ cell priming } & \multirow[t]{2}{*}{ Disruption of APC recruitment } & Wnt- $\beta$-catenin pathway-mediated CCL4 down-regulation & {$[22]$} \\
\hline & & Cox1/2-PGE2 pathway-mediated CCL5 and XCR1 down-regulation & {$[56]$} \\
\hline & \multirow[t]{2}{*}{ Disruptions of APC function } & Cytokines (M-CSF, TGF- $\beta$, IL-6, IL-10) & {$[57-60]$} \\
\hline & & MYC-associated CD47 up-regulation & {$[61]$} \\
\hline & \multirow[t]{3}{*}{ Decreased immunogenicity } & $\begin{array}{l}\text { Impairment of antigen processing through alterations in proteasomal } \\
\text { or post-proteasomal machinery }\end{array}$ & {$[63,64]$} \\
\hline & & Regulation of antigen presentation through MHC-I mutations & {$[65,66]$} \\
\hline & & Antigenic discontinuum driven by KRAS or BCR-ABL1 & {$[67-70]$} \\
\hline
\end{tabular}




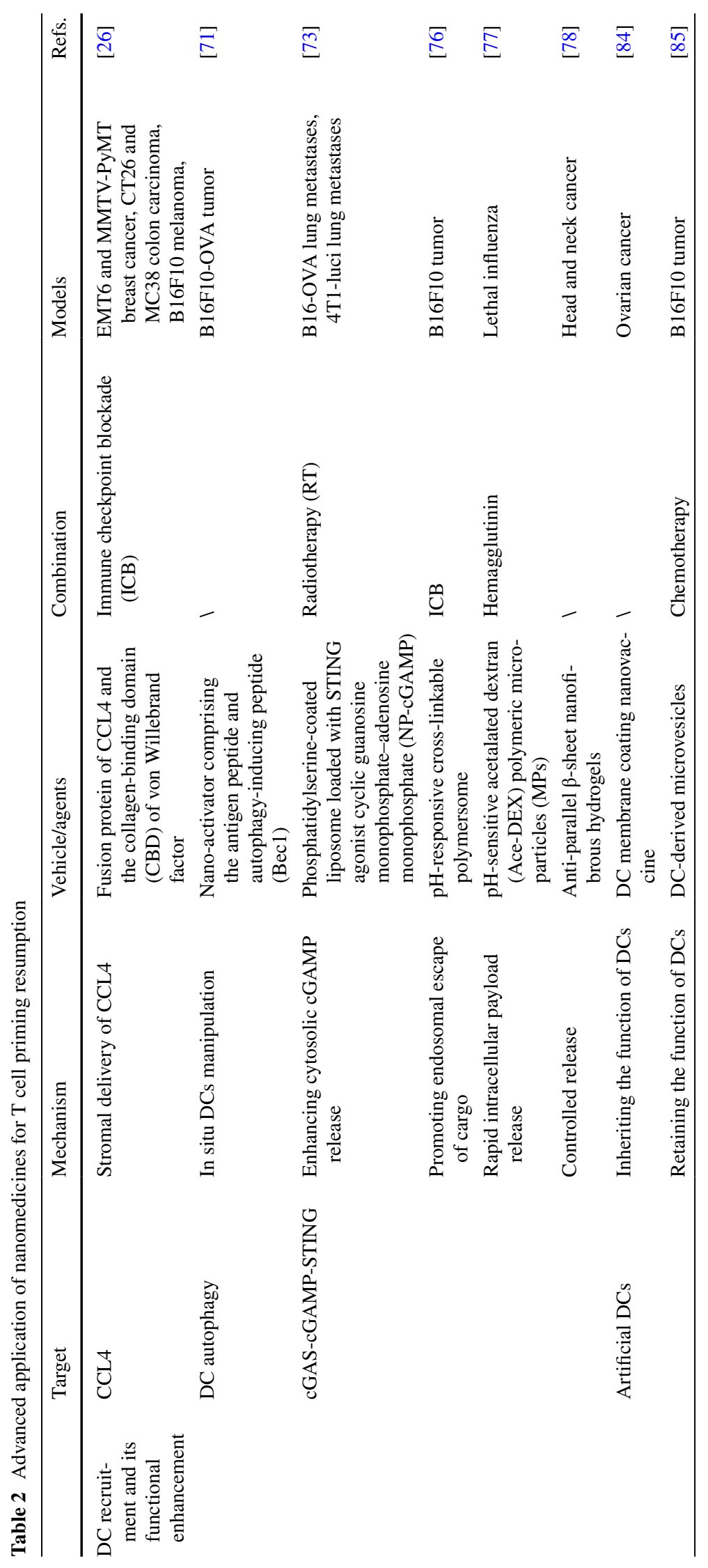




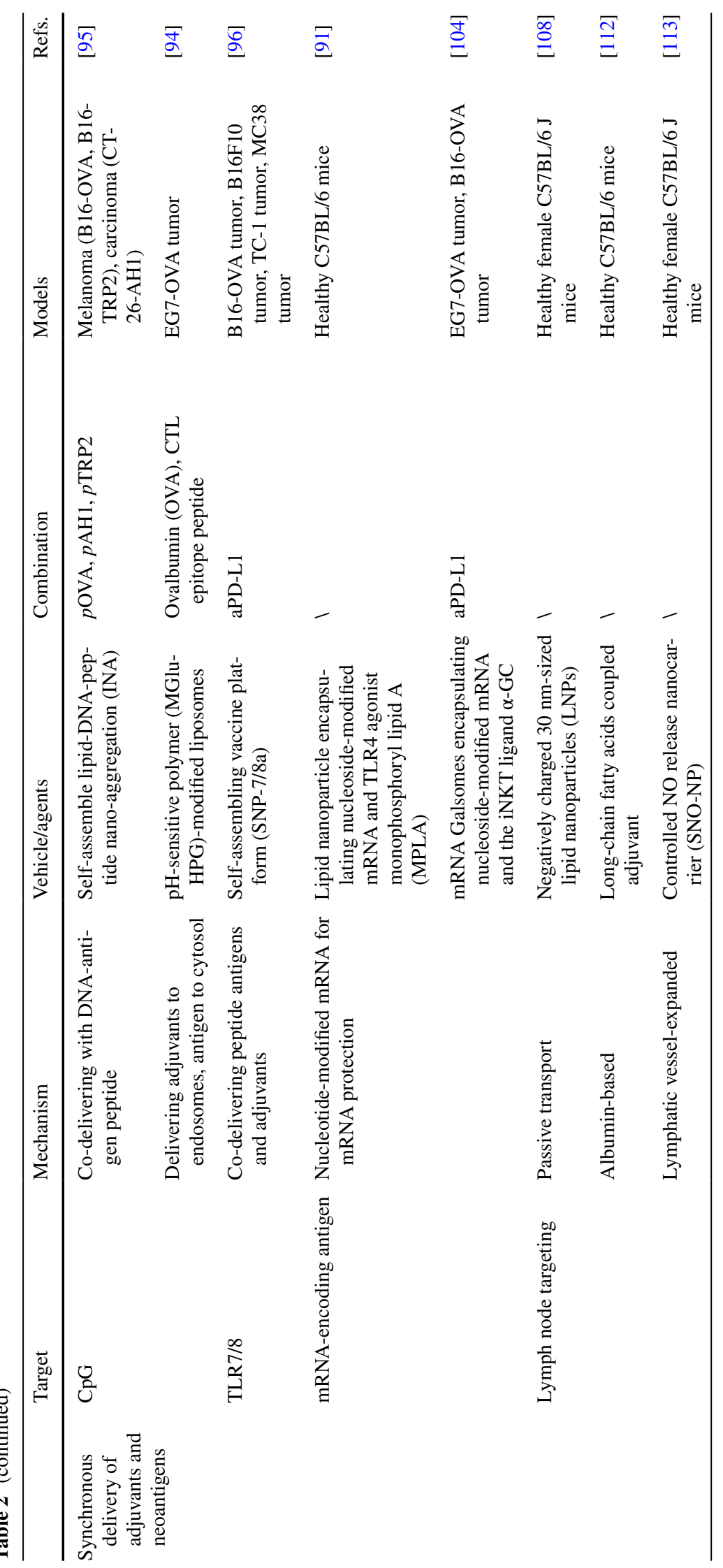




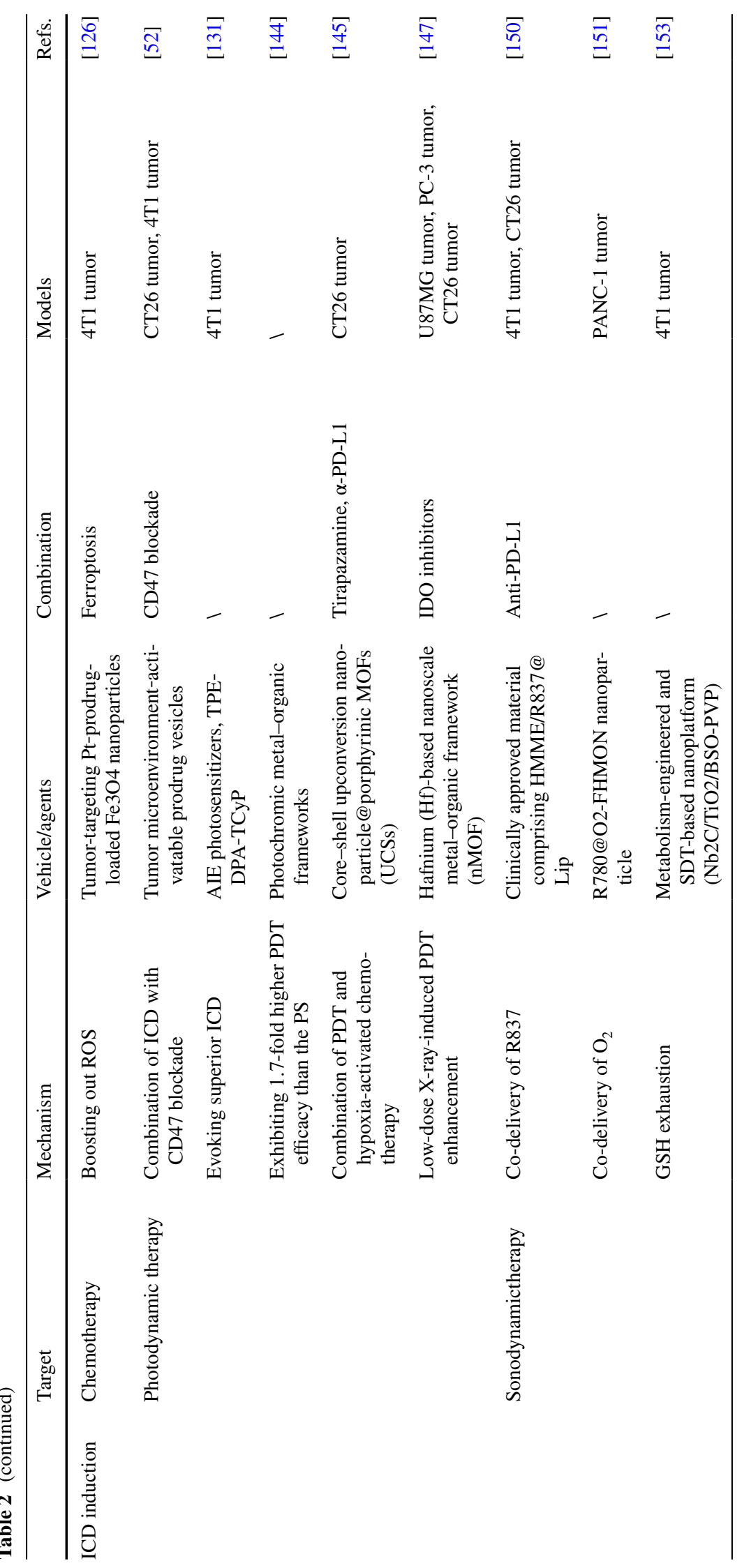


Table 3 Characteristics of T cell exclusion in cold tumors

\begin{tabular}{|c|c|c|c|}
\hline Categories & Components & Mechanism & Refs. \\
\hline \multirow[t]{9}{*}{ Blockade of $\mathrm{T}$ cell infiltration } & \multirow{3}{*}{$\begin{array}{l}\text { Down-regulation } \\
\text { of } \mathrm{T} \text { cell homing } \\
\text { factors }\end{array}$} & $\begin{array}{l}\text { Histone modifications and DNA methylation down-regulating CXCL9 and } \\
\text { CXCL10 }\end{array}$ & {$[154,155]$} \\
\hline & & $\begin{array}{l}\text { IDH-1/2-mediated R-2-hydroxyglutatate generation inhibiting CXCL9 and } \\
\text { CXCL10 production }\end{array}$ & {$[156]$} \\
\hline & & CXCL9 and CXCL10 down-regulation due to reduced type I IFN & {$[157]$} \\
\hline & \multirow[t]{3}{*}{ Physical barriers } & $\begin{array}{l}\text { Release of mitogenic and fibrogenic factors (VEGF, PDGF, TGF- } \beta \text {, and SHH) } \\
\text { for TAF activation owing to KRAS or NF- } \mathrm{kB} \text { mutations }\end{array}$ & {$[161-164]$} \\
\hline & & $\begin{array}{l}\text { Positive feedback network of pro-inflammatory cytokines (VEGF and TGF- } \beta \text { ) } \\
\text { for ECM deposition }\end{array}$ & {$[165]$} \\
\hline & & $\begin{array}{l}\text { Abundant ECM components (collagens, glycoproteins, elastin, and hyaluro- } \\
\text { nan) }\end{array}$ & [165] \\
\hline & \multirow[t]{3}{*}{ Hypoxia } & $\begin{array}{l}\text { VEGF resulting from HIF-1 } \alpha \text { up-regulation inducing FasL/Fas-mediated T } \\
\text { cell apoptosis }\end{array}$ & {$[166,167]$} \\
\hline & & $\begin{array}{l}\text { High VEGF-mediated increase in neovascular permeability inducing plasma } \\
\text { protein extravasation for facilitating ECM deposition }\end{array}$ & {$[158,168]$} \\
\hline & & $\begin{array}{l}\text { VEGF expression-mediated defects in leukocyte adhesion molecules (ICAM- } \\
1 / 2 \text {, VCAM-1, and CD34) }\end{array}$ & [169] \\
\hline
\end{tabular}

model to investigate immunomodulatory effects of ICD therapy, as well as even though a right cold tumor cells chosen, usually a subcutaneous tumor-bearing model was employed for research rather than the in situ tumor-bearing model, which is also not advisable. In particular, as for pancreatic cancer, a well-known cold tumor, where the fibrosis of pancreatic stellate cells in pancreas is also one of the critical factors involved in cold TIME, is of little significance to investigate the effect of anti-tumor immunotherapy on subcutaneous tumor-bearing model, instead, resulting in a waste of resources.

However, limited by the heterogeneity between individual animals and current clinically disjointed methods of diagnosis and evaluation in preclinical studies, there exists difficulty in defining a right animal model. At least, a realtime biopsy method, which can monitor the change of TIME before and after treatment in the same animal by flow cytometry or immunofluorescence staining, should be introduced into preclinical trials to replace current one-time terminal evaluation. In addition, a tempo-spatio testing standard should be established, such as biopsy of experimental animals, the appropriate time spot to test the T cell levels, and quantity of the $\mathrm{T}$ cells detected would be considered as a primal cold tumor or a fired-up cold tumor.

Second, it's a cliché topic, drug safety. In addition to efficacy, the safety of new drug is another key determinant of whether the new drug is eligible for an investigation new drug (IND) approval from FDA, as well as the goal of phase I clinical trial is to determine the safety profile and pharmacology of new drug [359]. Although the damage to metabolic organs, such as liver and kidney, has been routinely evaluated by hematoxylin-eosin (H\&E) staining or by further blood examination of aspartate aminotransferase (AST), alanine aminotransferase (ALT), etc., there are few other toxicity assessment of chemicals or nanomedicines (such as ototoxicity [360]), as well as the investigation of immunetoxicity (such as the detection of IL-17 [51]), that have been implemented on animal model. Therefore, it is essential and necessary to establish a sound evaluation mechanism for adverse immune reactions in preclinical study about the immunotherapeutic agents. Besides, the major feature of clinically validated nanomedicines for immunotherapy is to reduce the immunogenicity and improve the stability of immunomodulators, for example, the PEGylated IFN alpha-2a protein for Hepatitis C (Pegasys ${ }^{\circledR}$, Genentech). With regard to nanomedicines composed of nanomaterials possessing the capability to activate the immune systems, we need to pay more attention to their potentially increased risk of adverse immune reaction during treatment, perhaps the applications of these nanomaterials could be suspended for a while.

Third, as for those 'easy' drugs that already have been approved and marketed, eutherapeutic and low-toxicity 


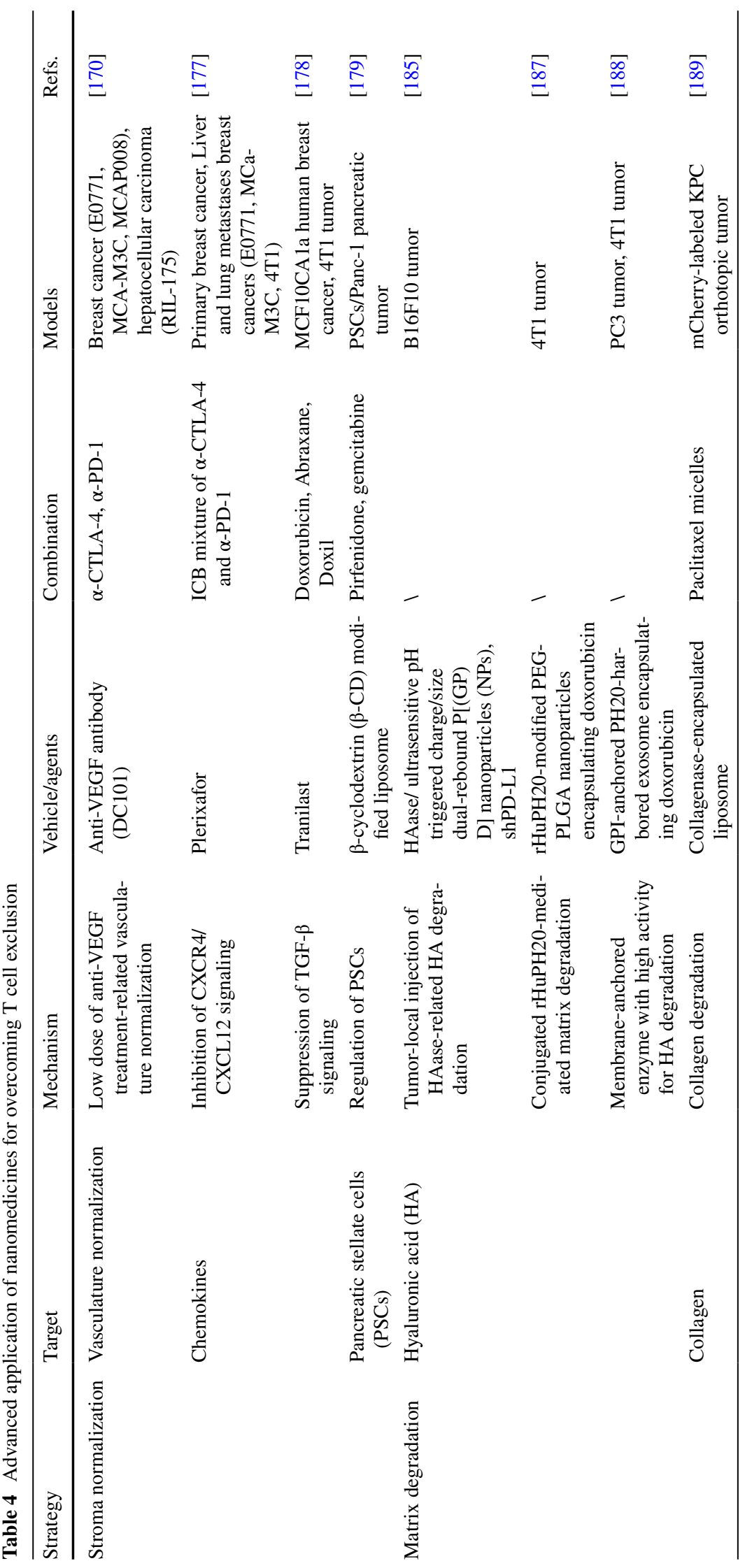




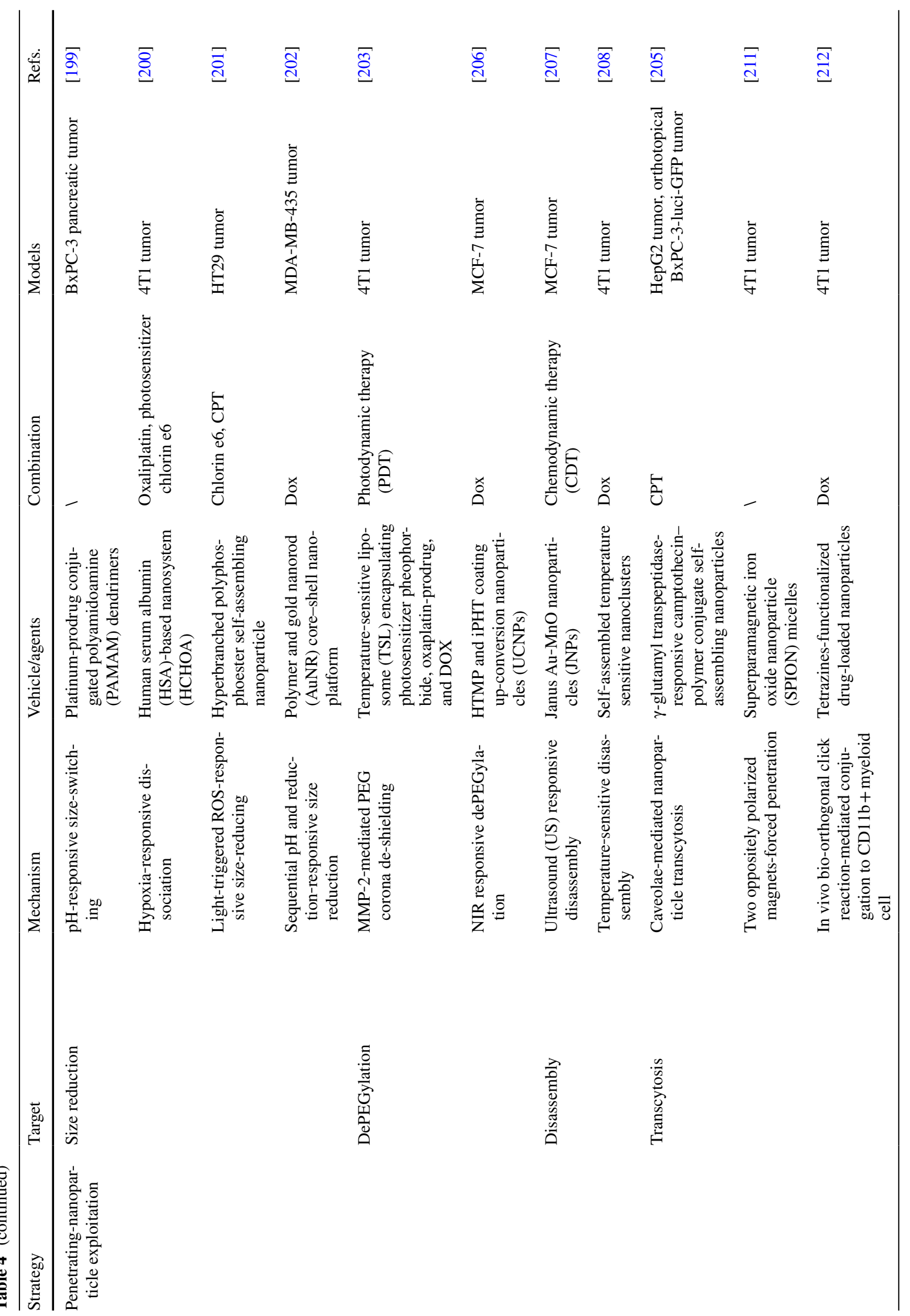




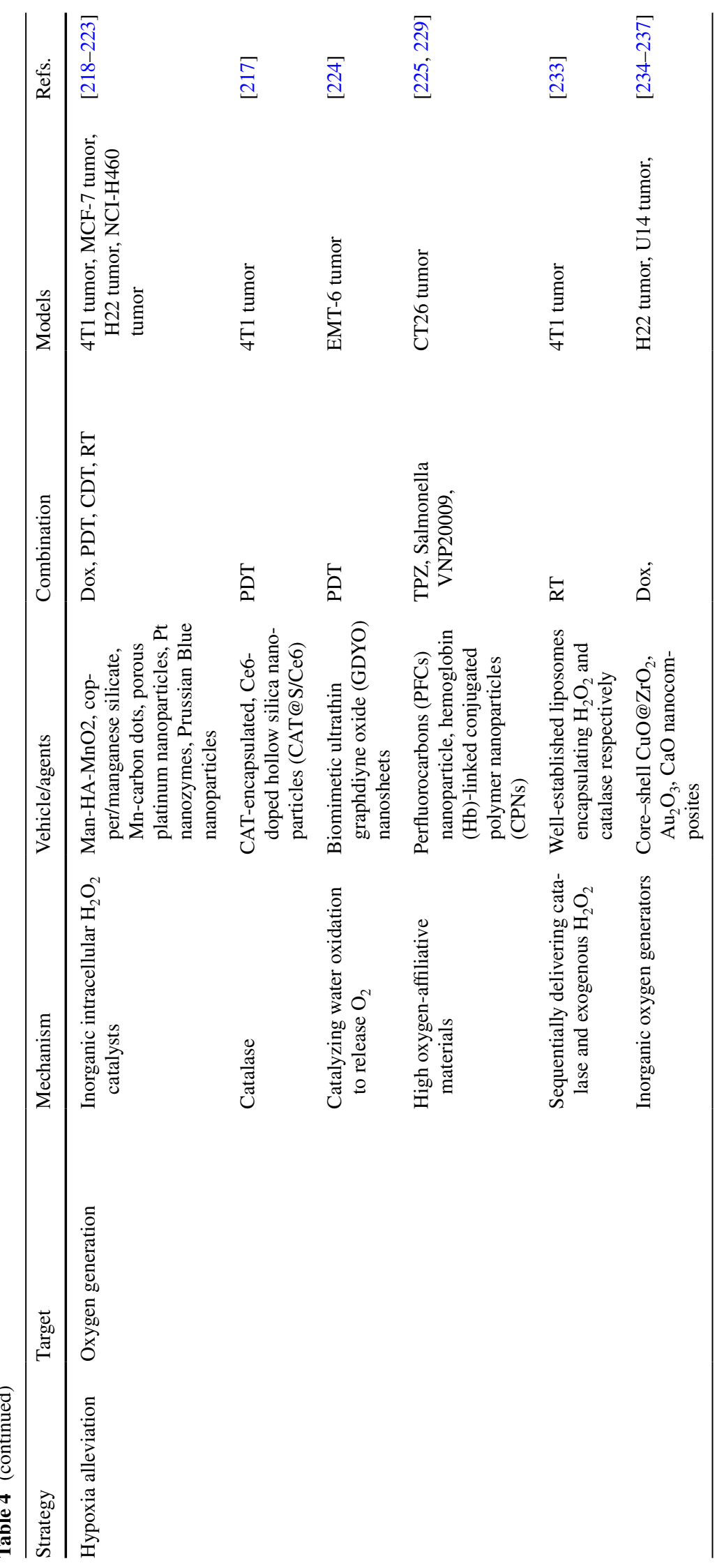


Table 5 Characteristics of $\mathrm{T}$ cell exhaustion in cold tumors

\begin{tabular}{|c|c|c|c|}
\hline Categories & Components & Mechanism & Refs. \\
\hline \multirow[t]{14}{*}{ T cell exhaustion } & \multirow[t]{5}{*}{ MDSCs } & ARG-1 activation-mediated $L$-arginine deprivation & {$[238,247]$} \\
\hline & & NOX and iNOS activation-mediated chemokine oxidation and TCR nitration & {$[248-250]$} \\
\hline & & Production of TGF- $\beta$ and IL-10 and up-regulation of PD-L1 & {$[245,251,252]$} \\
\hline & & Up-regulation of angiogenic factors (VEGF, bFGF, and PD-ECGF) & {$[253,254]$} \\
\hline & & Activation of Tregs & {$[238,241]$} \\
\hline & \multirow[t]{5}{*}{ TAMs } & Expression of angiogenic factors (Wnt7b, TIE2, TP, and VEGF) & [255] \\
\hline & & Expression of PD-1 and CTLA-4 ligands & {$[261,262]$} \\
\hline & & Up-regulation of TRAIL or Fas inducing T cell apoptosis & {$[261,263]$} \\
\hline & & Secretion of cytokines (TGF- $\beta$ and IL-10) for T cell inhibition & {$[264,265]$} \\
\hline & & Release of chemokines (CCL5, CCL20, and CCL22) for Treg recruitment & {$[266,267]$} \\
\hline & \multirow[t]{4}{*}{ Tregs } & Secretion of cytokines (TGF- $\beta$ and IL-10) for T cell inhibition & [271] \\
\hline & & IL-2 deprivation & [3] \\
\hline & & CD39/CD73-mediated adenosine generation & [3] \\
\hline & & CTLA-4 expression-mediated competition with CD28 for CD80/CD86 binding & [3] \\
\hline
\end{tabular}

nanoformulations, such as paclitaxel (Abraxane) and doxorubicin (Doxil), would be extremely hard to develop new formulation to heighten the clinical benefits; instead, there have been many clinical trials focused on expanding the spectrum of approved nanomedicines for anti-tumor immunotherapies. Hence, a potential is to use the same approved nanomaterials, such as liposome and albumin, to prepare similar nanoformulations of new drugs, or to adjust the minimal structural alterations on approved nanomaterials to achieve our goal, such as $\mathrm{pH}$ or enzymeresponsive drug release, and targeted modification. Meanwhile, the studies on several promising nanoformulations, including polymeric micelle, iron oxide nanoparticle, gold nanoparticle, and PLGA nanoparticle, should be continued to obtain enough data to support the safety and efficacy evaluation.

In summary, the application of nanomedicines has shown favorable results in enhancing or even dramatically improving the efficacy of immunotherapeutic agents, as well as reducing toxicity. Currently, although there is not likely to be a mass clinical translation of nanomedicines owing to the immature technology for monitoring the fate of nanomedicines in vivo, thousands of different types of nanomedicines have been accumulated in this field waiting for a qualitative leap, once a sound evaluation system is established (Tables 1, 2, 3, 4, 5, 6). 
Table 6 Advanced application of nanomedicines for rescuing T cell exhaustion

\begin{tabular}{|c|c|c|c|c|c|c|}
\hline Strategy & Target & Mechanism & Vehicle/agents & Combination & Models & Refs. \\
\hline \multirow[t]{6}{*}{$\begin{array}{l}\text { MDSCs-targeting } \\
\text { treatments }\end{array}$} & \multirow[t]{6}{*}{ MDSCs } & MDSC elimination & $\begin{array}{l}\text { Gemcitabine-loaded } \\
\text { nanocarriers }\end{array}$ & $\begin{array}{l}\text { Anticancer adop- } \\
\text { tive T cell therapy } \\
\text { (ACT) }\end{array}$ & $\begin{array}{l}\text { EG7-OVA tumor, } \\
\text { B16 tumor }\end{array}$ & {$[205,300,301]$} \\
\hline & & $\begin{array}{l}\text { Hypoxia alleviation- } \\
\text { mediated MDSC } \\
\text { impediment }\end{array}$ & $\begin{array}{l}\text { Platelet membrane- } \\
\text { based co-encapsu- } \\
\text { lation of metformin } \\
\text { and IR780 }\end{array}$ & PDT & 4T1 tumor & [303] \\
\hline & & $\begin{array}{c}\text { Phosphoinositide-3- } \\
\text { kinases- } \gamma(\mathrm{PI} 3 \mathrm{~K}-\gamma) \\
\text { inhibition-mediated } \\
\text { MDSC remodeling }\end{array}$ & $\begin{array}{l}\text { IPI-549-loaded } \\
\text { targeted polymeric } \\
\text { nanoparticles }\end{array}$ & 1 & $\begin{array}{l}\text { KPC98027 RFP/Luc } \\
\text { allografts }\end{array}$ & [304] \\
\hline & & $\begin{array}{l}\text { Disruption of MDSC } \\
\text { expansion }\end{array}$ & $\begin{array}{l}\text { Pseudoneutriphil } \\
\text { cytokine sponges }\end{array}$ & $\alpha-P D-1$ & $\begin{array}{l}\text { B16F10 tumor, } 4 \mathrm{~T} 1 \\
\text { tumor }\end{array}$ & [305] \\
\hline & & MDSC modulation & $\begin{array}{l}\text { RNAi and CCL2 co- } \\
\text { loaded nanocap- } \\
\text { sules }\end{array}$ & 1 & In vitro MDSC & [306] \\
\hline & & $\begin{array}{l}\text { Inhibition of MDSC } \\
\text { recruitment }\end{array}$ & $\begin{array}{l}\text { Micellar hypotoxic } \\
\text { low molecular } \\
\text { weight heparin- } \\
\text { tocopherol succi- } \\
\text { nate nanoparticle }\end{array}$ & Dox & $\begin{array}{l}\text { B16F10 tumor lung } \\
\text { metastases }\end{array}$ & [307] \\
\hline \multirow[t]{8}{*}{$\begin{array}{l}\text { TAMs-targeting treat- } \\
\text { ments }\end{array}$} & \multirow[t]{8}{*}{ TAMs } & $\begin{array}{l}\text { CCL2/CCR2 chemot- } \\
\text { axis blockade }\end{array}$ & $\begin{array}{l}\text { Monocyte-targeting } \\
\text { cationic nanoparti- } \\
\text { cles encapsulating } \\
\text { CCR2 siRNA }\end{array}$ & 1 & 4T1 tumor & [313] \\
\hline & & $\begin{array}{l}\text { Reinforcing phagocy- } \\
\text { tosis of TAMs }\end{array}$ & $\begin{array}{l}\text { CSF1R- and SHP2- } \\
\text { inhibitor-loaded } \\
\text { nanoparticle }\end{array}$ & 1 & 4T1 tumor & [315] \\
\hline & & $\begin{array}{l}\text { Selective toxicity to } \\
\text { TAMs }\end{array}$ & $\begin{array}{l}\text { Calcium bisphospho- } \\
\text { nate nanoparticles } \\
\text { with chelator-free } \\
\text { radiolabeling }\end{array}$ & $\begin{array}{l}\text { radioisotope therapy } \\
\text { (RIT) }\end{array}$ & 4T1 tumor & [319] \\
\hline & & \multirow[t]{4}{*}{$\begin{array}{l}\text { M2-TAM repolariza- } \\
\text { tion }\end{array}$} & $\begin{array}{l}\text { R848-loaded } \\
\beta \text {-cyclodextrin } \\
\text { nanoparticles } \\
(\text { CDNP-R848) }\end{array}$ & anti-PD-1 & $\begin{array}{l}\text { MC38 tumor, } \\
\text { B16F10 melanoma }\end{array}$ & [321] \\
\hline & & & $\begin{array}{l}\text { Liposome-encapsu- } \\
\text { lated zoledronate } \\
\text { acid treatment }\end{array}$ & 1 & 4T1 tumor cells & {$[322]$} \\
\hline & & & $\begin{array}{l}\text { Nanoparticle encap- } \\
\text { sulating M1-like } \\
\text { TAM-related active } \\
\text { microRNAs }\end{array}$ & 1 & B16F10 tumor & [323] \\
\hline & & & $\begin{array}{l}\text { Myeloid-derived } \\
\text { suppressor cell } \\
\text { (MDSC) mem- } \\
\text { brane-coated iron } \\
\text { oxide magnetic } \\
\text { nanoparticle }\end{array}$ & PTT, ICD & B16/F10 tumor & [327] \\
\hline & & $\begin{array}{l}\text { Improvement of TAM } \\
\text { targeting }\end{array}$ & $\begin{array}{l}\text { Surface-manno- } \\
\text { sylated nanopar- } \\
\text { ticles }\end{array}$ & aPD-L1 & CT26-tumor & [329] \\
\hline
\end{tabular}


Table 6 (continued)

\begin{tabular}{|c|c|c|c|c|c|c|}
\hline Strategy & Target & Mechanism & Vehicle/agents & Combination & Models & Refs. \\
\hline \multirow[t]{2}{*}{$\begin{array}{l}\text { Tregs-targeting treat- } \\
\text { ments }\end{array}$} & Tregs & $\begin{array}{l}\text { Down-regulation of } \\
\text { CTLA-4 }\end{array}$ & $\begin{array}{l}\text { CTLA-4-siRNA } \\
\text { loaded PLGA nano- } \\
\text { particle }\end{array}$ & OVA & B16 tumor & [347] \\
\hline & & $\begin{array}{l}\text { Preferential Treg } \\
\text { depletion }\end{array}$ & $\begin{array}{l}\text { Cyclophosphamide- } \\
\text { loaded engineering } \\
\text { PD-1-presenting } \\
\text { platelets }\end{array}$ & 1 & $\begin{array}{l}\text { postsurgery B16F10 } \\
\text { tumor }\end{array}$ & [350] \\
\hline
\end{tabular}

Acknowledgements The work was supported by the grants from National Natural Science Foundation of China (21602030 and 81872808) and Program of Shanghai Academic Research Leader (18XD1400500), Project Supported by Shanghai Municipal Science and Technology Major Project (2018SHZDZX01) and ZJLab, Fudan-SIMM Joint Research Fund (FU-SIMM20182006) and Scientific Research Program of Shanghai Health and Family Planning Commission (20184Y0149).

Open Access This article is licensed under a Creative Commons Attribution 4.0 International License, which permits use, sharing, adaptation, distribution and reproduction in any medium or format, as long as you give appropriate credit to the original author(s) and the source, provide a link to the Creative Commons licence, and indicate if changes were made. The images or other third party material in this article are included in the article's Creative Commons licence, unless indicated otherwise in a credit line to the material. If material is not included in the article's Creative Commons licence and your intended use is not permitted by statutory regulation or exceeds the permitted use, you will need to obtain permission directly from the copyright holder. To view a copy of this licence, visit http://creativecommons.org/licenses/by/4.0/.

\section{References}

1. Y. Iwai, J. Hamanishi, K. Chamoto, T. Honjo, Cancer immunotherapies targeting the PD-1 signaling pathway. J. Biomed. Sci. 24(1), 26 (2017). https://doi.org/10.1186/s1292 9-017-0329-9

2. C. Zheng, L. Zheng, J.-K. Yoo, H. Guo, Y. Zhang et al., Landscape of infiltrating T cells in liver cancer revealed by singlecell sequencing. Cell 169(7), 1342-1356 (2017). https://doi. org/10.1016/j.cell.2017.05.035

3. S. Spranger, Mechanisms of tumor escape in the context of the T-cell-inflamed and the non-T-cell-inflamed tumor microenvironment. Int. Immunol. 28(8), 383-391 (2016). https:// doi.org/10.1093/intimm/dxw014

4. S. Pan, Y. Zhan, X. Chen, B. Wu, B. Liu, Bladder cancer exhibiting high immune infiltration shows the lowest response rate to immune checkpoint inhibitors. Front. Oncol. 9, 1101 (2019). https://doi.org/10.3389/fonc.2019.01101

5. G. Roviello, F. Andre, S. Venturini, B. Pistilli, G. Curigliano et al., Response rate as a potential surrogate for survival and efficacy in patients treated with novel immune checkpoint inhibitors: A meta-regression of randomised prospective studies. Eur. J. Cancer 86, 257-265 (2017). https://doi. org/10.1016/j.ejca.2017.09.018

6. R.W. Jenkins, D.A. Barbie, K.T. Flaherty, Mechanisms of resistance to immune checkpoint inhibitors. Br. J. Cancer 118(1), 9-16 (2018). https://doi.org/10.1038/bjc.2017.434

7. P. Andre, C. Denis, C. Soulas, C. Bourbon-Caillet, J. Lopez et al., Anti-NKG2A mab is a checkpoint inhibitor that promotes anti-tumor immunity by unleashing both $\mathrm{T}$ and NK cells. Cell 175(7), 1731-1743 (2018). https://doi. org/10.1016/j.cell.2018.10.014

8. D. Sun, J. Ma, J. Wang, F. Zhang, L. Wang et al., Clinical observation of immune checkpoint inhibitors in the treatment of advanced pancreatic cancer: a real-world study in Chinese cohort. Ther. Clin. Risk Manag. 14, 1691-1700 (2018). https ://doi.org/10.2147/tcrm.S173041

9. M. Kowanetz, W. Zou, S.N. Gettinger, H. Koeppen, M. Kockx et al., Differential regulation of PD-L1 expression by immune and tumor cells in NSCLC and the response to treatment with Atezolizumab (anti-PD-L1). Proc. Natl. Acad. Sci. USA. 115(43), E10119-E10126 (2018). https://doi.org/10.1073/ pnas. 1802166115

10. Y. Liu, J. Zugazagoitia, F.S. Ahmed, B.S. Henick, S.N. Gettinger et al., Immune cell PD-L1 colocalizes with macrophages and is associated with outcome in PD-1 pathway blockade therapy. Clin. Cancer Res. 26(4), 970-977 (2020). https://doi.org/10.1158/1078-0432.CCR-19-1040z

11. L. Li, R. Sun, Y. Miao, T. Tran, L. Adams et al., PD-1/PD-L1 expression and interaction by automated quantitative immunofluorescent analysis show adverse prognosticiImpact in patients with diffuse large B-cell lymphoma having T-cell infiltration: a study from the international DLBCL consortium program. Mod. Pathol. 32(6), 741-754 (2019). https:// doi.org/10.1038/s41379-018-0193-5

12. Y. Jiang, M. Chen, H. Nie, Y. Yuan, PD-1 and PD-L1 in cancer immunotherapy: clinical implications and future considerations. Hum. Vaccin. Immunother 15(5), 1111-1122 (2019). https://doi.org/10.1080/21645515.2019.1571892

13. R.H. Vonderheide, The immune revolution: a case for priming, not checkpoint. Cancer Cell 33(4), 563-569 (2018). https ://doi.org/10.1016/j.ccell.2018.03.008

14. S. Spranger, R.M. Spaapen, Y. Zha, J. Williams, Y. Meng et al., Up-regulation of PD-L1, IDO, and T-regs in the 
melanoma tumor microenvironment is driven by CD8(+) $\mathrm{T}$ cells. Sci. Transl. Med. 5(200), 200ra116 (2013). https://doi. org/10.1126/scitranslmed.3006504

15. P. Sharma, J.P. Allison, The future of immune checkpoint therapy. Science 348(6230), 56-61 (2015). https://doi. org/10.1126/science.aaa8172

16. R.N. Ramos, E. Piaggio, E. Romano, Mechanisms of resistance to immune checkpoint antibodies. Handb. Exp. Pharmaco. 249, 109-128 (2018). https://doi. org/10.1007/164_2017_11

17. I. Melero, D.M. Berman, M. Angela, A.J. Korman, J.L. Perez et al., Evolving synergistic combinations of targeted immunotherapies to combat cancer. Nat. Rev. Cancer 15(8), 457-472 (2015). https://doi.org/10.1038/nrc3973

18. M. Anraku, K.S. Cunningham, Z. Yun, M.-S. Tsao, L. Zhang et al., Impact of tumor-infiltrating $\mathrm{T}$ cells on survival in patients with malignant pleural mesothelioma. J. Thorac. Cardiovasc. Surg. 135(4), 823-829 (2008). https://doi. org/10.1016/j.jtcvs.2007.10.026

19. W.-T. Hwang, S.F. Adams, E. Tahirovic, I.S. Hagemann, G. Coukos, Prognostic significance of tumor-infiltrating T cells in ovarian cancer: a Meta-Analysis. Gynecol. Oncol. 124(2), 192-198 (2012). https://doi.org/10.1016/j.ygyno.2011.09.039

20. W. Ding, X. Xu, Y. Qian, W. Xue, Y. Wang et al., Prognostic value of tumor-infiltrating lymphocytes in hepatocellular carcinoma a meta-analysis. Medicine 97(50), e13301 (2018). https://doi.org/10.1097/md.0000000000013301

21. M. Peled, A. Onn, R.S. Herbst, Tumor-infiltrating lymphocytes-location for prognostic evaluation. Clin. Cancer Res. 25(5), 1449-1451 (2019). https://doi.org/10.1158/1078-0432. Ccr-18-3803

22. W.-C. Cheng, P.-C. Ho, Firing up cold tumors. Trends. Cancer 5(9), 528-530 (2019). https://doi.org/10.1016/j.treca n.2019.06.005

23. K. Paul, D. Kretzschmar, A. Yilmaz, B. Baerthlein, S. Titze et al., Circulating dendritic cell precursors in chronic kidney disease: a cross-sectional study. BMC Nephrol. 14, 274 (2013). https://doi.org/10.1186/1471-2369-14-274

24. J. Liu, E.A. Rozeman, J.S. O’Donnell, S. Allen, L. Fanchi et al., Batf ${ }^{3+}$ DCs and type I IFN are critical for the efficacy of neoadjuvant cancer immunotherapy. Oncoimmunology 8(2), e1546068 (2019). https://doi.org/10.1080/21624 02x.2018.1546068

25. J.J. Engelhardt, B. Boldajipour, P. Beemiller, P. Pandurangi, C. Sorensen et al., Marginating dendritic cells of the tumor microenvironment cross-present tumor antigens and stably engage tumor-specific T cells. Cancer Cell 21(3), 402-417 (2012). https://doi.org/10.1016/j.ccr.2012.01.008

26. J.-M. Williford, J. Ishihara, A. Ishihara, A. Mansurov, P. Hosseinchi et al., Recruitment of CD103(+) dendritic cells via tumor-targeted chemokine delivery enhances efficacy of checkpoint inhibitor immunotherapy. Sci. Adv. 5(12), eaay1357 (2019). https://doi.org/10.1126/sciadv.aay1357

27. K. Hildner, B.T. Edelson, W.E. Purtha, M. Diamond, H. Matsushita et al., Batf3 deficiency reveals a critical role for CD8 Alpha(+) dendritic cells in cytotoxic T cell immunity. Science
322(5904), 1097-1100 (2008). https://doi.org/10.1126/scien ce. 1164206

28. Y. Mi, C.T. Hagan, B.G. Vincent, A.Z. Wang, Emerging nano-/microapproaches for cancer immunotherapy. Adv. Sci. 6(6), 1801847 (2019). https://doi.org/10.1002/advs.20180 1847

29. T. Gajewski, Y. Zha, K. Hernandez, Y. Li, R. Bao et al., Density of immunogenic antigens and presence or absence of the T cell-inflamed tumor microenvironment in metastatic melanoma. J. Clin. Oncol. 33(15), suppl.3002 (2015). https ://doi.org/10.1200/jco.2015.33.15_suppl.3002

30. M.E. Mikucki, D.T. Fisher, J. Matsuzaki, J.J. Skitzki, N.B. Gaulin et al., Non-redundant requirement for CXCR3 signalling during tumoricidal T-cell trafficking across tumour vascular checkpoints. Nat. Commun. 6, 7458 (2015). https ://doi.org/10.1038/ncomms8458

31. Y. Zhang, W. Chen, C. Yang, Q. Fan, W. Wu et al., Enhancing tumor penetration and targeting using size-minimized and zwitterionic nanomedicines. J. Controlled Release 237, 115-124 (2016). https://doi.org/10.1016/j.jconr el.2016.07.011

32. K. Ley, C. Laudanna, M.I. Cybulsky, S. Nourshargh, Getting to the site of inflammation: the leukocyte adhesion cascade updated. Nat. Rev. Immunol. 7(9), 678-689 (2007). https:// doi.org/10.1038/nri2156

33. B.Y. Kim, J.T. Rutka, W.C. Chan, Nanomedicine. N. Engl. J. Med. 363(25), 2434-2443 (2010). https://doi.org/10.1056/ NEJMra0912273

34. F. Scaletti, J. Hardie, Y.-W. Lee, D.C. Luther, M. Ray et al., Protein delivery into cells using inorganic nanoparticleprotein supramolecular assemblies. Chem. Soc. Rev. 47(10), 3421-3432 (2018). https://doi.org/10.1039/c8cs00008e

35. S.M. Dadfar, K. Roemhild, N.I. Drude, S. von Stillfried, R. Knuechel et al., Iron oxide nanoparticles: diagnostic, therapeutic and theranostic applications. Adv. Drug Delivery Rev. 138, 302-325 (2019). https://doi.org/10.1016/j. addr.2019.01.005

36. C. Saraiva, C. Praca, R. Ferreira, T. Santos, L. Ferreira et al., Nanoparticle-mediated brain drug delivery: overcoming blood-brain barrier to treat neurodegenerative diseases. J. Controlled Release 235, 34-47 (2016). https://doi. org/10.1016/j.jconrel.2016.05.0444

37. N. Amreddy, A. Babu, R. Muralidharan, J. Panneerselvam, A. Srivastava et al., In Recent Advances in Nanoparticle-Based Cancer Drug and Gene Delivery. ed. by TEW K D, FISHER P B 2018), pp. 115-170

38. A. Gupta, S. Mumtaz, C.-H. Li, I. Hussain, V.M. Rotello, Combatting antibiotic-resistant bacteria using nanomaterials. Chem. Soc. Rev. 48(2), 415-427 (2019). https://doi. org/10.1039/c7cs00748e

39. Y. Min, J.M. Caster, M.J. Eblan, A.Z. Wang, Clinical translation of nanomedicine. Chem. Rev. 115(19), 11147-11190 (2015). https://doi.org/10.1021/acs.chemrev.5b00116

40. Y. Shi, Clinical translation of nanomedicine and biomaterials for cancer immunotherapy: progress and perspectives. 
Adv. Ther. 3(9), 1900215 (2020). https://doi.org/10.1002/ adtp. 201900215

41. M.A. Postow, R. Sidlow, M.D. Hellmann, Immune-related adverse events associated with immune checkpoint blockade. N. Engl. J. Med. 378(2), 158-168 (2018). https://doi. org/10.1056/NEJMra1703481

42. D. Schmid, C.G. Park, C.A. Hartl, N. Subedi, A.N. Cartwright et al., T cell-targeting nanoparticles focus delivery of immunotherapy to improve antitumor immunity. Nat. Commun. 8(1), 1747 (2017). https://doi.org/10.1038/s41467-01701830-8

43. C.F. Friedman, T.A. Proverbs-Singh, M.A. Postow, Treatment of the immune-related adverse effects of immune checkpoint inhibitors a review. JAMA Oncol. 2(10), 1346-1353 (2016). https://doi.org/10.1001/jamaoncol.2016.1051

44. A.C. Anselmo, S. Mitragotri, Nanoparticles in the clinic: An update. Bioeng. Transl. Med. 4(3), e10143 (2019). https:// doi.org/10.1002/btm2.10143

45. S. Vecchi, S. Bufali, T. Uno, T. Wu, L. Arcidiacono et al., Conjugation of a TLR7 agonist and antigen enhances protection in the $\mathrm{S}$. pneumoniae murine infection model. Eur. J. Pharm. Biopharm. 87(2), 310-317 (2014). https://doi. org/10.1016/j.ejpb.2014.01.002

46. D.S. Wilson, S. Hirosue, M.M. Raczy, L. Bonilla-Ramirez, L. Jeanbart et al., Antigens reversibly conjugated to a polymeric glyco-adjuvant induce protective humoral and cellular immunity. Nat. Mater. 18(2), 175-185 (2019). https://doi. org/10.1038/s41563-018-0256-5

47. D. Passlick, K. Piradashvili, D. Bamberger, M. Li, S. Jiang et al., Delivering all in one: antigen-nanocapsule loaded with dual adjuvant yields superadditive effects by DC-directed T cell stimulation. J. Controlled Release 289, 23-34 (2018). https://doi.org/10.1016/j.jconrel.2018.09.008

48. S. Gujar, J.G. Pol, G. Kroemer, Heating it up: Oncolytic viruses make tumors "hot'" and suitable for checkpoint blockade immunotherapies." Oncoimmunology 7(8), e1442169 (2018). https://doi.org/10.1080/2162402x.2018.1442169

49. H. Phuengkham, C. Song, S.H. Um, Y.T. Lim, Implantable synthetic immune niche for spatiotemporal modulation of tumor-derived immunosuppression and systemic antitumor immunity: postoperative immunotherapy. Adv. Mater. 30(18), e1706719 (2018). https://doi.org/10.1002/adma.201706719

50. L.L. van der Woude, M.A.J. Gorris, A. Halilovic, C.G. Figdor, I.J.M. de Vries, Migrating into the tumor: a roadmap for T cells. Trends. Cancer 3(11), 797-808 (2017). https://doi. org/10.1016/j.trecan.2017.09.006

51. W. Song, L. Shen, Y. Wang, Q. Liu, T.J. Goodwin et al., Synergistic and low adverse effect cancer immunotherapy by immunogenic chemotherapy and locally expressed PD-L1 trap. Nat. Commun. 9(1), 2237 (2018). https://doi. org/10.1038/s41467-018-04605-X

52. F. Zhou, B. Feng, H. Yu, D. Wang, T. Wang, Y. Ma, S. Wang, Y. Li, Tumor microenvironment-activatable prodrug vesicles for nanoenabled cancer chemoimmunotherapy combining immunogenic cell death induction and CD47 blockade. Adv.
Mater. 31(14), e1805888 (2019). https://doi.org/10.1002/ adma.201805888

53. Q. Sun, X. Bai, A.M. Sofias, R. van der Meel, E. Ruiz-Hernandez, G. Storm et al., Cancer nanomedicine meets immunotherapy: Opportunities and challenges. Acta Pharmacol. Sin. 41(7), 954-958 (2020). https://doi.org/10.1038/s4140 1-020-0448-9

54. T.F. Gajewski, H. Schreiber, Y.X. Fu, Innate and adaptive immune cells in the tumor microenvironment. Nat. Immunol. 14(10), 1014-1022 (2013). https://doi.org/10.1038/ni.2703

55. S. Spranger, R. Bao, T.F. Gajewski, Melanoma-intrinsic betacatenin signalling prevents anti-tumour immunity. Nature 523(7559), 231-U261 (2015). https://doi.org/10.1038/natur e14404

56. L. Ding, H.-J. Kim, Q. Wang, M. Kearns, T. Jiang et al., Parp Inhibition elicits STING-dependent antitumor immunity in brca1-deficient ovarian cancer. Cell Rep. 25(11), 2972-2980 (2018). https://doi.org/10.1016/j.celrep.2018.11.054

57. C. Menetrier-Caux, G. Montmain, M.C. Dieu, C. Bain, M.C. Favrot et al., Inhibition of the differentiation of dendritic cells from $\mathrm{CD} 34^{+}$progenitors by tumor cells: role of interleukin- 6 and macrophage colony-stimulating factor. Blood 92(12), 4778-4791 (1998). https://doi.org/10.1182/blood .V92.12.4778

58. G. Li, S. Abediankenari, Y.-J. Kim, T.B. Campbell, S. Ito et al., TGF-beta combined with M-CSF and IL-4 induces generation of immune inhibitory cord blood dendritic cells capable of enhancing cytokine-induced ex vivo expansion of myeloid progenitors. Blood 110(8), 2872-2879 (2007). https://doi.org/10.1182/blood-2006-10-050583

59. H. Kitamura, Y. Ohno, Y. Toyoshima, J. Ohtake, S. Homma et al., Interleukin-6/STAT3 signaling as a promising target to improve the efficacy of cancer immunotherapy. Cancer Sci. 108(10), 1947-1952 (2017). https://doi.org/10.1111/ cas. 13332

60. J. Qiao, Z. Liu, C. Dong, Y. Luan, A. Zhang et al., Targeting tumors with IL-10 prevents dendritic cell-mediated CD8(+) T cell apoptosis. Cancer Cell 35(6), 901-915 (2019). https ://doi.org/10.1016/j.ccell.2019.05.005

61. S. Jaiswal, C.H.M. Jamieson, W.W. Pang, C.Y. Park, M.P. Chao et al., CD47 is upregulated on circulating hematopoietic stem cells and leukemia cells to avoid phagocytosis. Cell 138(2), 271-285 (2009). https://doi.org/10.1016/j. cell.2009.05.046

62. E. Reeves, E. James, Antigen processing and immune regulation in the response to tumours. Immunology 150(1), 16-24 (2017). https://doi.org/10.1111/imm.12675

63. A. Rousseau, A. Bertolotti, Regulation of proteasome assembly and activity in health and disease. Nat. Rev. Mol. Cell Biol. 19(11), 697-712 (2018). https://doi.org/10.1038/ s41580-018-0040-z

64. T. Blankenstein, P.G. Coulie, E. Gilboa, E.M. Jaffee, The determinants of tumour immunogenicity. Nat. Rev. Cancer 12(4), 307-313 (2012). https://doi.org/10.1038/nrc3246

65. M. Leclerc, L. Mezquita, G.G. De Nerville, I. Tihy, I. Malenica et al., Recent advances in lung cancer 
immunotherapy: Input of T-cell epitopes associated with impaired peptide processing. Front. Immunol. 10, 1505 (2019). https://doi.org/10.3389/fimmu.2019.01505

66. W. Ji, L. Niu, W. Peng, Y. Zhang, H. Cheng et al., Salt bridge-forming residues positioned over viral peptides presented by MHC Class I impacts T-cell recognition in a binding-dependent manner. Mol. Immunol. 112, 274-282 (2019). https://doi.org/10.1016/j.molimm.2019.06.005

67. T. Pradeu, E.D. Carosella, On the definition of a criterion of immunogenicity. Proc. Natl. Acad. Sci. USA 103(47), 17858-17861 (2006). https://doi.org/10.1073/pnas.06086 83103

68. K. Rezvani, H. de Lavallade, Vaccination strategies in lymphomas and leukaemias recent progress. Drugs 71(13), 1659-1674 (2011). https://doi.org/10.2165/11593270-00000 0000-00000

69. D. Laheru, E.M. Jaffee, Immunotherapy for pancreatic cancer - science driving clinical progress. Nat. Rev. Cancer 5(6), 459-467 (2005). https://doi.org/10.1038/nrc1630

70. S. Spranger, T.F. Gajewski, Tumor-intrinsic oncogene pathways mediating immune avoidance. Oncoimmunology 5(3), e1086862 (2016). https://doi.org/10.1080/21624 $02 x .2015 .1086862$

71. Y. Wang, Y.-X. Lin, J. Wang, S.-L. Qiao, Y.-Y. Liu et al., In situ manipulation of dendritic cells by an autophagyregulative nanoactivator enables effective cancer immunotherapy. ACS Nano 13(7), 7568-7577 (2019). https://doi. org/10.1021/acsnano.9b00143

72. J. Sprooten, P. Agostinis, A.D. Garg, in Type I Interferons and Dendritic Cells in Cancer Immunotherapy. ed.by LHUILLIER C, GALLUZZI L 2019), pp. 217-262

73. Y. Liu, W.N. Crowe, L. Wang, Y. Lu, W.J. Petty et al., An inhalable nanoparticulate STING agonist synergizes with radiotherapy to confer long-term control of lung metastases. Nat. Commun. 10(1), 5108 (2019). https://doi. org/10.1038/s41467-019-13094-5

74. G. Tresset, W.C.D. Cheong, Y.L.S. Tan, J. Boulaire, Y.M. Lam, Phospholipid-based artificial viruses assembled by multivalent cations. Biophys. J. 93(2), 637-644 (2007). https://doi.org/10.1529/biophysj.107.104448

75. K.B. Knudsen, H. Northeved, P.E.K. Kumar, A. Permin, T. Gjetting et al., In vivo toxicity of cationic micelles and liposomes. Nanomedicine 11(2), 467-477 (2015). https:// doi.org/10.1016/j.nano.2014.08.004

76. D. Shae, K.W. Becker, P. Christov, D.S. Yun, A.K.R. Lytton-Jean et al., Endosomolytic polymersomes increase the activity of cyclic dinucleotide STING agonists to enhance cancer immunotherapy. Nat. Nanotechnol. 14(3), 269-278 (2019). https://doi.org/10.1038/s41565-018-0342-5

77. R.D. Junkins, M.D. Gallovic, B.M. Johnson, M.A. Collier, R. Watkins-Schulz et al., A robust microparticle platform for a STING-targeted adjuvant that enhances both humoral and cellular immunity during vaccination. J. Controlled Release 270, 1-13 (2018). https://doi.org/10.1016/j.jconr el.2017.11.030
78. D.G. Leach, N. Dharmaraj, S.L. Piotrowski, T.L. LopezSilva, Y.L. Lei et al., Stingel: controlled release of a cyclic dinucleotide for enhanced cancer immunotherapy. Biomaterials 163, 67-75 (2018). https://doi.org/10.1016/j.bioma terials.2018.01.035

79. S.H. Van der Burg, R. Arens, F. Ossendorp, T. van Hall, C.J. Melief, Vaccines for established cancer: overcoming the challenges posed by immune evasion. Nat. Rev. Cancer 16(4), 219-233 (2016). https://doi.org/10.1038/nrc.2016.16

80. K. Takeda, S. Akira, Toll-like receptors. Curr. Protoc. Immunol. 109(1), 14.12.11-14.12.10 (2015). https://doi. org/10.1002/0471142735.im1412s109

81. G. Traini, A. Ruiz-de-Angulo, J.B. Blanco-Canosa, K. Zamacola Bascarán, A. Molinaro et al., Cancer immunotherapy of TLR4 agonist-antigen constructs enhanced with pathogen-mimicking magnetite nanoparticles and checkpoint blockade of PD-L1. Small 15(4), e1803993 (2019). https://doi.org/10.1002/smll.201803993

82. L. Nuhn, S. De Koker, S. Van Lint, Z. Zhong, J.P. Catani et al., Nanoparticle-conjugate TLR7/8 agonist localized immunotherapy provokes safe antitumoral responses. Adv. Mater. 30(45), e1803397 (2018). https://doi.org/10.1002/ adma.201803397

83. B. Wang, S. Van Herck, Y. Chen, X. Bai, Z. Zhong et al., Potent and prolonged innate immune activation by enzymeresponsive imidazoquinoline TLR7/8 agonist prodrug vesicles. J. Am. Chem. Soc. 142(28), 12133-12139 (2020). https://doi.org/10.1021/jacs.0c01928

84. S. Cheng, C. Xu, Y. Jin, Y. Li, C. Zhong et al., Artificial mini dendritic cells boost $\mathrm{T}$ cell-based immunotherapy for ovarian cancer. Adv. Sci. 7(7), 1903301 (2020). https://doi. org/10.1002/advs.201903301

85. T. Wu, Y. Qi, D. Zhang, Q. Song, C. Yang et al., Bone marrow dendritic cells derived microvesicles for combinational immunochemotherapy against tumor. Adv. Funct. Mater. 27(42), 1703191 (2017). https://doi.org/10.1002/adfm.20170 3191

86. A. Jain, C. Pasare, Innate control of adaptive immunity: Beyond the three-signal paradigm. J. Immunol. 198(10), 3791-3800 (2017). https://doi.org/10.4049/jimmunol.16020 00

87. S.G. Reed, M.T. Orr, C.B. Fox, Key roles of adjuvants in modern vaccines. Nat. Med. 19(12), 1597-1608 (2013). https ://doi.org/10.1038/nm.3409

88. T. Storni, T.M. Kundig, G. Senti, P. Johansen, Immunity in response to particulate antigen-delivery systems. Adv. Drug Delivery Rev. 57(3), 333-355 (2005). https://doi. org/10.1016/j.addr.2004.09.008

89. X. Duan, C. Chan, W. Lin, Nanoparticle-mediated immunogenic cell death enables and potentiates cancer immunotherapy. Angew. Chem. Int. Ed. 58(3), 670-680 (2019). https ://doi.org/10.1002/anie.201804882

90. K. Wang, S. Wen, L. He, A. Li, Y. Li et al., "Minimalist" nanovaccine constituted from near whole antigen for cancer immunotherapy. ACS Nano 12(7), 6398-6409 (2018). https ://doi.org/10.1021/acsnano.8b00558 
91. R. Verbeke, I. Lentacker, L. Wayteck, K. Breckpot, M. Van Bockstal et al., Co-delivery of nucleoside-modified mRNA and TLR agonists for cancer immunotherapy: restoring the immunogenicity of immunosilent mRNA. J. Controlled Release 266, 287-300 (2017). https://doi.org/10.1016/j.jconr el.2017.09.041

92. Y.-C. Lu, W.-C. Yeh, P.S. Ohashi, LPS/TLR4 signal transduction pathway. Cytokine 42(2), 145-151 (2008). https://doi. org/10.1016/j.cyto.2008.01.006

93. M.P. Schoen, M. Schoen, TLR7 and TLR8 as targets in cancer therapy. Oncogene 27(2), 190-199 (2008). https://doi. org/10.1038/sj.onc.1210913

94. Y. Yoshizaki, E. Yuba, N. Sakaguchi, K. Koiwai, A. Harada et al., pH-sensitive polymer-modified liposome-based immunity-inducing system: effects of inclusion of cationic lipid and CPG-DNA. Biomaterials 141, 272-283 (2017). https://doi. org/10.1016/j.biomaterials.2017.07.001

95. J.-O. Jin, H. Kim, Y.H. Huh, A. Herrmann, M. Kwak, Soft matter DNA nanoparticles hybridized with CPG motifs andpPeptide nucleic acids enable immunological treatment of cancer. J. Controlled Release 315, 76-84 (2019). https://doi. org/10.1016/j.jconrel.2019.09.013

96. G.M. Lynn, C. Sedlik, F. Baharom, Y. Zhu, R.A. RamirezValdez et al., Peptide-TLR-7/8a conjugate vaccines chemically programmed for nanoparticle self-assembly enhance CD8 T-cell immunity to tumor antigens. Nat. Biotechnol. 38(3), 320-332 (2020). https://doi.org/10.1038/s4158 7-019-0390-х

97. J.H. Wang, E.L. Reinherz, Structural basis of cell-cell interactions in the immune system. Curr. Opin. Struct. Biol. 10(6), 656-661 (2000). https://doi.org/10.1016/s0959 $-440 x(00) 00150-0$

98. A.L. Blasius, Beutler B. Intracellular toll-like receptors. Immunity 32(3), 305-315 (2010). https://doi.org/10.1016/j. immuni.2010.03.012

99. J.B. Ulmer, Geall AJ. Recent innovations in mRNA vaccines. Curr. Opin. Immunol. 41, 18-22 (2016). https://doi. org/10.1016/j.coi.2016.05.008

100. U. Sahin, K. Kariko, O. Tuereci, mRNA-based therapeutics - developing a new class of drugs. Nat. Rev. Drug Discov. 13(10), 759-780 (2014). https://doi.org/10.1038/nrd4278

101. M.A. Kutzler, D.B. Weiner, DNA vaccines: ready for prime time? Nat. Rev. Genet. 9(10), 776-788 (2008). https://doi. org/10.1038/nrg2432

102. A. De Beuckelaer, C. Pollard, S. Van Lint, K. Roose, L. Van Hoecke et al., Type I interferons interfere with the capacity of mRNA lipoplex vaccines to elicit cytolytic T cell responses. Mol. Ther. 24(11), 2012-2020 (2016). https ://doi.org/10.1038/mt.2016.161

103. T. Pepini, A.-M. Pulichino, T. Carsillo, A.L. Carlson, F. Sari-Sarraf et al., Induction of an IFN-mdiated antiviral response by a self-amplifying RNA vaccine: implications for vaccine design. J. Immunol. 198(10), 4012-4024 (2017). https://doi.org/10.4049/jimmunol.1601877

104. R. Verbeke, I. Lentacker, K. Breckpot, J. Janssens, S. Van Calenbergh et al., Broadening the Message: A nanovaccine co-loaded with messenger RNA and alpha-galcer induces antitumor immunity through conventional and natural killer T cells. ACS Nano 13(2), 1655-1669 (2019). https://doi. org/10.1021/acsnano.8b07660

105. T.J. Moyer, A.C. Zmolek, D.J. Irvine, Beyond antigens and adjuvants: formulating future vaccines. J. Clin. Invest. 126(3), 799-808 (2016). https://doi.org/10.1172/jci81083

106. X. Ke, G.P. Howard, H. Tang, B. Cheng, M.T. Saung et al., Physical and chemical profiles of nanoparticles for lymphatic targeting. Adv. Drug Delivery Rev. 151-152, 72-93 (2019). https://doi.org/10.1016/j.addr.2019.09.005

107. Y. Chen, S. De Koker, B.G. De, Geest Engineering strategies for lymph node targeted immune activation. Acc. Chem. Res. 53(10), 2055-2067 (2020). https://doi. org/10.1021/acs.accounts.0c00260

108. T. Nakamura, M. Kawai, Y. Sato, M. Maeki, M. Tokeshi et al., The effect of size and charge of lipid nanoparticles prepared by microfluidic mixing on their lymph node transitivity and distribution. Mol. Pharm. 17(3), 944-953 (2020). https://doi.org/10.1021/acs.molpharmaceut.9b011 82

109. J.M. Irache, H.H. Salman, C. Gamazo, S. Espuelas, Mannose-targeted systems for the delivery of therapeutics. Expert Opin. Drug Delivery 5(6), 703-724 (2008). https:// doi.org/10.1517/17425247.5.6.703

110. W. Wang, Z. Liu, X. Zhou, Z. Guo, J. Zhang et al., Ferritin nanoparticle-based spytag/spycatcher-enabled click vaccine for tumor immunotherapy. Nanomedicine 16, 69-78 (2019). https://doi.org/10.1016/j.nano.2018.11.009

111. C. Zhang, G. Shi, J. Zhang, H. Song, J. Niu et al., Targeted antigen delivery to dendritic cell via functionalized alginate nanoparticles for cancer Immunotherapy. J. Controlled Release 256, 170-181 (2017). https://doi.org/10.1016/j. jconrel.2017.04.020

112. H. Liu, K.D. Moynihan, Y. Zheng, G.L. Szeto, A.V. Li et al., Structure-based programming of lymph-node targeting in nolecular vaccines. Nature 507(7493), 519-522 (2014). https://doi.org/10.1038/nature 12978

113. L.F. Sestito, S.N. Thomas, Lymph-directed nitric oxide increases immune cell access to lymph-borne nanoscale solutes. Biomaterials 265, 120411 (2021). https://doi. org/10.1016/j.biomaterials.2020.120411

114. J. Park, R. Ramanathan, L. Pham, K.A. Woodrow, Chitosan enhances nanoparticle delivery from the reproductive tract to target draining lymphoid organs. Nanomedicine 13(6), 2015-2025 (2017). https://doi.org/10.1016/j. nano.2017.04.012

115. V. Bhurani, A. Mohankrishnan, A. Morrot, S.K. Dalai, Developing effective Vvccines: cues from natural infection. Int. Rev. Immunol. 37(5), 249-265 (2018). https://doi. org/10.1080/08830185.2018.1471479

116. R.S. Gejman, A.Y. Chang, H.F. Jones, K. DiKun, A.A. Hakimi et al., Rejection of immunogenic tumor clones is limited by clonal fraction. Elife 7, e41090 (2018). https:// doi.org/10.7554/eLife.41090 
117. E.R. Miller, P.L. Moro, M. Cano, T.T. Shimabukuro, Deaths following vaccination: what does the evidence show? Vaccine 33(29), 3288-3292 (2015). https://doi.org/10.1016/j. vaccine. 2015.05 .023

118. A. Batista-Duharte, D.T. Martinez, I.Z. Carlos, Efficacy and safety of immunological adjuvants. where is the cut-off? Biomed. Pharmacother 105, 616-624 (2018). https://doi. org/10.1016/j.biopha.2018.06.026

119. K. Twumasi-Boateng, J.L. Pettigrew, Y.Y.E. Kwok, J.C. Bell, B.H. Nelson, Oncolytic viruses as engineering platforms for combination immunotherapy. Nat. Rev. Cancer. 18(7), 419432 (2018). https://doi.org/10.1038/s41568-018-0009-4

120. D.V. Krysko, A.D. Garg, A. Kaczmarek, O. Krysko, P. Agostinis et al., Immunogenic cell death and damps in cancer therapy. Nat. Rev. Cancer 12(12), 860-875 (2012). https:// doi.org/10.1038/nrc3380

121. L. Galluzzi, A. Buque, O. Kepp, L. Zitvogel, G. Kroemer, Immunogenic cell death in cancer and infectious disease. Nat. Rev. Immunol. 17(2), 97-111 (2017). https://doi.org/10.1038/ nri.2016.107

122. B.L. Rapoport, R. Anderson, Realizing the clinical potential of immunogenic cell death in cancer chemotherapy and radiotherapy. Int. J. Mol. Sci. 20(4), 959 (2019). https://doi. org/10.3390/ijms20040959

123. L. Liu, Q. Chen, C. Ruan, X. Chen, X. He et al., Nanoengineered lymphocytes for alleviating suppressive tumor immune microenvironment. Appl. Mater. Today 16, 273-279 (2019). https://doi.org/10.1016/j.apmt.2019.06.009

124. Y. Fan, R. Kuai, Y. Xup, L.J. Ochyl, D.J. Irvine et al., Immunogenic cell death amplified by co-localized adjuvant delivery for cancer immunotherapy. Nano Lett. 17(12), 7387-7393 (2017). https://doi.org/10.1021/acs.nanolett.7b03218

125. S. Gebremeskel, L. Lobert, K. Tanner, B. Walker, T. Oliphant et al., Natural killer T-cell immunotherapy in combination with chemotherapy-induced immunogenic cell Death targets metastatic breast cancer. Cancer Immunol. Res. 5(12), 10861097 (2017). https://doi.org/10.1158/2326-6066.Cir-17-0229

126. Q. Chen, J. Chen, Z. Yang, J. Xu, L. Xu et al., Nanoparticleenhanced radiotherapy to trigger robust cancer immunotherapy. Adv. Mater. 31(10), e1802228 (2019). https://doi. org/10.1002/adma.201802228

127. W. Li, J. Yang, L. Luo, M. Jiang, B. Qin et al., Targeting photodynamic and photothermal therapy to the endoplasmic reticulum enhances immunogenic cancer cell death. Nat. Commun. 10(1), 3349 (2019). https://doi.org/10.1038/s4146 7-019-11269-8

128. Y. Li, X. Liu, W. Pan, N. Li, B. Tang, Photothermal therapyinduced immunogenic cell death based on natural melanin nanoparticles against breast cancer. Chem. Commun. 56(9), 1389-1392 (2020). https://doi.org/10.1039/c9cc08447a

129. Z. Wang, F. Zhang, D. Shao, Z. Chang, L. Wang et al., Janus nanobullets combine photodynamic therapy and magnetic hyperthermia to potentiate synergetic anti-metastatic immunotherapy. Adv. Sci. 6(22), 1901690 (2019). https://doi. org/10.1002/advs.201901690
130. A.A. Farooqi, K.-T. Li, S. Fayyaz, Y.-T. Chang, M. Ismail et al., Anticancer drugs for the Modulation of endoplasmic reticulum stress and oxidative stress. Tumor Biol. 36(8), 5743-5752 (2015). https://doi.org/10.1007/s1327 7-015-3797-0

131. C. Chen, X. Ni, S. Jia, Y. Liang, X. Wu et al., Massively evoking immunogenic cell death by focused mitochondrial oxidative stress using an AIE luminogen with a twisted molecular structure. Adv. Mater. 31(52), e1904914 (2019). https://doi. org/10.1002/adma.201904914

132. Q. Chen, L. Liu, Y. Lu, X. Chen, Y. Zhang et al., Tumor microenvironment-triggered aggregated magnetic nanoparticles for reinforced image-guided immunogenic chemotherapy. Adv. Sci. 6(6), 1802134 (2019). https://doi.org/10.1002/ advs. 201802134

133. A. Lin, Y. Gorbanev, J. De Backer, J. Van Loenhout, W. Van Boxem et al., Non-thermal plasma as a unique delivery system of short-lived reactive oxygen and nitrogen species for immunogenic cell death in melanoma cells. Adv. Sci. 6(6), 1802062 (2019). https://doi.org/10.1002/advs.201802062

134. W. Yang, F. Zhang, H. Deng, L. Lin, S. Wang et al., Smart nanovesicle-mediated immunogenic cell death through tumor microenvironment modulation for effective photodynamic immunotherapy. ACS Nano 14(1), 620-631 (2020). https:// doi.org/10.1021/acsnano.9b07212

135. O. Kepp, L. Menger, E. Vacchelli, C. Locher, S. Adjemian et al., Crosstalk between ER stress and immunogenic cell death. Cytokine Growth Factor Rev. 24(4), 311-318 (2013). https://doi.org/10.1016/j.cytogfr.2013.05.001

136. W. Fan, P. Huang, X. Chen, Overcoming the achilles' heel of photodynamic therapy. Chem. Soc. Rev. 45(23), 64886519 (2016). https://doi.org/10.1039/c6cs00616g

137. A.P. Castano, P. Mroz, M.R. Hamblin, Photodynamic therapy and anti-tumour immunity. Nat. Rev. Cancer 6(7), 535-545 (2006). https://doi.org/10.1038/nrc1894

138. J. Dobson, G.F. de Queiroz, J.P. Golding, Photodynamic therapy and diagnosis: principles and comparative aspects. Vet. J. 233, 8-18 (2018). https://doi.org/10.1016/j. tvj1.2017.11.012

139. C. Conte, S. Maiolino, D.S. Pellosi, A. Miro, F. Ungaro et al., In Polymeric Nanoparticles for Cancer Photodynamic Therapy. ed. by SORTINO S 2016), pp. 61-112

140. K. Zhang, Y. Fang, Y. He, H. Yin, X. Guan et al., Extravascular gelation shrinkage-derived internal stress enables tumor starvation therapy with suppressed metastasis and recurrence. Nat. Commun. 10(1), 5380 (2019). https://doi.org/10.1038/ s41467-019-13115-3

141. M. Lismont, L. Dreesen, S. Wuttke, Metal-organic framework nanoparticles in photodynamic therapy: Current status and perspectives. Adv. Funct. Mater. 27(14), 1606314 (2017). https://doi.org/10.1002/adfm.201606314

142. Y. Liu, W. Hou, L. Xia, C. Cui, S. Wan et al., Zr-MOF nanoparticles as quenchers to conjugate DNA aptamers for target-induced bioimaging and photodynamic therapy. Chem. Sci. 9(38), 7505-7509 (2018). https://doi.org/10.1039/c8sc0 2210k 
143. X. Li, S. Lee, J. Yoon, Supramolecular photosensitizers rejuvenate photodynamic therapy. Chem. Soc. Rev. 47(4), 1174-1188 (2018). https://doi.org/10.1039/c7cs00594f

144. J. Park, D. Feng, S. Yuan, H.-C. Zhou, Photochromic metalorganic frameworks: Reversible control of singlet oxygen generation. Angew. Chem. Int. Ed. 54(2), 430-435 (2015). https://doi.org/10.1002/anie.201408862

145. Y. Shao, B. Liu, Z. Di, G. Zhang, L.-D. Sun et al., Engineering of upconverted metal-organic frameworks for nearinfrared light-triggered combinational photodynamic/chemo-/ immunotherapy against hypoxic tumors. J. Am. Chem. Soc. 142(8), 3939-3946 (2020). https://doi.org/10.1021/ jacs.9b12788

146. Y. Li, Z. Di, J. Gao, P. Cheng, C. Di et al., Heterodimers made of upconversion nanoparticles and metal-organic frameworks. J. Am. Chem. Soc. 139(39), 13804-13810 (2017). https://doi. org/10.1021/jacs.7b07302

147. K. Ni, G. Lan, S.S. Veroneau, X. Duan, Y. Song et al., Nanoscale metal-organic frameworks for mitochondriatargeted radiotherapy-radiodynamic therapy. Nat. Commun. 9(1), 4321 (2018). https://doi.org/10.1038/s41467-018-06655 $-7$

148. K. Lu, C. He, N. Guo, C. Chan, K. Ni et al., Low-dose X-ray radiotherapy-radiodynamic therapy via nanoscale metalorganic frameworks enhances checkpoint blockade immunotherapy. Nat. Biomed. Eng. 2(8), 600-610 (2018). https:// doi.org/10.1038/s41551-018-0203-4

149. W. Sun, T. Shi, L. Luo, X. Chen, P. Lv et al., Monodisperse and uniform mesoporous silicate nanosensitizers achieve low-dose X-ray-induced deep-penetrating photodynamic therapy. Adv. Mater. 31(16), e1808024 (2019). https://doi. org/10.1002/adma.201808024

150. W. Yue, L. Chen, L. Yu, B. Zhou, H. Yin et al., Checkpoint blockade and nanosonosensitizer-augmented noninvasive sonodynamic therapy combinationrReduces tumour growth and metastases in mice. Nat. Commun. 10(1), 2025 (2019). https://doi.org/10.1038/s41467-019-09760-3

151. J. Chen, H. Luo, Y. Liu, W. Zhang, H. Li et al., Oxygen-selfproduced nanoplatform for relieving hypoxia and breaking resistance to sonodynamic Treatment of Pancreatic Cancer. ACS Nano 11(12), 12849-12862 (2017). https://doi. org/10.1021/acsnano.7b08225

152. Y.F. Yin, X.W. Jiang, L.P. Sun, H.Y. Li, C.X. Su et al., Continuous inertial cavitation evokes massive ROS for reinforcing sonodynamic therapy and immunogenic cell death against breast carcinoma. Nano Today 36, 101009 (2021). https://doi. org/10.1016/j.nantod.2020.101009

153. X. Guan, H.H. Yin, X.H. Xu, G. Xu, Y. Zhang et al., Tumor metabolism-engineered composite nanoplatforms potentiate sonodynamic therapy via reshaping tumor microenvironment and facilitating electron-hole pairs' separation. Adv. Funct. Mater. 30(27), 2000326 (2020). https://doi.org/10.1002/ adfm. 202000326

154. D. Peng, I. Kryczek, N. Nagarsheth, L. Zhao, S. Wei et al., Hensley-Alford S, Munkarah A, Liu R, Zou W. Epigenetic silencing of T(h)1-type chemokines shapes tumour immunity and immunotherapy. Nature 527(7577), 249-253 (2015). https://doi.org/10.1038/nature15520

155. N. Nagarsheth, D. Peng, I. Kryczek, K. Wu, W. Li et al., PRC2 epigenetically silences Th1-type chemokines to suppress effector T-cell trafficking in colon cancer. Cancer Res. 76(2), 275-282 (2016). https://doi.org/10.1158/0008-5472. Can-15-1938

156. L. Dang, D.W. White, S. Gross, B.D. Bennett, M.A. Bittinger et al., Cancer-associated IDH1 mutations produce 2-hydroxyglutarate. Nature 462(7274), 739-U752 (2009). https://doi. org/10.1038/nature08617

157. M. Ayers, J. Lunceford, M. Nebozhyn, E. Murphy, A. Loboda et al., IFN-gamma-related mRNA profile predicts clinical response to PD-1 blockade. J. Clin. Invest. 127(8), 29302940 (2017). https://doi.org/10.1172/jci91190

158. R. Kalluri, M. Zeisberg, Fibroblasts in cancer. Nat. Rev. Cancer 6(5), 392-401 (2006). https://doi.org/10.1038/nrc1877

159. L. Miao, J.M. Newby, C.M. Lin, L. Zhang, F. Xu et al., Milowsky MI, Wobker SE, Huang L. The binding site barrier elicited by tumor associated fibroblasts interferes disposition of nanoparticles in stroma-vessel type tumors. ACS Nano 10(10), 9243-9258 (2016). https://doi.org/10.1021/acsna no.6b02776

160. H. Jiang, S. Hegde, D.G. DeNardo, Tumor-associated fibrosis as a regulator of tumor immunity and response to immunotherapy. Cancer Immunol. Immunother. 66(8), 1037-1048 (2017). https://doi.org/10.1007/s00262-017-2003-1

161. M.H. Sherman, R.T. Yu, D.D. Engle, N. Ding, A.R. Atkins et al., Vitamin D Receptor-mediated stromal reprogramming suppresses pancreatitis and enhances pancreatic cancer therapy. Cell 159(1), 80-93 (2014). https://doi. org/10.1016/j.cell.2014.08.007

162. D. Liao, R.S. Johnson, Hypoxia: A key regulator of angiogenesis in cancer. Cancer Metastasis Rev. 26(2), 281-290 (2007). https://doi.org/10.1007/s10555-007-9066-y

163. N. Erez, M. Truitt, P. Olson, D. Hanahan, Cancer-associated fibroblasts are activated in incipient neoplasia to orchestrate tumor-promoting inflammation in an NF-Kappa B-cdpendent manner. Cancer Cell 17(2), 135-147 (2010). https://doi.org/10.1016/j.ccr.2009.12.041

164. R.T.P. Poon, S.T. Fan, J. Wong, Clinical implications of circulating angiogenic factors in cancer patients. J. Clin. Oncol. 19(4), 1207-1225 (2001). https://doi.org/10.1200/ jco.2001.19.4.1207

165. P.P. Provenzano, C. Cuevas, A.E. Chang, V.K. Goel, D.D. Von Hoff et al., Enzymatic targeting of the stroma ablates physical barriers to treatment of pancreatic ductal adenocarcinoma. Cancer Cell 21(3), 418-429 (2012). https://doi. org/10.1016/j.ccr.2012.01.007

166. Y. Tsuzuki, D. Fukumura, B. Oosthuyse, C. Koike, P. Carmeliet et al., Vascular endothelial growth factor (VEGF) modulation by targeting hypoxia-inducible factor- 1 alpha $->$ hypoxia response element -> VEGF cascade differentially regulates vascular response and growth rate in tumors. Cancer Res. 60(22), 6248-6252 (2000). (PMID: 11103778) 
167. G.T. Motz, S.P. Santoro, L.-P. Wang, T. Garrabrant, R.R. Lastra et al., Tumor endothelium Fasl establishes a selective immune barrier promoting tolerance in tumors. Nat. Med. 20(6), 607-615 (2014). https://doi.org/10.1038/nm.3541

168. M.B. Schaaf, A.D. Garg, P. Agostinis, Defining the Role of the Tumor Vasculature in Antitumor Immunity and Immunotherapy. Cell Death Dis. 9(2), 115 (2018). https://doi. org/10.1038/s41419-017-0061-0

169. C. Bouzin, A. Brouet, J. De Vriese, J. DeWever, O. Feron, Effects of vascular endothelial growth factor on the lymphocyte-endothelium interactions: identification of caveolin-1 and nitric oxide as control points of endothelial cell anergy. J. Immunol. 178(3), 1505-1511 (2007). https://doi.org/10.4049/ jimmunol.178.3.1505

170. F. Mpekris, C. Voutouri, J.W. Baish, D.G. Duda, L.L. Munn, Stylianopoulos T, Jain RK. Combining microenvironment normalization strategies to improve cancer immunotherapy. Proc. Natl. Acad. Sci. USA 117(7), 3728-3737 (2020). https ://doi.org/10.1073/pnas.1919764117

171. J.D. Martin, G. Seano, R.K. Jain, in Normalizing Function of Tumor Vessels: Progress, Opportunities, and Challenges. ed. by NELSON M T, WALSH K 2019), pp. 505-534

172. H.F. Dvorak, Tumor stroma, tumor blood vessels, and antiangiogenesis therapy. Cancer J. 21(4), 237-243 (2015). https:// doi.org/10.1097/ppo.0000000000000124

173. L. Caja, F. Dituri, S. Mancarella, D. Caballero-Diaz, A. Moustakas et al., TGF-beta and the tissue microenvironment: Relevance in fibrosis and cancer. Int. J. Mol. Sci. 19(5), 1294 (2018). https://doi.org/10.3390/ijms19051294

174. A. Costa, Y. Kieffer, A. Scholer-Dahirel, F. Pelon, B. Bourachot et al., Fibroblast heterogeneity and immunosuppressive environment in human breast cancer. Cancer Cell 33(3), 463-479 (2018). https://doi.org/10.1016/j.ccell .2018.01.011

175. A. Laitala, J.T. Erler, Hypoxic signalling in tumour stroma. Front. Oncol. 8, 189 (2018). https://doi.org/10.3389/ fonc. 2018.00189

176. S.J. Scales, F.J. de Sauvage, Mechanisms of hedgehog pathway activation in cancer and implications for therapy. Trends. Pharmacol. Sci. 30(6), 303-312 (2009). https://doi. org/10.1016/j.tips.2009.03.007

177. I.X. Chen, V.P. Chauhan, J. Posada, M.R. Ng, M.W. Wu et al., Blocking CXCR4 alleviates desmoplasia, increases T-lymphocyte infiltration, and improves immunotherapy in metastatic breast cancer. Proc. Natl. Acad. Sci. USA 116(10), 4558-4566 (2019). https://doi.org/10.1073/pnas.1815515116

178. P. Papageorgis, C. Polydorou, F. Mpekris, C. Voutouri, E. Agathokleous et al., Tranilast-induced stress alleviation in solid tumors improves the efficacy of chemo- and nanotherapeutics in a size-independent manner. Sci. Rep. 7, 46140 (2017). https://doi.org/10.1038/srep46140

179. T. Ji, S. Li, Y. Zhang, J. Lang, Y. Ding et al., An MMP-2 responsive liposome integrating antifibrosis and chemotherapeutic drugs for enhanced drug perfusion and efficacy in pancreatic cancer. ACS Appl. Mater. Interfaces 8(5), 3438-3445 (2016). https://doi.org/10.1021/acsami.5b11619
180. A.D. Theocharis, S.S. Skandalis, C. Gialeli, N.K. Karamanos, Extracellular matrix structure. Adv. Drug Delivery Rev. 97, 4-27 (2016). https://doi.org/10.1016/j.addr.2015.11.001

181. J. Prakash, M. Pinzani, Fibroblasts and extracellular matrix: Targeting and therapeutic tools in fibrosis and cancer preface. Adv. Drug Delivery Rev. 121, 1-2 (2017). https://doi. org/10.1016/j.addr.2017.11.008

182. G.C. Weber, B.A. Buhren, H. Schrumpf, J. Wohlrab, P.A. Gerber, in Clinical Applications of Hyaluronidase. ed. by LABROU N 2019), pp. 255-277

183. S.H. Lv, S.F. Rong, B.G. Cai, S.M. Guan, Q.Q. Li, Property and current clinical applications of mammal hyaluronidase. Eur. Rev. Med. Pharmacol. Sci. 19(20), 3968-3976 (2015)

184. K.M. Wong, K.J. Horton, A.L. Coveler, S.R. Hingorani, W.P. Harris, Targeting the Tumor Stroma: the biology and clinical development of pegylated recombinant human hyaluronidase (PEG-PH20). Curr. Oncol. Rep. 19(7), 47 (2017). https://doi. org/10.1007/s11912-017-0608-3

185. X. Guan, L. Lin, J. Chen, Y. Hu, P. Sun et al., Efficient PD-L1 gene silence promoted by hyaluronidase for cancer immunotherapy. J. Controlled Release 293, 104-112 (2019). https:// doi.org/10.1016/j.jconrel.2018.11.022

186. X. Guan, J. Chen, Y. Hu, L. Lin, P. Sun et al., Highly enhanced cancer immunotherapy by combining nanovaccine with hyaluronidase. Biomaterials 171, 198-206 (2018). https ://doi.org/10.1016/j.biomaterials.2018.04.039

187. H. Zhou, Z. Fan, J. Deng, P.K. Lemons, D.C. Arhontoulis et al., Hyaluronidase embedded in nanocarrier PEG shell for enhanced tumor penetration and highly efficient antitumor efficacy. Nano Lett. 16(5), 3268-3277 (2016). https:// doi.org/10.1021/acs.nanolett.6b00820

188. Y. Hong, G.-H. Nam, E. Koh, S. Jeon, G.B. Kim et al., Exosome as a vehicle for delivery of membrane protein therapeutics, $\mathrm{PH} 20$, for enhanced tumor penetration and antitumor efficacy. Adv. Funct. Mater. 28(5), 1703074 (2018). https://doi.org/10.1002/adfm.201703074

189. A. Zinger, L. Koren, O. Adir, M. Poley, M. Alyan et al., Collagenase nanoparticles enhance the penetration of drugs into pancreatic tumors. ACS Nano 13(10), 11008-11021 (2019). https://doi.org/10.1021/acsnano.9b02395

190. C.H. Heldin, K. Rubin, K. Pietras, A. Ostman, High interstitial fluid pressure: an obstacle in cancer therapy. Nat. Rev. Cancer 4(10), 806-813 (2004). https://doi.org/10.1038/nrc1456

191. A.I. Minchinton, I.F. Tannock, Drug penetration in solid tumours. Nat. Rev. Cancer 6(8), 583-592 (2006). https:// doi.org/10.1038/nrc1893

192. M.F. Flessner, J. Choi, K. Credit, R. Deverkadra, K. Henderson, Resistance of tumor interstitial pressure to the penetration of intraperitoneally delivered antibodies into metastatic ovarian tumors. Clinl. Cancer Res. 11(8), 3117-3125 (2005). https://doi.org/10.1158/1078-0432.Ccr-04-2332

193. E. Blanco, H. Shen, M. Ferrari, Principles of nanoparticle design for overcoming biological barriers to drug delivery. Nat. Biotechnol. 33(9), 941-951 (2015). https://doi. org/10.1038/nbt.3330 
194. O. Tredan, C.M. Galmarini, K. Patel, I.F. Tannock, Drug resistance and the solid tumor microenvironment. J. Natl. Cancer Inst. 99(19), 1441-1454 (2007). https://doi. org/10.1093/jnci/djm135

195. B. Pelaz, C. Alexiou, R.A. Alvarez-Puebla, F. Alves, A.M. Andrews et al., Diverse applications of nanomedicine. ACS Nano 11(3), 2313-2381 (2017). https://doi.org/10.1021/ acsnano.6b06040

196. M. Overchuk, G. Zheng, Overcoming obstacles in the tumor microenvironment: recent advancements in nanoparticle delivery for cancer theranostics. Biomaterials 156, 217-237 (2018). https://doi.org/10.1016/j.biomaterials.2017.10.024

197. B. Chen, W. Dai, B. He, H. Zhang, X. Wang et al., Current multistage drug delivery systems based on the tumor microenvironment. Theranostics 7(3), 538-558 (2017). https:// doi.org/10.7150/thno.16684

198. H. He, L. Sun, J. Ye, E. Liu, S. Chen et al., Enzyme-triggered, cell penetrating peptide-mediated delivery of antitumor agents. J. Controlled Release 240, 67-76 (2016). https://doi.org/10.1016/j.jconrel.2015.10.040

199. H.-J. Li, J.-Z. Du, J. Liu, X.-J. Du, S. Shen et al., Smart superstructures with ultrahigh $\mathrm{pH}$-sensitivity for targeting acidic tumor microenvironment: Instantaneous sizesSwitching and improved tumor penetration. ACS Nano 10(7), 6753-6761 (2016). https://doi.org/10.1021/acsnano.6b023 26

200. G. Yang, S.Z.F. Phua, W.Q. Lim, R. Zhang, L. Feng et al., A hypoxia-responsive albumin-based nanosystem for deep tumor penetration and excellent therapeutic efficacy. Adv. Mater. 31(25), e1901513 (2019). https://doi.org/10.1002/ adma. 201901513

201. H. Jin, T. Zhu, X. Huang, M. Sun, H. Li et al., ROS-responsive nanoparticles based on amphiphilic hyperbranched polyphosphoester for drug delivery: light-triggered sizereducing and enhanced tumor penetration. Biomaterials 211, 68-80 (2019). https://doi.org/10.1016/j.biomateria 1s.2019.04.029

202. T. Liu, L. Tong, N. Lv, X. Ge, Q. Fu et al., Two-stage size decrease and enhanced photoacoustic performance of stimuli-responsive polymer-gold nanorod assembly for increased tumor penetration. Adv. Funct. Mater. 29(16), 1806429 (2019). https://doi.org/10.1002/adfm.201806429

203. F. Zhou, B. Feng, T. Wang, D. Wang, Q. Meng et al., Programmed multiresponsive vesicles for enhanced tumor penetration and combination therapy of triple-negative breast cancer. Adv. Funct. Mater. 27(20), 1606530 (2017). https:// doi.org/10.1002/adfm.201606530

204. J. Yoo, N.S. Rejinold, D. Lee, S. Jon, Y.-C. Kim, Proteaseactivatable cell-penetrating peptide possessing ROS-triggered phase transition for enhanced cancer therapy. J. Controlled Release 264, 89-101 (2017). https://doi.org/10.1016/j.jconr el.2017.08.026

205. Q. Zhou, S. Shao, J. Wang, C. Xu, J. Xiang et al., Enzymeactivatable polymer-drug conjugate augments tumour penetration and treatment efficacy. Nat. Nanotechnol.
14(8), 799-809 (2019). https://doi.org/10.1038/s4156 5-019-0485-Z

206. M. Zhou, H. Huang, D. Wang, H. Lu, J. Chen et al., Lighttriggered PEGylation/dePEGylation of the nanocarriers for enhanced tumor penetration. Nano Lett. 19(6), 3671-3675 (2019). https://doi.org/10.1021/acs.nanolett.9b00737

207. X. Lin, S. Liu, X. Zhang, R. Zhu, S. Chen et al., An ultrasound activated vesicle of Janus Au-MNO nanoparticles for promoted tumor penetration and sono-chemodynamic therapy of orthotopic liver cancer. Angew. Chem. Int. Ed. 59(4), 1682-1688 (2020). https://doi.org/10.1002/anie.201912768

208. J. Ji, F. Ma, H. Zhang, F. Liu, J. He et al., Light-activatable assembled nanoparticles to improve tumor penetration and eradicate metastasis in triple negative breast cancer. Adv. Funct. Mater. 28(33), 1801738 (2018). https://doi. org/10.1002/adfm.201801738

209. Z. Yang, Q. Chen, J. Chen, Z. Dong, R. Zhang et al., Tumor$\mathrm{pH}$-responsive dissociable albumin-tamoxifen nanocomplexes enabling efficient tumor penetration and hypoxia relief for enhanced cancer photodynamic therapy. Small 14(49), e1803262 (2018). https://doi.org/10.1002/smll.201803262

210. S.-Y. Sung, Y.-L. Su, W. Cheng, P.-F. Hu, C.-S. Chiang fet al., Graphene quantum dots-mediated theranostic penetrative delivery of drug and photolytics in deep tumors bytTargeted biomimetic nanosponges. Nano Lett. 19(1), 69-81 (2019). https://doi.org/10.1021/acs.nanolett.8b03249

211. J.F. Liu, Z. Lan, C. Ferrari, J.M. Stein, E. Higbee-Dempsey et al., Use of oppositely polarized external magnets to improve the accumulation and penetration of magnetic nanocarriers into solid tumors. ACS Nano 14(1), 142-152 (2020). https://doi.org/10.1021/acsnano.9b05660

212. S.H. Lee, O.K. Park, J. Kim, K. Shin, C.G. Pack et al., Deep tumor penetration of drug-loaded nanoparticles by click reaction-assisted immune cell targeting strategy. J. Am. Chem. Soc. 141(35), 13829-13840 (2019). https://doi.org/10.1021/ jacs.9b04621

213. D.M. Gilkes, G.L. Semenza, D. Wirtz, Hypoxia and the extracellular matrix: Drivers of tumour metastasis. Nat. Rev. Cancer. 14(6), 430-439 (2014). https://doi.org/10.1038/nrc3726

214. T.P. Szatrowski, C.F. Nathan, Production of large amounts of hydrogen-peroxide by human tumor-cells. Cancer Res. 51(3), 794-798 (1991)

215. J. Kim, H.R. Cho, H. Jeon, D. Kim, C. Song et al., Continuous o-2-evolving $\mathrm{MnFe} 2 \mathrm{O} 4$ nanoparticle-anchored mesoporous silica nanoparticles for efficient photodynamic therapy in hypoxic cancer. J. Am. Chem. Soc. 139(32), 10992-10995 (2017). https://doi.org/10.1021/jacs.7b05559

216. B. Halliwell, M.V. Clement, L.H. Long, Hydrogen peroxide in the human body. Febs. Lett. 486(1), 10-13 (2000). https:// doi.org/10.1016/s0014-5793(00)02197-9

217. G. Yang, L. Xu, J. Xu, R. Zhang, G. Song et al., Smart nanoreactors for $\mathrm{pH}$-responsive tumor homing, mitochondriatargeting, and enhanced photodynamic-immunotherapy of cancer. Nano Lett. 18(4), 2475-2484 (2018). https://doi. org/10.1021/acs.nanolett.8b00040 
218. M. Song, T. Liu, C. Shi, X. Zhang, X. Chen, Bioconjugated manganese dioxide nanoparticles enhance chemotherapy response by priming tumor-associated macrophages toward M1-like phenotype and attenuating tumor hypoxia. ACS Nano 10(1), 633-647 (2016). https://doi.org/10.1021/acsna no. 5 b06779

219. C. Liu, D. Wang, S. Zhang, Y. Cheng, F. Yang et al., Biodegradable biomimic copper/manganese silicate nanospheres for chemodynamic/photodynamic synergistic therapy with simultaneous glutathione depletion and hypoxia relief. ACS Nano 13(4), 4267-4277 (2019). https://doi.org/10.1021/acsna no. 8 b09387

220. Q. Jia, J. Ge, W. Liu, X. Zheng, S. Chen et al., A magnetofluorescent carbon dot assembly as an acidic $\mathrm{H} 2 \mathrm{O} 2$-driven oxygenerator to regulate tumor hypoxia for simultaneous bimodal imaging and enhanced photodynamic therapy. Adv. Mater. 30(13), e1706090 (2018). https://doi.org/10.1002/ adma.201706090

221. Y. Li, K.-H. Yun, H. Lee, S.-H. Goh, Y.-G. Suh et al., Porous platinum nanoparticles as a high- $\mathrm{Z}$ and oxygen generating nanozyme for enhanced radiotherapy in vivo. Biomaterials 197, 12-19 (2019). https://doi.org/10.1016/j.biomateria 1s.2019.01.004

222. Y. Zhang, F. Wang, C. Liu, Z. Wang, L. Kang et al., Nanozyme decorated metal-organic frameworks for enhanced photodynamic therapy. ACS Nano 12(1), 651-661 (2018). https://doi.org/10.1021/acsnano.7b07746

223. Z.L. Yang, W. Tian, Q. Wang, Y. Zhao, Y.L. Zhang et al., Oxygen-evolving mesoporous organosilica coated prussian blue nanoplatform for highly efficient photodynamic therapy of tumors. Adv. Sci. 5(5), 1700847 (2018). https://doi. org/10.1002/advs.201700847

224. W. Jiang, Z. Zhang, Q. Wang, J. Dou, Y. Zhao et al., Tumor reoxygenation and blood perfusion enhanced photodynamic therapy using ultrathin graphdiyne oxide nanosheets. Nano Lett. 19(6), 4060-4067 (2019). https://doi.org/10.1021/acs. nanolett.9b01458

225. W. Wang, Y. Cheng, P. Yu, H. Wang, Y. Zhang et al., Perfluorocarbon regulates the intratumoural environment to enhance hypoxia-based agent efficacy. Nat. Commun. 10(1), 1580 (2019). https://doi.org/10.1038/s41467-019-09389-2

226. L. Zhang, D. Wang, K. Yang, D. Sheng, B. Tan et al., Mitochondria-targeted artificial "Nano-RBCs" for amplified synergistic cancer phototherapy by a single NIR irradiation. Adv. Sci. 5(8), 1800049 (2018). https://doi.org/10.1002/ advs.201800049

227. W. Jiang, Q. Li, L. Xiao, J. Dou, Y. Liu et al., Hierarchical multiplexing nanodroplets foriImaging-guided cancer radiotherapy via DNA damage enhancement and concomitant DNA repair prevention. ACS Nano 12(6), 5684-5698 (2018). https://doi.org/10.1021/acsnano.8b01508

228. W. Tang, Z. Yang, S. Wang, Z. Wang, J. Song et al., Organic semiconducting photoacoustic nanodroplets for laser-activatable ultrasound imaging and combinational cancer therapy. ACS Nano 12(3), 2610-2622 (2018). https://doi.org/10.1021/ acsnano. $7 \mathrm{~b} 08628$
229. L. Jiang, H. Bai, L. Liu, F. Lv, X. Ren et al., Luminescent, Oxygen-Supplying, Hemoglobin-linked conjugated polymer nanoparticles for photodynamic therapy. Angew. Chem. Int. Ed. 58(31), 10660-10665 (2019). https://doi.org/10.1002/ anie. 201905884

230. H. Cao, L. Wang, Y. Yang, J. Li, Y. Qi et al., An assembled nanocomplex for improving both therapeutic efficiency and treatment depth in photodynamic therapy. Angew. Chem. Int. Ed. 57(26), 7759-7763 (2018). https://doi.org/10.1002/ anie. 201802497

231. W.-L. Liu, T. Liu, M.-Z. Zou, W.-Y. Yu, C.-X. Li et al., Aggressive man-made eed blood cells for hypoxia-resistant photodynamic therapy. Adv. Mater. 30(35), e1802006 (2018). https://doi.org/10.1002/adma.201802006

232. H. Tian, Z. Luo, L. Liu, M. Zheng, Z. Chen et al., Cancer cell membrane-biomimetic oxygen nanocarrier for breaking hypoxia-induced chemoresistance. Adv. Funct. Mater. 27(38), 1703197 (2017). https://doi.org/10.1002/adfm.201703197

233. X. Song, J. Xu, C. Liang, Y. Chao, Q. Jin et al., Self-supplied tumor oxygenation through separated liposomal delivery of $\mathrm{H}_{2} \mathrm{O}_{2}$ and catalase for enhanced radio-immunotherapy of cancer. Nano Lett. 18(10), 6360-6368 (2018). https://doi. org/10.1021/acs.nanolett.8b02720

234. Z. Chen, M. Niu, G. Chen, Q. Wu, L. Tan et al., Oxygen production of modified Core-Shell CuO@ZrO2 manocomposites by microwave radiation to Alleviate Cancer Hypoxia for enhanced chemo-microwave thermal therapy. ACS Nano 12(12), 12721-12732 (2018). https://doi.org/10.1021/acsna no. 8 b07749

235. Z. Zhang, N. Niu, X. Gao, F. Han, Z. Chen et al., A new drug carrier with oxygen generation function for modulating tumor hypoxia microenvironment in cancer chemotherapy. Colloids Surf. B: Biointerfaces 173, 335-345 (2019). https ://doi.org/10.1016/j.colsurfb.2018.10.008

236. C.C. Huang, W.T. Chia, M.F. Chung, K.J. Lin, C.W. Hsiao et al., An implantable depot That can generate oxygen in situ for overcoming hypoxia-induced resistance to anticancer drugs in chemotherapy. J. Am. Chem. Soc. 138(16), 52225225 (2016). https://doi.org/10.1021/jacs.6b01784

237. Y. Sheng, H. Nesbitt, B. Callan, M.A. Taylor, M. Love et al., Oxygen generating nanoparticles forpImproved photodynamic therapy of hypoxic tumours. J. Controlled Release 264, 333-340 (2017). https://doi.org/10.1016/j.jconr el.2017.09.004

238. D.I. Gabrilovich, S. Nagaraj, Myeloid-derived suppressor cells as regulators of the immune system. Nat. Rev. Immunol. 9(3), 162-174 (2009). https://doi.org/10.1038/nri2506

239. A. Mantovani, F. Marchesi, A. Malesci, L. Laghi, P. Allavena, Tumour-associated macrophages as treatment targets in oncology. Nat. Rev. Clin. Oncol. 14(7), 399-416 (2017). https ://doi.org/10.1038/nrclinonc.2016.217

240. J.A. Bluestone, Q. Tang, T-reg cells-the next frontier of cell therapy will regulatory $\mathrm{T}$ cells be a frontline therapy for autoimmunity and other diseases? Science 362(6411), 154-155 (2018). https://doi.org/10.1126/science.aau2688 
241. D.F. Quail, J.A. Joyce, Microenvironmental regulation of tumor progression and metastasis. Nat. Med. 19(11), 14231437 (2013). https://doi.org/10.1038/nm.3394

242. V.L. Silva, W.T. Al-Jamal, Exploiting the cancer niche: tumor-associated macrophages and hypoxia as promising synergistic targets for nano-based therapy. J. Controlled Release 253, 82-96 (2017). https://doi.org/10.1016/j.jconr el.2017.03.013

243. L. Schito, G.L. Semenza, Hypoxia-inducible factors: Master regulators of cancer progression. Trends. Cancer 2(12), 758-770 (2016). https://doi.org/10.1016/j.trecan.2016.10.016

244. J. Galon, D. Bruni, Approaches to treat immune hot, altered and cold tumours with combination immunotherapies. Nat. Rev. Drug Discov. 18(3), 197-218 (2019). https://doi. org/10.1038/s41573-018-0007-y

245. V. Umansky, C. Blattner, C. Gebhardt, J. Utikal, The role of myeloid-derived suppressor cells (MDSC) in cancer progression. Vaccines 4(4), 36 (2016). https://doi.org/10.3390/vacci nes 4040036

246. S. Nagaraj, J.-I. Youn, H. Weber, C. Iclozan, L. Lu et al., Anti-inflammatory triterpenoid blocks immune suppressive function of MDSCs and improves immune response in cancer. Clin. Cancer Res. 16(6), 1812-1823 (2010). https://doi. org/10.1158/1078-0432.Ccr-09-3272

247. P. Raber, A.C. Ochoa, P.C. Rodriguez, Metabolism of L-arginine by myeloid-derived suppressor cells in cancer: Mechanisms of T cell suppression and therapeutic perspectives. Immunol. Invest. 41(6-7), 614-634 (2012). https://doi. org/10.3109/08820139.2012.680634

248. C. Bogdan, Nitric oxide and the immune response. Nat. Immunol. 2(10), 907-916 (2001). https://doi.org/10.1038/ ni1001-907

249. V. Kumar, S. Patel, E. Tcyganov, D.I. Gabrilovich, The Nature of Myeloid-Derived Suppressor Cells in the Tumor Microenvironment. Trends. Immunol. 37(3), 208-220 (2016). https://doi.org/10.1016/j.it.2016.01.004

250. A.M. Bruger, A. Dorhoi, G. Esendagli, K. Barczyk-Kahlert, P. van der Bruggen et al., How to measure the immunosuppressive activity of MDSC: Assays, problems and potential solutions. Cancer Immunol. Immunother. 68(4), 631-644 (2019). https://doi.org/10.1007/s00262-018-2170-8

251. M. Pickup, S. Novitskiy, H.L. Moses, The roles of TGF beta in the tumour microenvironment. Nat. Rev. Cancer 13(11), 788-799 (2013). https://doi.org/10.1038/nrc3603

252. M.Z. Noman, G. Desantis, B. Janji, M. Hasmim, S. Karray et al., PD-L1 is a novel direct target of HIF-1 alpha., and its blockade under hypoxia enhanced MDSC-mediated T cell activation. J. Exp. Med. 211(5), 781-790 (2014). https://doi. org/10.1084/jem.20131916

253. J.E. Talmadge, D.I. Gabrilovich, History of myeloid-derived suppressorcCells. Nat. Rev. Cancer 13(10), 739-779 (2013). https://doi.org/10.1038/nrc3581

254. E. Brogi, T.G. Wu, A. Namiki, J.M. Isner, Indirect angiogenic cytokines up-regulate VEGF and BFGF gene-expression in vascular smooth-muscle cells, whereas hypoxia up-regulates
VEGF expression only. Circulation 90(2), 649-652 (1994). https://doi.org/10.1161/01.Cir.90.2.649

255. A. Mantovani, T. Schioppa, C. Porta, P. Allavena, A. Sica, Role of tumor-associated macrophages in tumor progression and invasion. Cancer Metastasis Rev. 25(3), 315-322 (2006). https://doi.org/10.1007/s10555-006-9001-7

256. V. Bronte, P.J. Murray, Understanding local macrophage phenotypes in disease: modulating macrophage function to treat cancer. Nat. Med. 21(2), 117-119 (2015). https://doi. org/10.1038/nm.3794

257. D.J. Ceradini, A.R. Kulkarni, M.J. Callaghan, O.M. Tepper, N. Bastidas et al., Progenitor cell trafficking is regulated by hypoxic gradients through HIF-1 induction of SDF-1. Nat. Med. 10(8), 858-864 (2004). https://doi.org/10.1038/nm1075

258. M.C. Schmid, C.J. Avraamides, H.C. Dippold, I. Franco, P. Foubert et al., Receptor tyrosine kinases and TLR/IL1 rs unexpectedly activate myeloid cell PI3K gamma, a single convergent point promoting tumor inflammation and progression. Cancer Cell 19(6), 715-727 (2011). https://doi. org/10.1016/j.ccr.2011.04.016

259. L.M. Coussens, L. Zitvogel, A.K. Palucka, Neutralizing tumor-promoting chronic inflammation: A magic bullet? Science 339(6117), 286-291 (2013). https://doi.org/10.1126/ science. 1232227

260. J.A. Trujillo, R.F. Sweis, R. Bao, J.J. Luke, T cell-inflamed versus non-T cell-inflamed tumors: a conceptual framework for cancer immunotherapy drug development and combination therapy selection. Cancer Immunol. Res. 6(9), 990-1000 (2018). https://doi.org/10.1158/2326-6066.Cir-18-0277

261. R. Noy, J.W. Pollard, Tumor-associated macrophages: from mechanisms to therapy. Immunity 41(1), 49-61 (2014). https://doi.org/10.1016/j.immuni.2014.06.010

262. V. Prima, L.N. Kaliberova, S. Kaliberov, D.T. Curiel, S. Kusmartsev, COX2/mPGES1/PGE2 pathway regulates PD-L1 expression in tumor-associated macrophages and myeloid-derived suppressor cells. Proc. Natl. Acad. Sci. USA 114(5), 1117-1122 (2017). https://doi.org/10.1073/ pnas. 1612920114

263. M. Liguori, C. Buracchi, F. Pasqualini, F. Bergomas, S. Pesce et al., Functional trail receptors in monocytes and tumor-associated macrophages: a possible targeting pathway in the tumor microenvironment. Oncotarget 7(27), 41662-41676 (2016). https://doi.org/10.18632/oncotarget .9340

264. S.A. Oh, M.O. Li, TGF-beta: Guardian of T cell function. J. Immunol. 191(8), 3973-3979 (2013). https://doi.org/10.4049/ jimmunol.1301843

265. T.H.S. Ng, G.J. Britton, E.V. Hill, J. Verhagen, B.R. Burton et al., Regulation of adaptive immunity; the role of interleukin-10. Front. Immunol. 4, 129 (2013). https://doi. org/10.3389/fimmu.2013.00129

266. D.O. Adeegbe, H. Nishikawa, Natural and induced T regulatory cells in cancer. Front. Immunol. 4, 190 (2013). https:// doi.org/10.3389/fimmu.2013.00190

267. J. Liu, H. Wang, Tumor-associated macrophages recruit CCR6+regulatory T cells and promote the development of 
colorectal cancer via enhancing CCL20 production in mice. PLoS One 6(4), e19495 (2011). https://doi.org/10.1371/journ al.pone.0019495

268. R. Hildenbrand, I. Dilger, A. Horlin, H.J. Stutte, Urokinase and macrophages in tumor angiogenesis. Br. J. Cancer 72(4), 818-823 (1995). https://doi.org/10.1038/bjc.1995.419

269. V. Klimetzek, C. Sorg, Lymphokine-induced secretion of plasminogen activator by murine macrophages. Eur. J. Immunol. 7(3), 185-187 (1977). https://doi.org/10.1002/eji.18300 70314

270. O.W.H. Yeung, C.-M. Lo, C.-C. Ling, X. Qi, W. Geng et al., Alternatively activated (M2) macrophages promote tumour growth and invasiveness in hepatocellular carcinoma. J. Hepatol. 62(3), 607-616 (2015). https://doi.org/10.1016/j. jhep.2014.10.029

271. A.G. Jarnicki, J. Lysaght, S. Todryk, K.H.G. Mills, Suppression of antitumor immunity by IL-10 and TGF-beta-producing T cells infiltrating the growing tumor: Influence of tumor environment on the induction of $\mathrm{CD} 4(+)$ and $\mathrm{CD} 8(+)$ regulatory T cells. J. Immunol. 177(2), 896-904 (2006). https://doi. org/10.4049/jimmunol.177.2.896

272. F. Veglia, M. Perego, D. Gabrilovich, Myeloid-derived suppressor cells coming of age. Nat. Immunol. 19(2), 108-119 (2018). https://doi.org/10.1038/s41590-017-0022-x

273. C. Groth, X. Hu, R. Weber, V. Fleming, P. Altevogt et al., Immunosuppression mediated by myeloid-derived suppressor cells (MDSCs) during tumour progression. Br. J. Cancer 120(1), 16-25 (2019). https://doi.org/10.1038/s4141 6-018-0333-1

274. A. Sevko, T. Michels, M. Vrohlings, L. Umansky, P. Beckhove et al., Antitumor effect of paclitaxel is mediated by inhibition of myeloid-derived suppressor cells and chronic inflammation in the spontaneous melanoma model. J. Immunol. 190(5), 2464-2471 (2013). https://doi.org/10.4049/ jimmunol.1202781

275. B. Schilling, A. Sucker, K. Griewank, F. Zhao, B. Weide et al., Vemurafenib reverses immunosuppression by myeloid derived suppressor cells. Int. J. Cancer 133(7), 1653-1663 (2013). https://doi.org/10.1002/ijc.28168

276. E. Suzuki, V. Kapoor, A.S. Jassar, L.R. Kaiser, S.M. Albelda, Gemcitabine selectively eliminates splenic Gr-1(+)/ $\mathrm{CD} 11 \mathrm{~b}(+)$ myeloid suppressor cells in tumor-bearing animals and enhances antitumor immune activity. Clin. Cancer Res. 11(18), 6713-6721 (2005). https://doi.org/10.1158/10780432.Ccr-05-0883

277. J. Vincent, G. Mignot, F. Chalmin, S. Ladoire, M. Bruchard et al., 5-Fluorouracil selectively kills tumor-associated myeloid-derived suppressor cells resulting in enhanced $\mathrm{T}$ cell-dependent antitumor immunity. Cancer Res. 70(8), 3052-3061 (2010). https://doi.org/10.1158/0008-5472. Can-09-3690

278. Y. Kodera, Y. Katanasaka, Y. Kitamura, H. Tsuda, K. Nishio et al., Sunitinib inhibits lymphatic endothelial cell functions and lymph node metastasis in a breast cancer model through inhibition of vascular endothelial growth
factorrReceptor 3. Breast Cancer Res. 13(3), R66 (2011). https://doi.org/10.1186/bcr2903

279. R. Weber, V. Fleming, X. Hu, V. Nagibin, C. Groth et al., Myeloid-derived suppressor cells hinder the anti-cancer activity of immune checkpoint inhibitors. Front. Immunol 9, 1310 (2018). https://doi.org/10.3389/fimmu.2018.01310

280. S.C. Robinson, K.A. Scott, J.L. Wilson, R.G. Thompson, A.E.I Proudfoot, Balkwill FR. A chemokine receptor antagonist inhibits experimental breast tumor growth. Cancer Res. 63(23), 8360-8365 (2003)

281. Y. Zhu, B.L. Knolhoff, M.A. Meyer, T.M. Nywening, B.L. West et al., CSF1/CSF1R blockade reprograms tumorinfiltrating macrophages and improves response to T-cell checkpoint immunotherapy in pancreatic cancer models. Cancer Res. 74(18), 5057-5069 (2014). https://doi. org/10.1158/0008-5472.Can-13-3723

282. H. Katoh, D. Wang, T. Daikoku, H. Sun, S.K. Dey et al., CXCR2-expressing myeloid-derived suppressor cells are essential to promote colitis-associated tumorigenesis. Cancer Cell 24(5), 631-644 (2013). https://doi.org/10.1016/j. ccr.2013.10.009

283. L.A. Elliott, G.A. Doherty, K. Sheahan, E.J. Ryan, Human tumor-infiltrating myeloid cells: Phenotypic and functional diversity. Front. Immunol. 8, 86 (2017). https://doi. org/10.3389/fimmu.2017.00086

284. M.J. Reilley, P. McCoon, C. Cook, P. Lyne, R. Kurzrock et al., STAT3 antisense oligonucleotide azd9150 in a subset of patients with heavily pretreated lymphoma: Results of a phase $1 \mathrm{~b}$ trial. J. Immunother. Cancer 6(1), 119 (2018). https ://doi.org/10.1186/s40425-018-0436-5

285. B. Molon, S. Ugel, F. Del Pozzo, C. Soldani, S. Zilio et al., Chemokine nitration prevents intratumoral infiltration of antigen-specific T cells. J. Exp. Med. 208(10), 1949-1962 (2011). https://doi.org/10.1084/jem.20101956

286. C. De Santo, P. Serafini, L. Marigo, L. Dolcetti, M. Bolla et al., Nitroaspirin corrects immune dysfunction in tumorbearing hosts and promotes tumor eradication by cancer vaccination. Proc. Natl. Acad. Sci. USA 102(11), 4185-4190 (2005). https://doi.org/10.1073/pnas.0409783102

287. M. Sarfati, V. Mateo, S. Baudet, M. Rubio, C. Fernandez et al., Sildenafil and vardenafil, types 5 and 6 phosphodiesterase inhibitors, induce caspase-dependent apoptosis of b-chronic lymphocytic leukemia cells. Blood 101(1), 265269 (2003). https://doi.org/10.1182/blood-2002-01-0075

288. P. Serafini, K. Meckel, M. Kelso, K. Noonan, J. Califano et al., Phosphodiesterase-5 inhibition augments endogenous antitumor immunity by reducing myeloid-derived suppressor cell function. J. Exp. Med. 203(12), 2691-2702 (2006). https ://doi.org/10.1084/jem.20061104

289. K.M. Leahy, R.L. Ornberg, Y. Wang, B.S. Zweifel, A.T. Koki et al., Cyclooxygenase- 2 inhibition by celecoxib reduces proliferation and induces apoptosis in angiogenic endothelial cells in vivo. Cancer Res. 62(3), 625-631 (2002). (PMID: 11830509)

290. M. Fujita, G. Kohanbash, W. Fellows-Mayle, R.L. Hamilton, Y. Komohara et al., COX-2 blockade suppresses gliomagenesis by inhibiting myeloid-derived suppressor cells. Cancer 
Res. 71(7), 2664-2674 (2011). https://doi.org/10.1158/00085472.Can-10-3055

291. A. Orillion, A. Hashimoto, N. Damayanti, L. Shen, R. Adelaiye-Ogala et al., Entinostat neutralizes myeloid-derived suppressor cells and enhances the antitumor effect of PD-1 inhibition in murine models of lung and renal cell carcinoma. Clin. Cancer Res. 23(17), 5187-5201 (2017). https://doi. org/10.1158/1078-0432.Ccr-17-0741

292. A. Fernandez, L. Oliver, R. Alvarez, A. Hernandez, J. Raymond et al., Very small size proteoliposomes abrogate cross-presentation of tumor antigens by myeloid-derived suppressor cells and induce their differentiation to dendritic cells. J. Immunother. Cancer 2, 5 (2014). https://doi. org/10.1186/2051-1426-2-5

293. P.-T. Chen, C.-C. Hsieh, C.-T. Wu, T.-C. Yen, P.-Y. Lin et al., 1 Alpha, 25-dihydroxyvitamin D3 inhibits esophageal squamous cell carcinoma Progression by reducing IL6 Signaling. Mol. Cancer Ther. 14(6), 1365-1375 (2015). https://doi. org/10.1158/1535-7163.Mct-14-0952

294. R. Bauer, F. Udonta, M. Wroblewski, I. Ben-Batalla, I.M. Santos et al., Blockade of myeloid-derived suppressor cell expansion with all-trans retinoic acid increases the Efficacy of antiangiogenic therapy. Cancer Res. 78(12), 3220-3232 (2018). https://doi.org/10.1158/0008-5472.Can-17-3415

295. K.N. Kodumudi, K. Woan, D.L. Gilvary, E. Sahakian, S. Wei et al., A bovel chemoimmunomodulating property of docetaxel: Suppression of myeloid-derived suppressor cells in tumor bearers. Clin. Cancer Res. 16(18), 4583-4594 (2010). https://doi.org/10.1158/1078-0432.Ccr-10-0733

296. L. Chen, L. Zhou, C. Wang, Y. Han, Y. Lu et al., Tumortargeted drug and CPG delivery system for phototherapy and docetaxel-enhanced immunotherapy with polarization toward M1-type macrophages on triple negative breast cancers. Adv. Mater. 31(52), e1904997 (2019). https://doi.org/10.1002/ adma.201904997

297. D. Liu, M. You, Y. Xu, F. Li, D. Zhang et al., Inhibition of curcumin on myeloid-derived suppressor cells is requisite for controlling lung cancer. Int. Immunopharmacol. 39, 265-272 (2016). https://doi.org/10.1016/j.intimp.2016.07.035

298. J. Tian, J. Ma, K. Ma, H. Guo, S.E. Baidoo et al., Beta-glucan enhances antitumor immune responses by regulating differentiation and function of monocytic myeloid-derived suppressor cells. Eur. J. Immunol. 43(5), 1220-1230 (2013). https://doi. org/10.1002/eji.201242841

299. P. Cheng, V. Kumar, H. Liu, J.-I. Youn, M. Fishman et al., Effects of notch signaling on regulation of myeloid cell differentiation in cancer. Cancer Res. 74(1), 141-152 (2014). https://doi.org/10.1158/0008-5472.Can-13-1686

300. M.S. Sasso, G. Lollo, M. Pitorre, S. Solito, L. Pinton et al., Low dose gemcitabine-loaded lipid nanocapsules target monocytic myeloid-derived suppressor cells and potentiate cancer immunotherapy. Biomaterials 96, 47-62 (2016). https ://doi.org/10.1016/j.biomaterials.2016.04.010

301. Y. Zhang, X. Bush, B. Yan, J.A. Chen, Gemcitabine nanoparticles promote antitumor immunity against melanoma.
Biomaterials 189, 48-59 (2019). https://doi.org/10.1016/j. biomaterials.2018.10.022

302. W. Zhang, Y. Wen, D.-X. He, Y.-F. Wang, X.-L. Liu et al., Near-infrared AIEgens as transformers to enhance tumor treatment efficacy with controllable self-assembled redoxresponsive carrier-Free nanodrug. Biomaterials 193, 12-21 (2019). https://doi.org/10.1016/j.biomaterials.2018.12.007

303. H. Phuengkham, C. Song, S.H. Um, Y.T. Lim, Implantable syntheticiImmune niche for spatiotemporal modulation of tumor-derived immunosuppression and systemic antitumor immunity: Postoperative immunotherapy. Adv. Mater. 30(18), e1706719 (2018). https://doi.org/10.1002/adma.201706719

304. X. Mai, Y. Zhang, H. Fan, W. Song, Y. Chang et al., Integration of immunogenic activation and immunosuppressive reversion using mitochondrial-respiration-inhibited plateletmimicking nanoparticles. Biomaterials 232, 119699 (2020). https://doi.org/10.1016/j.biomaterials.2019.119699

305. X. Zhang, L. Shen, Q. Liu, L. Hou, L. Huang, Inhibiting PI3 Kinase-gamma in both myeloid and plasma cells remodels the suppressive tumor microenvironment in desmoplastic tumors. J. Controlled Release 309, 173-180 (2019). https:// doi.org/10.1016/j.jconrel.2019.07.039

306. S. Li, Q. Wang, Y. Shen, M. Hassan, J. Shen et al., Pseudoneutrophil cytokine sponges disrupt myeloid expansion and tumor trafficking to improve cancer immunotherapy. Nano Lett. 20(1), 242-251 (2020). https://doi.org/10.1021/acs. nanolett.9b03753

307. A.M. Ledo, M.S. Sasso, V. Bronte, I. Marigo, B.J. Boyd et al., Co-delivery of RNAi and chemokine by polyarginine nanocapsules enables the modulation of myeloid-derived suppressor cells. J. Controlled Release 295, 60-73 (2019). https://doi.org/10.1016/j.jconrel.2018.12.041

308. Y. Long, Z. Lu, S. Xu, M. Li, X. Wang et al., Self-felivery micellar nanoparticles prevent premetastatic niche formation by interfering with the early recruitment and vascular destruction of granulocytic myeloid-derived suppressor cells. Nano Lett. 20(4), 2219-2229 (2020). https://doi. org/10.1021/acs.nanolett.9b03883

309. M. Ovais, M. Guo, C. Chen, Tailoring nanomaterials for targeting tumor-associated macrophages. Adv. Mater. 31(19), e1808303 (2019). https://doi.org/10.1002/adma.201808303

310. Y. Singh, V.K. Pawar, J.G. Meher, K. Raval, A. Kumar et al., TargetingtTumor associated macrophages (TAMs) via nanocarriers. J. Controlled Release 254, 92-106 (2017). https://doi.org/10.1016/j.jconrel.2017.03.395

311. K. Binnemars-Postma, G. Storm, J. Prakash, Nanomedicine strategies to target tumor-associated macrophages. Int. J. Mol. Sci. 18(5), 979 (2017). https://doi.org/10.3390/ijms1 8050979

312. S. Lee, S. Kivimae, A. Dolor, F.C. Szoka, Macrophage-based cell therapies: The long and winding road. J. Controlled Release 240, 527-540 (2016). https://doi.org/10.1016/j.jconr el.2016.07.018

313. Y. Zhu, J. Yang, D. Xu, X.-M. Gao, Z. Zhang et al., Disruption of tumour-associated macrophage trafficking by the osteopontin-induced colony-stimulating factor-1 signalling 
sensitises hepatocellular carcinoma to anti-PD-L1 blockade. Gut 68(9), 1653-1666 (2019). https://doi.org/10.1136/gutjn 1-2019-318419

314. S. Shen, Y. Zhang, K.G. Chen, Y.L. Luo, J. Wang, Cationic polymeric nanoparticle delivering CCR2 siRNA to inflammatory monocytes for tumor microenvironment modification and cancer therapy. Mol. Pharm. 15(9), 3642-3653 (2018). https://doi.org/10.1021/acs.molpharmaceut.7b00997

315. F. Leuschner, P. Dutta, R. Gorbatov, T.I. Novobrantseva, J.S. Donahoe et al., Therapeutic siRNA silencing in inflammatory monocytes in mice. Nat. Biotechnol. 29(11), 1005-U1073 (2011). https://doi.org/10.1038/nbt.1989

316. A. Ramesh, S. Kumar, D. Nandi, A. Kulkarni, CSF1R-and SHP2-inhibitor-loaded nanoparticles enhance cytotoxic activity and phagocytosis in Tumor-Associated Macrophages. Adv. Mater. 31(51), e1904364 (2019). https://doi. org/10.1002/adma.201904364

317. T.L. Rogers, I. Holen, Tumour macrophages as potential targets of bisphosphonates. J. Transl. Med. 9, 177 (2011). https ://doi.org/10.1186/1479-5876-9-177

318. S. Junankar, G. Shay, J. Jurczyluk, N. Ali, J. Down et al., Real-time intravital imaging establishes tumor-associated macrophages as the extraskeletal target of bisphosphonate action in cancer. Cancer Discov. 5(1), 35-42 (2015). https:// doi.org/10.1158/2159-8290.Cd-14-0621

319. R. Sabatino, S. Battistelli, M. Magnani, L. Rossi, Preclinical evaluation of an innovative anti-TAM approach based on zoledronate-loaded erythrocytes. Drug Deliv. Trans. Res. 8(5), 1355-1364 (2018). https://doi.org/10.1007/s1334 6-018-0560-2

320. L. Tian, X. Yi, Z. Dong, J. Xu, C. Liang et al., Calcium bisphosphonate nanoparticles with chelator-free radiolabeling to deplete tumor-associated macrophages for enhanced cancer radioisotope therapy. ACS Nano 12(11), 11541-11551 (2018). https://doi.org/10.1021/acsnano.8b06699

321. M.A.F. Yahaya, M.A.M. Lila, S. Ismail, M. Zainol, N.A.R.N.M. Afizan, Tumour-associated macrophages (TAMs) in colon cancer and how to reeducate them. J. Immunol. Res. 2368249 (2019). https://doi. org/10.1155/2019/2368249

322. C.B. Rodell, S.P. Arlauckas, M.F. Cuccarese, C.S. Garris, R.L.M.S. Ahmed et al., TLR7/8-agonist-loaded nanoparticles promote the polarization of tumour-associated macrophages to enhance cancer immunotherapy. Nat. Biomed. Eng. 2(8), 578-588 (2018). https://doi.org/10.1038/s4155 $1-018-0236-8$

323. S. Sousa, S. Auriola, J. Monkkonen, J. Maatta, Liposome encapsulated zoledronate favours M1-like behaviour in murine macrophages cultured with soluble factors from breast cancer cells. BMC Cancer 15, 4 (2015). https://doi. org/10.1186/s12885-015-1005-7

324. L. Liu, H. Yi, H. He, H. Pan, L. Cai et al., Tumor associated macrophage-targeted microRNA delivery with dual-responsive polypeptide nanovectors for anti-cancer therapy. Biomaterials 134, 166-179 (2017). https://doi.org/10.1016/j. biomaterials.2017.04.043
325. N.N. Parayath, A. Parikh, M.M. Amiji, Repolarization of tumor-associated macrophages in a genetically rngineered nonsmall cell lung cancer model by intraperitoneal administration of hyaluronic acid-based nanoparticles encapsulating microRNA-125b. Nano Lett. 18(6), 3571-3579 (2018). https://doi.org/10.1021/acs.nanolett.8b00689

326. Z. Gu, T. Liu, J. Tang, Y. Yang, H. Song et al., Mechanism of Iron Oxide-induced macrophage activation: the impact of composition and the underlying signaling pathway. J. Am. Chem. Soc. 141(15), 6122-6126 (2019). https://doi. org/10.1021/jacs.8b10904

327. R. Jin, L. Liu, W. Zhu, D. Li, L. Yang et al., Iron oxide nanoparticles promote macrophage autophagy and inflammatory response through activation of toll-like receptor-4 signaling. Biomaterials 203, 23-30 (2019). https://doi. org/10.1016/j.biomaterials.2019.02.026

328. G.-T. Yu, L. Rao, H. Wu, L.-L. Yang, L.-L. Bu et al., Myeloid-derived suppressor cell membrane-coated magnetic nanoparticles for cancer theranostics by inducing macrophage polarization and synergizing immunogenic cell death. Adv. Funct. Mater. 28(37), 1801389 (2018). https:// doi.org/10.1002/adfm.201801389

329. S. Zanganeh, G. Hutter, R. Spitler, O. Lenkov, M. Mahmoudi et al., Iron oxide nanoparticles inhibit tumour growth by inducing pro-inflammatory macrophage polarization in tumour tissues. Nat. Nanotechnol. 11(11), 986994 (2016). https://doi.org/10.1038/nnano.2016.168

330. Y. Song, C. Tang, C. Yin, Combination antitumor immunotherapy with VEGF and PIGF siRNA via systemic delivery of multi-functionalized nanoparticles to tumor-associated macrophages and breast cancer cells. Biomaterials $\mathbf{1 8 5}$, 117-132 (2018). https://doi.org/10.1016/j.biomateria 1s.2018.09.017

331. H. Peng, B. Chen, W. Huang, Y. Tang, Y. Jiang et al., Reprogramming tumor-associated macrophages to reverse EGFR(T790m) Resistance by dual-targeting codelivery of gefitinib/vorinostat. Nano Lett. 17(12), 7684-7690 (2017). https://doi.org/10.1021/acs.nanolett.7b03756

332. J. Gan, Y. Dou, Y. Li, Z. Wang, L. Wang et al., Producing anti-inflammatory macrophages by nanoparticle-triggered clustering of mannose receptors. Biomaterials 178, 95-108 (2018). https://doi.org/10.1016/j.biomaterials.2018.06.015

333. H. Wang, Y. Tang, Y. Fang, M. Zhang, H. Wang et al., Reprogramming tumor immune microenvironment (TIME) and metabolism via biomimetic targeting codelivery of Shikonin/JQ1. Nano Lett. 19(5), 2935-2944 (2019). https:// doi.org/10.1021/acs.nanolett.9b00021

334. H. Jonuleit, T. Bopp, C. Becker, Treg cells as potential cellular targets for functionalized nanoparticles in cancer therapy. Nanomedicine 11(20), 2699-2709 (2016). https:// doi.org/10.2217/nnm-2016-0197

335. R.J. Davis, C. Van Waes, C.T. Allen, Overcoming barriers to effective immunotherapy: MDSCs, TAMs, and Tregs as mediators of the immunosuppressive microenvironment in head and neck cancer. Oral Oncol. 58, 59-70 (2016). https ://doi.org/10.1016/j.oraloncology.2016.05.002 
336. M. de Palma, D. Biziato, T.V. Petrova, Microenvironmental regulation of tumour angiogenesis. Nat. Rev. Cancer 17(8), 457-474 (2017). https://doi.org/10.1038/nrc.2017.51

337. C. Deng, Q. Zhang, M. Jia, J. Zhao, X. Sun et al., Tumors andtTheir microenvironment dual-targeting chemotherapy with local immune adjuvant therapy for effective antitumor immunity against breast cancer. Adv. Sci. 6(6), 1801868 (2019). https://doi.org/10.1002/advs.201801868

338. M. Yu, X. Duan, Y. Cai, F. Zhang, S. Jiang et al., Multifunctional nanoregulator reshapes immune microenvironment and enhances immune memory for tumor immunotherapy. Adv. Sci. 6(16), 1900037 (2019). https://doi.org/10.1002/ advs.201900037

339. L. Yang, J. Sun, Q. Liu, R. Zhu, Q. Yang et al., Synergetic functional nanocomposites enhance immunotherapy in solid tumors by remodeling the immunoenvironment. Adv. Sci. 6(8), 1802012 (2019). https://doi.org/10.1002/ advs. 201802012

340. J.F.M. Jacobs, C.J.A. Punt, W.J. Lesterhuis, R.P.M. Sutmuller, H.M.-1H. Brouwer et al., Dendritic cell vaccination in combination with anti-CD25 monoclonal antibody treatment: A phase I/II study in metastatic melanoma patients. Clin. Cancer Res. 16(20), 5067-5078 (2010). https://doi. org/10.1158/1078-0432.Ccr-10-1757

341. R. Ueda, Clinical application of anti-CCR4 Monoclonal Antibody. Oncology 89, 16-21 (2015). https://doi. org/10.1159/000431059

342. P.A. Ascierto, F.M. Marincola, A. Ribas, Anti-CTLA4 monoclonal antibodies: the past and the future in clinical application. J. Trans. Med. 9, 196 (2011). https://doi. org/10.1186/1479-5876-9-196

343. S. Aspeslagh, S. Postel-Vinay, S. Rusakiewicz, J.-C. Soria, L. Zitvogel et al., Rationale for anti-OX40 cancer immunotherapy. Eur. J. Cancer 52, 50-66 (2016). https://doi. org/10.1016/j.ejca.2015.08.021

344. R. Zappasodi, C. Sirard, Y. Li, S. Budhu, M. Abu-Akeel et al., Rational design of anti-GITR-based combination immunotherapy. Nat. Med. 25(5), 759-+ (2019). https://doi. org/10.1038/s41591-019-0420-8

345. D.A. Knee, B. Hewes, J.L. Brogdon, Rationale for anti-GITR cancer immunotherapy. Eur. J. Cancer 67, 1-10 (2016). https ://doi.org/10.1016/j.ejca.2016.06.028

346. A. Emadi, R.J. Jones, R.A. Brodsky, Cyclophosphamide and cancer: golden anniversary. Nat. Rev. Clin. Oncol. 6(11), 638-647 (2009). https://doi.org/10.1038/nrclinonc.2009.146

347. I.M. Desar, J.H. Jacobs, C.A. Hulsbergen-vandeKaa, W.J. Oyen, P.F. Mulders et al., Sorafenib reduces the percentage of tumour infiltrating regulatory $\mathrm{T}$ cells in renal cell carcinoma patients. Int. J. Cancer 129(2), 507-512 (2011). https://doi. org/10.1002/ijc.25674

348. S.-Y. Li, Y. Liu, C.-F. Xu, S. Shen, R. Sun et al., Restoring anti-tumor functions of $\mathrm{T}$ cells via nanoparticle-mediated immune checkpoint modulation. J. Controlled Release 231, 17-28 (2016). https://doi.org/10.1016/j.jconrel.2016.01.044
349. Q. Liu, P. Ma, L. Liu, G. Ma, J. Ma et al., Evaluation of PLGA containing anti-CTLA4 inhibited endometriosis progression by regulating CD4+CD25+Treg cells in peritoneal fluid of mouse endometriosis model. Eur. J. Pharm. Sci. 96, 542-550 (2017). https://doi.org/10.1016/j.ejps.2016.10.031

350. L. Zhang, J. Zhou, L. Hu, X. Han, X. Zou et al., In situ formed fibrin scaffold with cyclophosphamide to synergize with immune checkpoint blockade for inhibition of cancer recurrence after surgery. Adv. Funct. Mater. 7(30), 1906922 (2019). https://doi.org/10.1002/adfm.201906922

351. X. Zhang, J. Wang, Z. Chen, Q. Hu, C. Wang et al., Engineering PD-1-presenting platelets for cancer immunotherapy. Nano Lett. 18(9), 5716-5725 (2018). https://doi.org/10.1021/ acs.nanolett.8b02321

352. T.S. Nowicki, S. Hu-Lieskovan, A. Ribas, Mechanisms of resistance to PD-1 and PD-L1 blockade. Cancer J. 24(1), 47-53 (2018). https://doi.org/10.1097/ppo.0000000000000303

353. T.N. Schumacher, R.D. Schreiber, Neoantigens in cancer immunotherapy. Science 348(6230), 69-74 (2015). https:// doi.org/10.1126/science.aaa4971

354. J.F. Gainor, A.T. Shaw, L.V. Sequist, X. Fu, C.G. Azzoli et al., EGFR mutations and ALK rearrangements are associated with low response rates to PD-1 pathway blockade in non-small cell lung cancer: A retrospective analysis. Clin. Cancer Res. 22(18), 4585-4593 (2016). https://doi. org/10.1158/1078-0432.Ccr-15-3101

355. S.L. Topalian, C.G. Drake, D.M. Pardoll, Immune checkpoint blockade: a common denominator approach to cancer therapy. Cancer Cell 27(4), 450-461 (2015). https://doi. org/10.1016/j.ccell.2015.03.001

356. S. Qin, L. Xu, M. Yi, S. Yu, K. Wu et al., Novel immune checkpoint targets: moving beyond PD-1 and CTLA-4. Mol. Cancer 18(1), 155 (2019). https://doi.org/10.1186/s 1294 3-019-1091-2

357. Y. Wu, W. Chen, Z.P. Xu, W. Gu, Pd-L1 Distribution and perspective for cancer immunotherapy-blockade, knockdown, oriInhibition. Front. Immunol. 10, 2022 (2019). https://doi. org/10.3389/fimmu.2019.02022

358. S. Chowdhury, J. Veyhl, F. Jessa, O. Polyakova, A. Alenzi et al., Programmed death-ligand 1 overexpression is a prognostic marker for aggressive papillary thyroid cancer andiIts variants. Oncotarget 7(22), 32318-32328 (2016). https://doi. org/10.18632/oncotarget.8698

359. D. Bobo, K.J. Robinson, J. Islam, K.J. Thurecht, S.R. Corrie, Nanoparticle-based medicines: A review of FDAapproved materials and clinical trials to date. Pharm. Res. 33(10), 2373-2387 (2016). https://doi.org/10.1007/s1109 5-016-1958-5

360. T. Sun, G. Zhang, Q. Wang, Z. Guo, Q. Chen et al., Preblocked molecular shuttle as an in-situ real-time theranostics. Biomaterials 204, 46-58 (2019). https://doi.org/10.1016/j. biomaterials.2019.02.019 